\title{
Investigation of Dynamic Responses and Vibration Serviceability of Temporary Grandstands by a 3 DOF Interaction Model due to Swaying Motion
}

\author{
Jian Yuan, ${ }^{1}$ Suhui Yu, ${ }^{1}$ Cong Liu $\mathbb{D}^{2},{ }^{2}$ Chengqiang Gao, ${ }^{1}$ Wei Wang, ${ }^{1}$ Lin He, ${ }^{3}$ and Feng Fan ${ }^{3}$ \\ ${ }^{1}$ Academy of Combat Support, Rocket Force University of Engineering, Xi'an 710025, China \\ ${ }^{2}$ School of Civil Engineering, Suzhou University of Science and Technology, Suzhou 215011, China \\ ${ }^{3}$ School of Civil Engineering, Harbin Institute of Technology, Harbin 150090, China \\ Correspondence should be addressed to Cong Liu; liucong618@126.com
}

Received 16 August 2021; Revised 17 November 2021; Accepted 29 November 2021; Published 6 January 2022

Academic Editor: Carlo Rosso

Copyright (c) 2022 Jian Yuan et al. This is an open access article distributed under the Creative Commons Attribution License, which permits unrestricted use, distribution, and reproduction in any medium, provided the original work is properly cited.

Excessive vibration of temporary grandstand by the crowd has lateral rhythmic motions, which attracted increasing attention in the recent years. This paper focuses on experiments where a temporary grandstand occupied by 20 participants is oscillated by a shaking table with a series of random waves and the crowd-induced rhythmic swaying motions at lateral direction, respectively. The dynamic forces that were induced by participants who have swayed at $0.5-1.8 \mathrm{~Hz}$ are recorded by a tri-axial human biomechanics force plate. A new relationship between the annoyance rate and structural acceleration at logarithmic coordinate is investigated and proposed, and the swaying load model is given. Based on these experimental results, a simplified three-degree-offreedom lumped dynamic model of the joint human-structure system is reinterpreted. Afterwards, combined with a feasible range of crowd/structural dynamic parameters, a series of interaction models are analyzed, the vibration dose value (VDV) of the structure is obtained and discussed, and the notable parameters for interaction model are predicted. The experimental results show that the lateral serviceability limit is $1.29 \mathrm{~m} / \mathrm{s}^{1.75}$ and the upper boundary is $2.32 \mathrm{~m} / \mathrm{s}^{1.75}$. The dynamic response of model indicated that the VDV of structure will be decreased with increasing the mass of static crowd and damping ratio of the dynamic crowd. The max response of the model is $\alpha \leq 0.6, f_{2}=1.8 \mathrm{~Hz}$ or $\alpha>0.6, f_{2}=1.5 \mathrm{~Hz}$ or $f_{1}=2.5-3.5 \mathrm{~Hz}$. It may be used as a reference value in vibration safety and serviceability assessment of TDGs, to estimate realistically the vibration response on the occasions when the crowds are swaying.

\section{Introduction}

The problems of vibration of structure such as in long-span floor structures [1], footbridges [2], and grandstands [3-5], which can gather large crowd, have become more prevalent in recent years. For temporary grandstand especially, excessive vibration of structure can cause crowd discomfort or panic, and what is more, it can induce the serious safety of structure due to the failure of structural component [6]. Moreover, the vibration serviceability of grandstand relates to the comfort of spectators, and human perception is of primary importance with any tendency to panic or feeling of discomfort being related to the dynamic response of the structure [7]. This seems to be a common problem in temporary demountable grandstands (TDGs), where the lightweight structural components of TDGs can be rapidly assembled, easily dismantled, and reused, which results in low stiffness of structure at the lateral direction, and can be susceptible to vibrations caused by active crowds. So, predicting the structural dynamic responses, mitigating the excessive structural vibrations, and ensuring occupant comfort are tasks familiar to structural engineers. This has stimulated considerable interest in crowd-structure dynamics and been designated as a design problem to be tackled. In 1931, Reiher and Meister studied the effect of a shaking platform [8]. In 1971, Khan and Parmelee used a rotating display table [9]. In 1972, Chen and Robertson investigated human perception of a wheeled windowless test 
room [10]. In 1974, Wiss and Parmelee investigated human perception of a rise floor [11]. All the previously mentioned researches investigated the human body vibration and the structure vibration. Thus, there are two key areas of human-structure interaction: first, the human body forces induced by crowds, which have rhythmic activities; second, the dynamic responses of structure and serviceability of human-induced vibrations. To date, a number of research projects have largely focused on producing load models to accurately represent the dynamic crowd load, and great advances have been done to investigate the human-structure interaction $[3,5,12-16]$, to better understand the vibration response of grandstand structure.

This paper follows with interest the latter key area issues for predicting the dynamic responses of temporary grandstand structure. The theory of interaction model usually considers that crowd and/or structure is mathematically assumed as a mass-spring-damper SDOF system [17-20], respectively. Other researchers such as Reynolds [21-23], Caprioli [24, 25], Salyards [26], Cigada [27, 28], Comer [29], Parkhouse [30], and Jones [31] monitored and analyzed the permanent grandstands using experiments. Ibrahim [32], Mandal [33], Salyards [34], Saudi [35], Pavic [36], Jian [37], and Lin [38] investigated and analyzed the responses of grandstand by FEM. For assessing the vibration serviceability, a series of classic experiments about human perception where participants rate their feeling of the vibration were conducted $[3,8,9,12,13]$, and as alluded to earlier, this method has been available for appraising the vibration comfort of vehicle suspension system [39, 40], highspeed train [41], pedestrian bridge [42], floor structure [43, 44], and noise annoyance $[45,46]$. Some achievements have been adopted by BS6472-1 [47] and ISO2631-1 [48] standards, and the limit acceleration value for permanent grandstand was given in some standards like ISO2631-1. Both a fuzzy logic method and the probability theory and the signal detecting theory of psychophysics [49-54] were also used to assess the vibration serviceability of permanent and temporary grandstand $[55,56]$ structure.

What these reviews have highlighted is that vibrations induced by humans have vertical motions, and few researches analyzed the lateral vibration in the TDG. What is more, lateral vibration is more likely to be induced than vertical vibration in reality for TDG $[14,20]$. This remains an open problem in the area, and the aim here is to investigate the lateral vibration of TDG.

So with this aim in mind, in this paper, an experiment to determine the human perception of horizontal vibrations at a TDG included 20 persons, where vibrations were derived from a shaking table and crowd motions, respectively. The dynamic forces that were induced by participants who have swayed $0.5-1.8 \mathrm{~Hz}$ are recorded using a tri-axial human biomechanics force plate. Based on these experimental results, the vibration serviceability of TDG is investigated, and then, a simplified three-degree-of-freedom lumped dynamic model of the joint human-structure system is reinterpreted under different parameters of this interaction model, which was used for analyzing the dynamic response of TDG.

Section 1 presents the lateral oscillation experiment. The evaluation method is introduced and the relationships of evaluation parameters of structural vibration are investigated in Section 2. Based on a feasible range of human dynamic parameters and structural parameters, the structural dynamic responses of interaction models are analyzed and discussed in Section 3. The conclusions will be presented in the final chapter.

\section{Lateral Vibration Experiments of Temporary Grandstand and Questionnaire Surveys}

Experimenting was executed on the basis of a rigorous risk assessment and approval of the experiment program by the university's research ethics committee, using its standard procedures for protecting the safety of participants and acquiring sensible data. A temporary grandstand with four rows and five columns of seats that can accommodate 20 persons were selected as the test rig. A unique reference number was allotted to each participant so that their position on the structure could be logged; for example, the first row of seats is 1-5 from left to right (Figure 1(a)).

The study included forty volunteers (Figures 1(b) and 1(c)) from the university and society to consider their different life experiences and educational backgrounds. The weight of each participant was also measured, and the gross weight of the twenty participants is $1405.7 \mathrm{~kg}$ and $1338.7 \mathrm{~kg}$, respectively. The participants consisted of 36 males with weights ranging from 54.0 to $90.5 \mathrm{~kg}$ (mean $70.6 \mathrm{~kg}$ ) and four females with weights between 41.0 and $57.0 \mathrm{~kg}$ (mean $50.5 \mathrm{~kg}$ ). All participants were aged between 20 and 35 years (mean age 26.2) and had a health body to participate in the test. All participants did not receive specialized training for perceiving the vibration. No specific posture was prescribed, and the participants sat or stood freely. Because this is a psychophysical experiment or survey by means of a category judgment method, this requires participants to rate their perception and/or comfort of the magnitude of the vibrations. Based on their perception, everyone filled in the questionnaire for rating the vibration that had been experienced during the lateral vibration tests when they sat and/or stood, respectively.

For simulating the lateral vibration of temporary grandstand, a series of random waves (Table 1) were chosen as external excitation when the test rig was occupied by participants and the test rig was fixed on a shaking table (Figure 1(b)). Table 1 shows there are three kinds of seismic waves: Chi Chi (1999s), EI Centro (1940s), and Kobe waves (1995s), including two lateral directions, West-East (W-E) and North-South (N$\mathrm{S})$, which were chosen as horizontal force to the test rig. The peak acceleration of these random waves was between $0.16 \mathrm{~m} / \mathrm{s}^{2}$ and $1.54 \mathrm{~m} / \mathrm{s}^{2}$ with 53 force testing sessions in total. For example, there are nine test curves of Chi Chi (W-E) from the peak acceleration 18.29 gal to 91.45 gal, increasing 0.5 times, that is, $18.29 \mathrm{gal}, 27.43 \mathrm{gal}(18.29 \times 1.5), 36.58 \mathrm{gal}(18.29 \times 2)$, $45.73 \mathrm{gal} \quad(18.29 \times 2.5), \quad 54.87 \mathrm{gal} \quad(18.29 \times 3), \quad 64.02 \mathrm{gal}$ $(18.29 \times 3.5), 73.16$ gal $(18.29 \times 4), 82.31 \mathrm{gal}(18.29 \times 4.5)$, and $91.45 \mathrm{gal}(18.29 \times 5.5)$. Other kinds of test curves used the same increasing method like Chi Chi test waves. The shaking table was controlled by displacement curve (acceleration curves converted to displacement curves), and one of them is shown in Figure 2. 


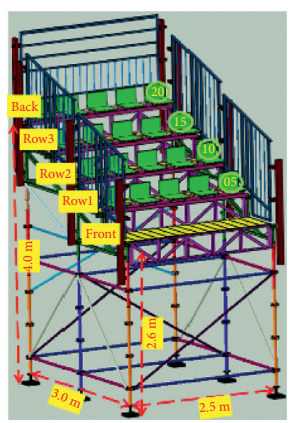

(a)

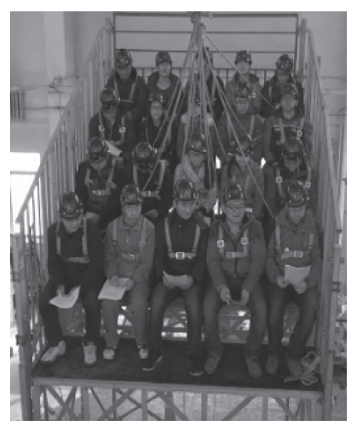

(b)

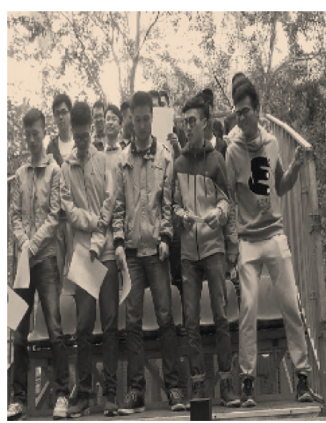

(c)

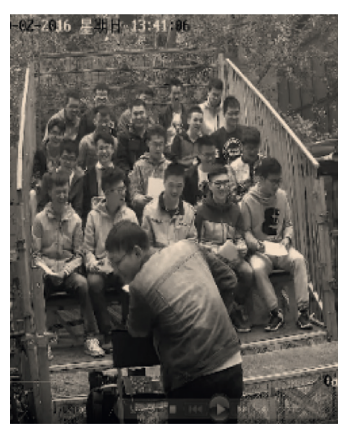

(d)

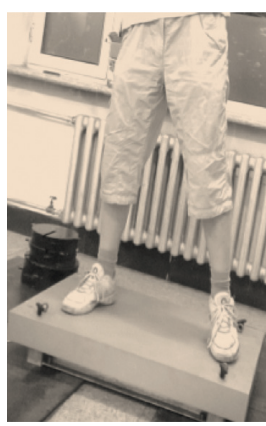

(e)

FIgURE 1: The lateral vibration experiment and single person swaying test. (a) Schematic of structure; (b) external excitation; (c) stand crowd swaying excitation; (d) seated crowd swaying excitation; (e) single person swaying.

TABLE 1: Details of test seismic waves.

\begin{tabular}{lcccc}
\hline \multicolumn{1}{c}{ Seismic wave } & & Peak acceleration (gal) & Duration (s) & Number \\
\hline \multirow{2}{*}{ Chi Chi (1999s) } & W-E & $18.29-91.45$ & 48 & 4 \\
& N-S & $16.26-89.43$ & 46 & 10 \\
\hline \multirow{2}{*}{ EI Centro (1940s) } & W-E & $21.48-96.66$ & 40 & 8 \\
\hline \multirow{2}{*}{ Kobe (1995s) } & N-S & $31.29-140.81$ & 30 & 8 \\
\hline
\end{tabular}

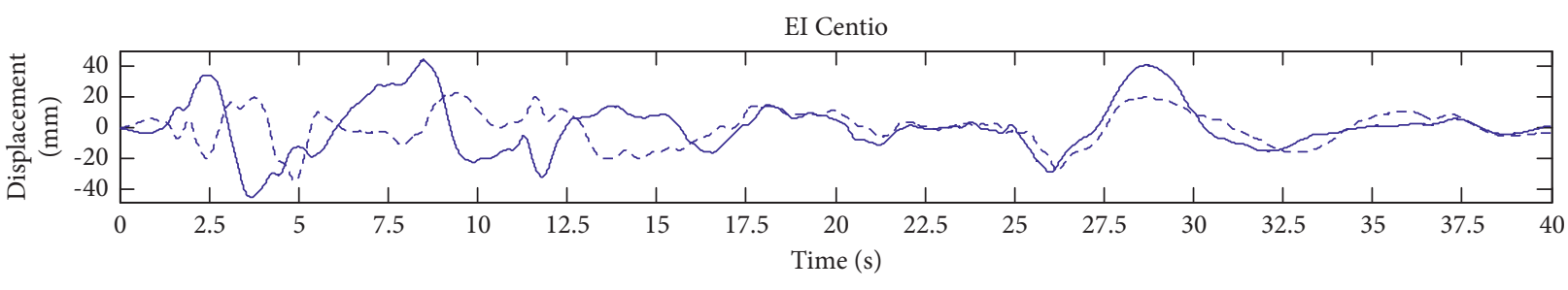

-- - N-S

- W-E

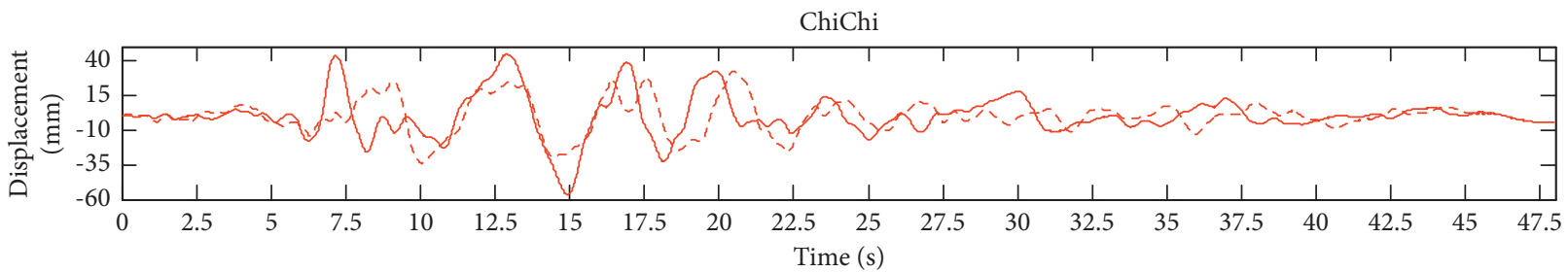

- - N-S

- W-E

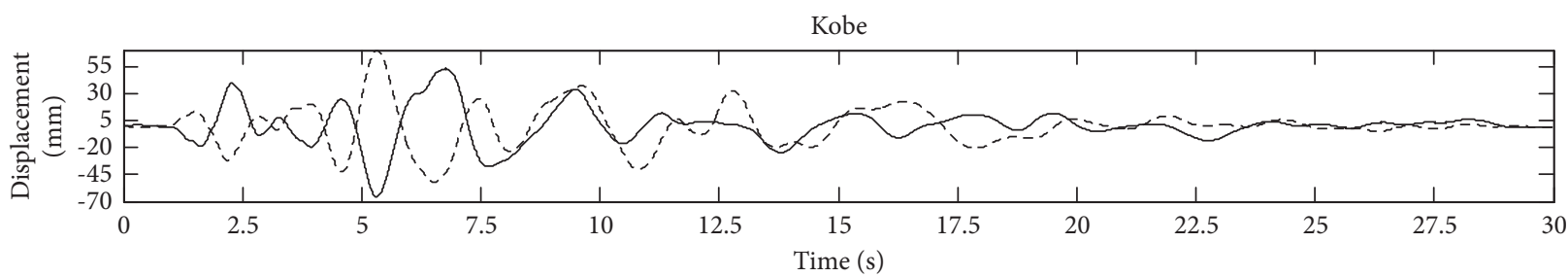

$---\mathrm{N}-\mathrm{S}$

- W-E

FIGURE 2: The shaking table under displacement-controlled loading. 
Besides, human-induced vibration was derived in the stand/seated active crowd when they have swaying movements on temporary grandstand (Figures $1(\mathrm{c})$ and $1(\mathrm{~d})$ ), and eight person were swayed at a triaxial human biomechanics force plate (Figure1(e)). (Figure 1(e)). For human internal excitation, eleven experimental conditions were designed for crowds with swaying activities at temporary grandstand. The swaying person's number, test conditions, and crowd swaying frequencies are shown in Table 2 [57]. In this paper, the passive and/or active crowd annoying levels of vibration is investigated.

In Figure 3, the main dimensions of a structure are height of front row $(2.6 \mathrm{~m})$, back $(4.0 \mathrm{~m})$, left-to-right span $(2.5 \mathrm{~m})$, and front-to-back span (up to $3 \mathrm{~m}$ ). Four accelerometer points $\mathrm{A} 1-\mathrm{A} 4$ stand for the accelerations of each row. Also, there are three linear variable differential transformers (L1-L3) shown in this figure. The responses of structural seating system are measured by the accelerator points $\mathrm{A} 1-\mathrm{A} 4$ and are presumed as the responses of the crowd-TDG-coupled model. Data were collected at a sampling frequency of $1 \mathrm{kHz}$ using IMC data acquisition software carrying a built-in anti-alias filter (German model IMC CRONOS compact-400-08 with robust housing) and a DH5922 (Dong Hua, China). The recorded curves were digitally filtered with a frequency content of up to $25 \mathrm{~Hz}$ in order to minimize the effect of background noise. Finally, the adjustable bearing of the test rig had to be sufficiently robust with a bolted connection in the shaking table and to prevent sliding due to the impact of seismic waves resulting from side-to-side motions.

As mentioned previously, only few standards or codes can provide specific clause on the assessment of human vibration acceptability for grandstand. Some researchers $[3,8,9,12,13]$ divided the human perception and vibration level into three to six categories, which are based on the concept of equidistance followed human psychological changes. The achievements have been adopted by BS6472-1 [47] and ISO2631-1 [48] standards. Introspection is used to describe an experimental technique that was first developed by psychologist Wilhelm Wundt, in Wundt's lab, and there were two key components that made up the contents of the human mind: sensations and feelings. Wundt believed that researchers needed to do more than simply identify the structure or elements of the mind. Instead, it was essential to look at the processes and activities that occur as people experience the world around them [58]. Therefore, it is necessary to conduct a psychophysical experiment survey by means of a category judgment method [59]. So, according to these findings, the level of vibration perception (six categories) [60] and comfort are provided with vibration perception questionnaires, which require participants to select their subjective perception and/or levels of comfort during exposure to vibration. The questionnaires contain the level of vibration perception with the level comfort and shows in Table 3, and the questionnaires are shown in Figure 4.

\section{Evaluation Method and Analysis of the Vibration Serviceability}

3.1. Annoyance Rate Method. Although the limit acceleration value for grandstand was given in some standards like ISO2631-1 [48], the membership between the limit value and comfortable level was not reasonablely extrapolated, especially for lateral vibration of temporary grandstand. The result of questionnaires includes the ambiguity of seismesthesia and the sensitivity randomness existing in participants' response to vibration environment. All these uncertainties need to be analyzed from a psychophysics view. So, first, the seismesthesia of membership function and corresponding conditional probability distribution [61] is calculated using (1) based on Table 3 and questionnaires.

$$
v_{j}=\frac{(j-1)}{(K-1)}, \quad j=1,2, \ldots, K,
$$

where $v_{j}$ is the seismesthesia of membership value of the jth type of the unacceptable range, and $K$ is the class number of the subjective response, according to Table $3, K=6$.

So, the subjective response corresponding to the value of $v_{j}$ can be shown in Table 4 .

An evaluation index annoyance rate method that is a fuzzy stochastic model for participant response to vibrations is cited [61]. The method considers these uncertainties with the fuzzy logic method and the probability theory, combined with the objective experimental data statistics. An annoyance rate is the proportion of some kind of subjective response under certain external stimulus intensity, which considers synthetically response ambiguity and randomness with fuzzy membership value. It is useful as a benchmark to determine the annoyance threshold for vibration serviceability criteria. The threshold indicates the ration of people who cannot accept the vibration to the statistical that total number. Under discrete distribution, the annoyance rate can be calculated as follows:

$$
R(x=i)=\frac{\sum\left(v_{i j} \cdot n_{i j}\right)}{\sum n_{i j}},
$$

where $R(x=i)$ is the annoyance rate of the $i$ th vibration intensity; $v_{i j}$ is the membership of value is calculated using (1) at the $i$ th vibration intensity; $n_{i j}$ is the number of subjective response of the $j$ th type of the $i$ th vibration intensity; $K$ is the class number of the subjective response, $K=6$ (Table 3 ).

\subsection{Relationship of Structural Vibration Evaluation} Parameters. According to the author's paper [20], there are three common approaches to determining vibration amplitude: peak, root-mean-square (RMS), and vibration dose value (VDV). VDV approach may be more suitable for assessing the structural vibration by dynamic curves especially the curve has distinct peaks that is different from RMS approach which depends too heavily on the duration of an event to act as an accurate gauge of response severity [4]. So, the shaking table's acceleration and structural dynamic responses are quantified in terms of the vibration dose value 
Table 2: Details of crowd rhythmic activities.

\begin{tabular}{lcc}
\hline Test condition number & Test conditions & Crowd swaying frequency $(\mathrm{Hz})$ \\
\hline 1 & All standing persons swaying & $0.5,0.75,1.0,1.1,1.25,1.4,1.5,1.7,1.8$ \\
2 & All seated persons swaying & $0.5,0.75,1.0,1.1,1.25,1.4,1.5,1.7,1.8$ \\
3 & $6-20$ standing swaying, $1-5$ seated & $0.5,0.75,1.0,1.1,1.25,1.4$ \\
4 & $11-20$ standing swaying, $1-10$ seated & $0.5,0.75,1.0,1.1,1.25,1.4$ \\
5 & $16-20$ standing swaying, $1-15$ seated & $0.5,0.75,1.0,1.1,1.25,1.4$ \\
6 & $6-20$ standing swaying; $1-5$ standing & $0.5,0.75,1.0,1.1,1.25,1.4$ \\
7 & $11-20$ standing swaying; $1-10$ standing & $0.5,0.75,1.0,1.1,1.25,1.4$ \\
8 & $16-20$ standing swaying; $1-15$ standing & $0.5,0.75,1.0,1.1,1.25,1.4$ \\
9 & $6-20$ seated swaying; $1-5$ seated & $0.5,0.75,1.0,1.1,1.25,1.4$ \\
10 & $11-20$ seated swaying; $1-10$ seated & $0.5,0.75,1.0,1.1,1.25,1.4$ \\
11 & $16-20$ seated swaying; $1-15$ seated & $0.5,0.75,1.0,1.1,1.25,1.4$ \\
\hline
\end{tabular}

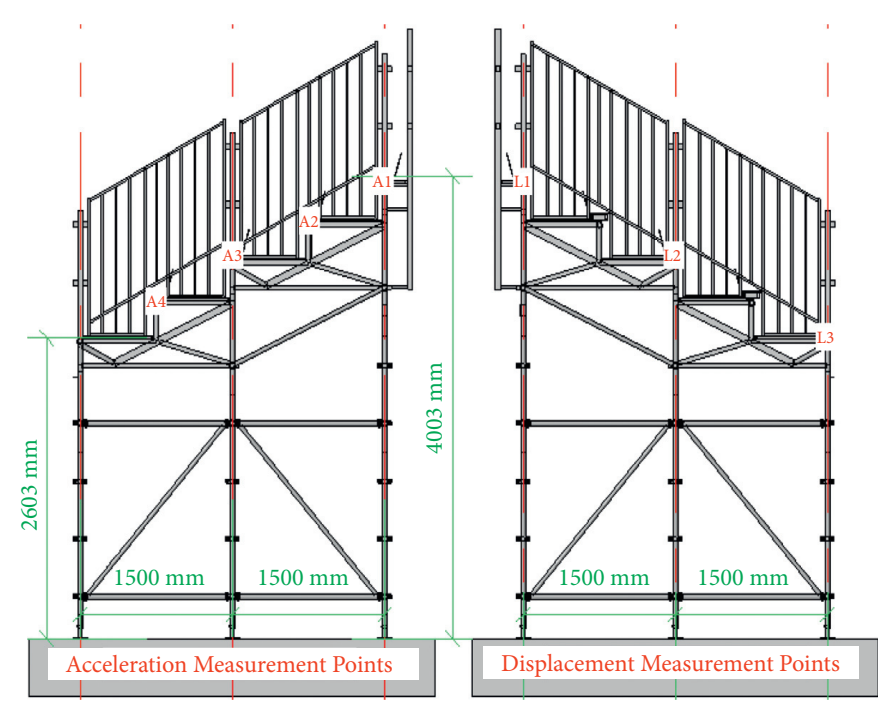

(a)

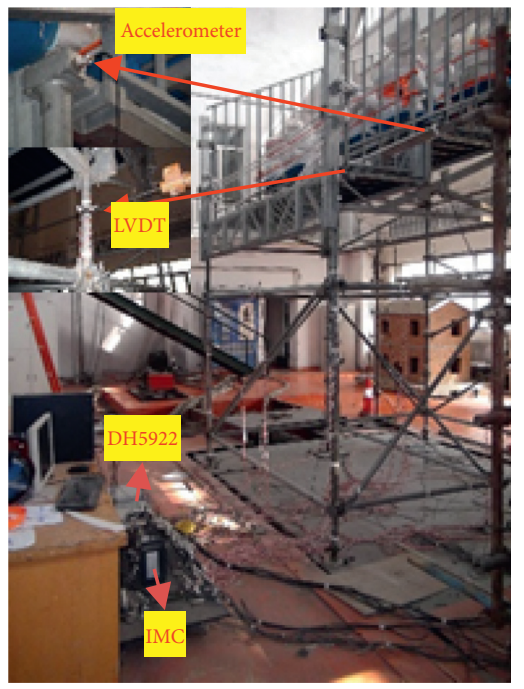

(b)

Figure 3: The test structure. (a) The test points of accelerometer and displacement; (b) test instruments.

TABLE 3: Human perception and comfort category.

\begin{tabular}{lcc}
\hline Ordinal & Perception category & Subjective response \\
\hline 1 & Imperceptible & No response (not uncomfortable) \\
2 & Litter perception & Normal (a little uncomfortable) \\
3 & Clear perception & Accept (fairly uncomfortable) \\
4 & Little strong perception & Litter nervous (uncomfortable) \\
5 & Strong perception & Nervous (very uncomfortable) \\
6 & Very strong vibration & Panic (extreme uncomfortable) \\
\hline
\end{tabular}

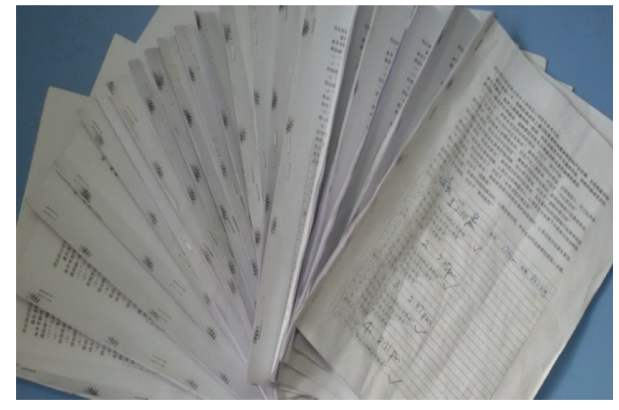

(a)

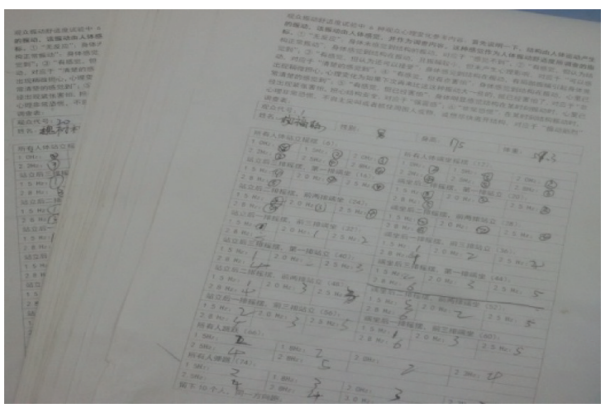

(b)

Figure 4: Participant response questionnaire. (a) The questionnaires of shaking table test; (b) the questionnaires of human induced vibration. 
TABLE 4: Seismesthesia membership values.

\begin{tabular}{lcccccc}
\hline Subjective response & $\begin{array}{c}j=1 \\
\text { No response }\end{array}$ & $\begin{array}{c}j=2 \\
\text { Normal }\end{array}$ & $\begin{array}{c}j=3 \\
\text { Acceptable }\end{array}$ & $\begin{array}{c}j=4 \\
\text { Litter nervous }\end{array}$ & $\begin{array}{c}j=5 \\
\text { Nervous }\end{array}$ & $\begin{array}{c}j=6 \\
\text { Panic }\end{array}$ \\
\hline Membership value & 0.0 & 0.2 & 0.4 & 0.6 & 0.8 & 1.0 \\
\hline
\end{tabular}

(VDV), which is calculated in (3) for both continuous and digitized signal:

$$
a_{\mathrm{VDV}}=\left\{\int_{0}^{T} a_{w}^{4}(t) \mathrm{d} t\right\}^{1 / 4}=\left(\lim _{\lambda \longrightarrow 0} \sum_{i=1}^{n} a_{w}^{4}\left(\varsigma_{i}\right) \cdot \Delta t_{i}\right)^{0.25}=\left(\sum_{i=1}^{n}\left[W\left(f_{s}\right) \cdot a\left(t_{i}\right)\right]^{4} \cdot f\right)^{0.25} \lambda=\max \left\{\Delta x_{1}, \Delta x_{2}, \ldots, \Delta x_{n}\right\}
$$

where $a_{\mathrm{vdv}}$ is the vibration dose value of acceleration $a(t)$ in $\mathrm{m} / \mathrm{s}^{1.75} ; \zeta_{i}$ is the integration point that equal to timing point $t_{i}$; $a_{w}(t)$ is the frequency weighted acceleration equal to $a_{w}(t) \cdot W$ $(f)$, and $W(f)$ is the frequency weight function from ISO2631 $[62,63] ; f_{\mathrm{s}}$ is the empty structure natural frequency (Figure 5). According to the ISO2631, the value of 0.74 is used in this paper; $a(t)$ is the digitized sample of the experimental acceleration, and it is the mean curve of $\mathrm{A} 1-\mathrm{A} 4$ in this paper; $T$ is the vibration duration in seconds, and $f$ is the sampling frequency, with $n=T / f$ being the number of points in the signal; $\Delta x_{i}$ is the $i$ th integral interval point. In this paper, (3) is used for calculating the same kind of excitation with different amplitudes to reflect the structural dynamic performance. So, for example, the set $\{1,2,3,4,5,6,7,8,9,10\}$ and set $\{10,9,8$, $7,6,5,4,3,2,1\}$ are different; if both of them were evaluated by Eq. (3), they will have the same answer. However, it is incorrect to think that the two datasets are similar. In this paper, the order of the elements of $a(t)$ is invariant, and only the size of element increases linearly, that is, $\{1,2,3,4,5,6,7$, $8,9,10\}$ and $\{2,4,6,8,10,12,14,16,18,20\}$ and so on.

The peak acceleration of A0 plotted against each form of structural acceleration is shown in the same window of Figure 6(a). In this figure, hollow dots stand for peak accelerations, square dots stand for RMS values, and diamond dots stand for VDV. All the dots include the results of A1 to A4. It should be noted that the fitting curve of VDV is lower than the other two, and the fitting curve of RMS is higher than the other two. For the human-induced vibration experiment, the results of excitations are derived from crowd with rhythmic activities Figure 6(b), which are different from the shaking table tests (Figure 6(a)). The peak acceleration, RMS, and VDV of each test condition results are also calculated, and the scatter plots were the three measures plotted against crowd swaying. In this figure, the hollow dots stand for peak accelerations, the square dots stand for RMS values, and the diamond dots stand for VDV. It is also found that RMS values are higher than the peak value and VDV, and the max value is about $13.49 \mathrm{~m} / \mathrm{s}^{2}$, which is out of the limits given by Kasperski [3], Setaerh [5], Nhleko [13], BS6472-1 [47], BS6841 [64], and some codes or guidelines [65-69]. Considering to the max value, based on the vibration perception questionnaires of these participants, it was found that they were in panic from the questionnaires.
The standard BS6472-1 [47] and ISO2631-1 [48] has given an approximate relationship between VDV and RMS when vibrations are statistically stationary, and Griffin [70] introduced the crest factor $C_{\mathrm{F}}$, and when $C_{\mathrm{F}}=a_{\mathrm{wp}} / a_{\mathrm{wrms}}$ is less than 6 , the VDV can be estimated using $a_{\text {wrms }}$. However, as can be seen in Figure 7(a), it is not applicable to the vibrations recorded in shaking table experiment as the calculated $C_{\mathrm{F}}$ are significantly smaller than 6 . Ellis with Littler [71] has given a linear relationship between VDV and peak acceleration, whereas it is also not applicable to this experiment's results. Besides, $C_{\mathrm{F}}$ plotted against $a_{\mathrm{wvdv}} / a_{\mathrm{wp}}$ is fitted by a linear curve and the fitting parameter R-Square is 0.74, which is different from that given by Setareh [5], a second-order relationship. This may be because Setareh researched excitations and structures that are different than that in this paper.

For human swaying experiment, the crest factor $C_{\mathrm{F}}$ values also are smaller than 6 , and $C_{F}$ plotted against $a_{\mathrm{wvdv}} / a_{\mathrm{wp}}$ is shown in Figure $7(\mathrm{~b})$. Compared with the shaking table experiment that excitations were exported with a linear increasing, even crowd-induced structure vibration has a certain randomness because the output energies of their bodies are uncertain. It is indicated that they have a linear relationship and even only a part of subjects have rhythmic swaying (such as 3-11 test conditions in Table 2). So, based on the computed $a_{\mathrm{wp}}, a_{\mathrm{wrms}}$ and $a_{\mathrm{wvdv}}$, Figure 8 shows the scattered plots of $a_{\mathrm{wp}}$ and $a_{\text {wrms }}$ plotted against $a_{\mathrm{wvdv}}$, and a linear relationship curve was fitted, which indicated that there existed a good linear relationship between each of them.

Bearing all this in mind, the structural acceleration VDV has a linear relationship with RMS and peak acceleration, and not only the structure was oscillated by shaking table with linear increasing excitations but also it was oscillated by crowd having rhythmic activities with linear increasing swaying frequencies. And what is more, crowd swaying movements can make structure's acceleration more than 10 $\mathrm{m} / \mathrm{s}^{2}$, which can cause the crowd to panic.

3.3. Acceptable VDV Limits. The external excitation and human internal vibration for the test structure were analyzed in this paper. The structural acceleration curves had 

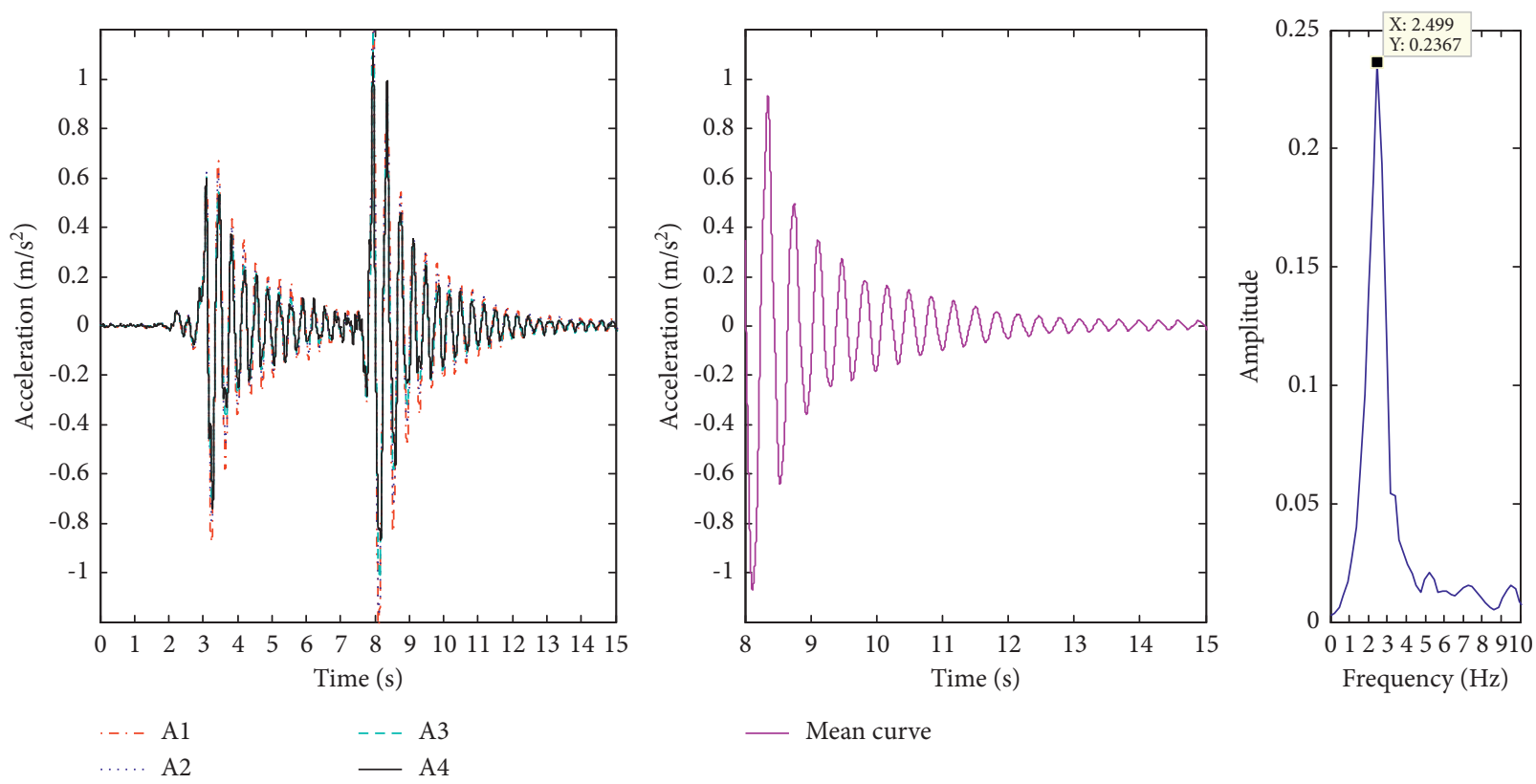

FIGURE 5: The measured points of time history and frequency domain analysis from free decaying vibration (empty structure).

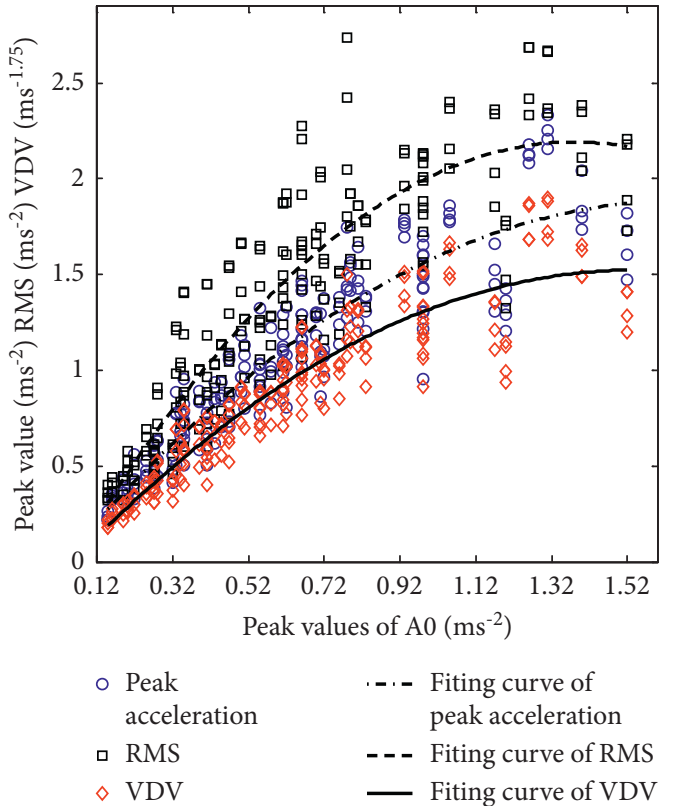

(a)

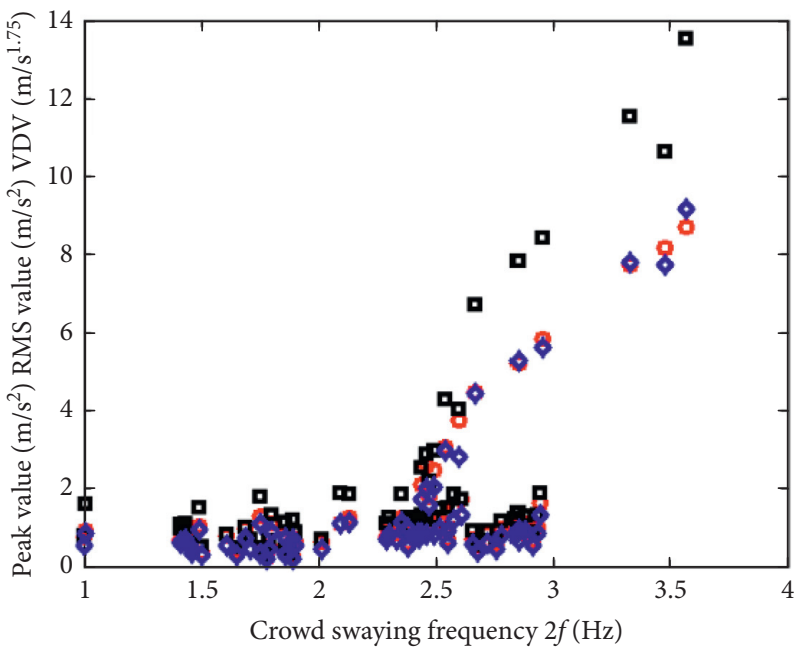

- Peak value

口 RMS value

$\diamond$ VDV

(b)

Figure 6: The relationship of input conditions and output accelerations: peak values, RMS values, and VDV. (a) Shaking table experiment results; (b) human-induced vibration experiment results.

characteristics thar varied with time. So, VDV is more versatile than RMS and has been calculated to quantify human reactions to numerous types of vibrations, and VDV will be used for finding the relationship with annoyance ratio in this paper.

The annoyance rate $R$ of the crowd occupying the structure when it oscillated by external excitations is calculated using (2). All the experiment data of the scattered plots annoyance rate $R$ plotted against VDV are shown in Figures 9 and 10. First, the distribution of annoyance rate of standing crowd experiment data (circle dots) is compared with seated crowd experiment data (star dots) in the same window, which is shown in Figure 9(a). It can be seen that the distribution of annoyance rate of the standing crowd is similar to the seated crowd results when structural VDV is no more than $1.55 \mathrm{~m} / \mathrm{s}^{1.75}$. It is found that the annoyance rates of the standing crowd are lower than the seated crowd when the structure has larger VDV, 


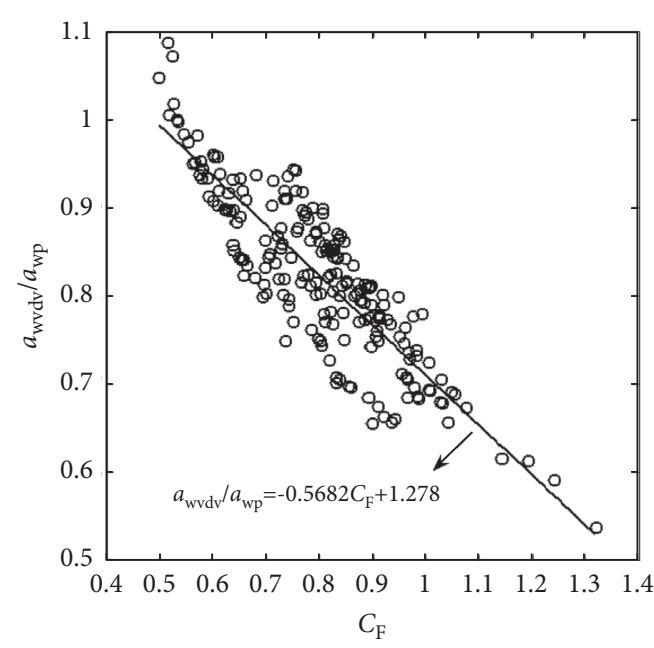

- $C_{\mathrm{F}}$ point

_ _ Fitting curve R-Square:0.76

(a)

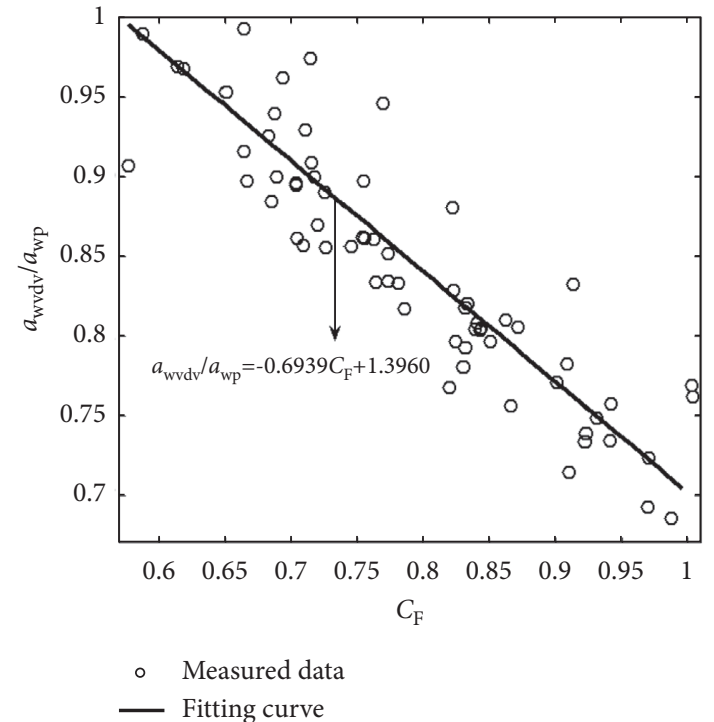

(b)

FIgURE 7: $a_{\mathrm{wvdv}} / a_{\mathrm{wp}}$ plotted against $C_{\mathrm{F}}$. (a) Measured data from shaking table tests; (b) measured data from human tests.
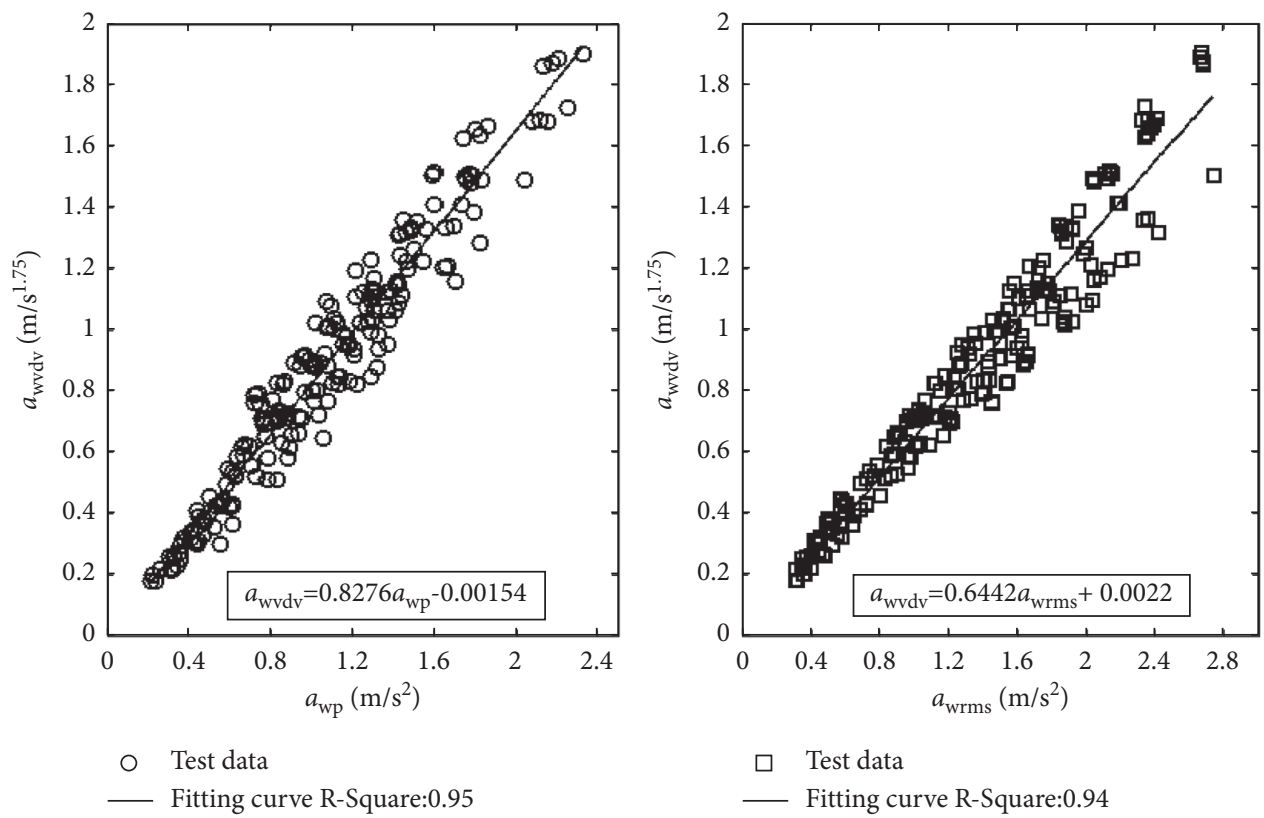

(a)

Figure 8: Continued. 

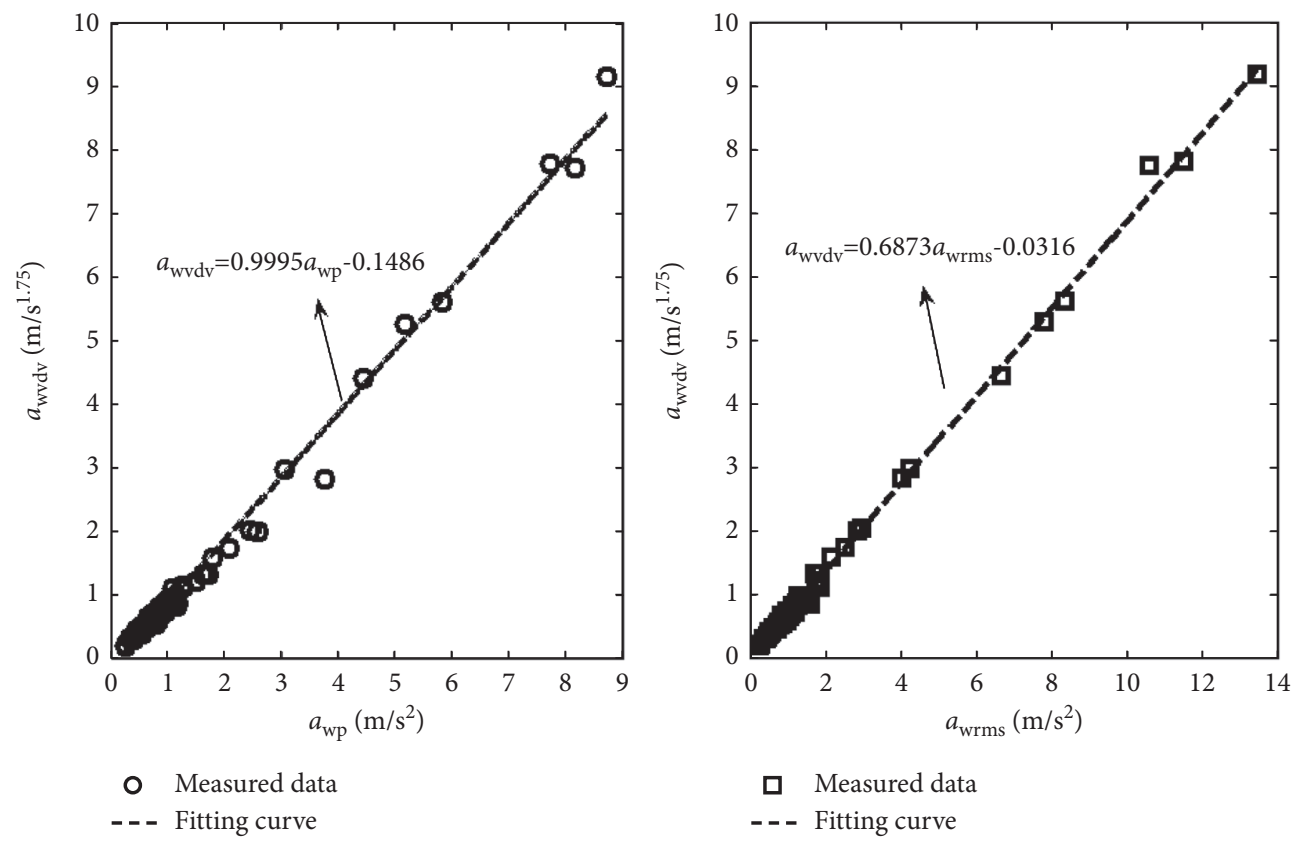

(b)

FIGURE 8: $a_{\mathrm{wvdv}}$ plotted against $a_{\mathrm{wp}}$ and $a_{\mathrm{wrms}}$. (a) Shaking table measured data; (b) crowd induced measured data.

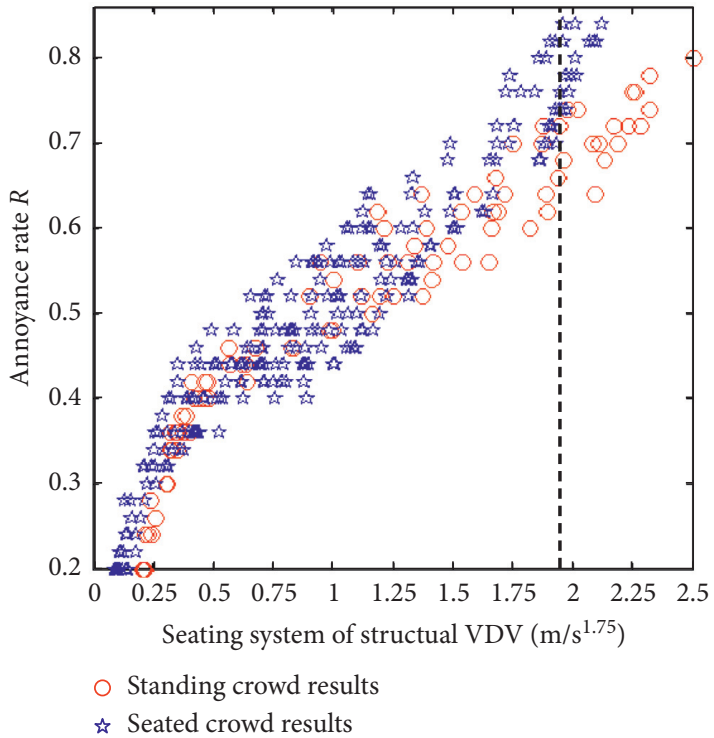

(a)

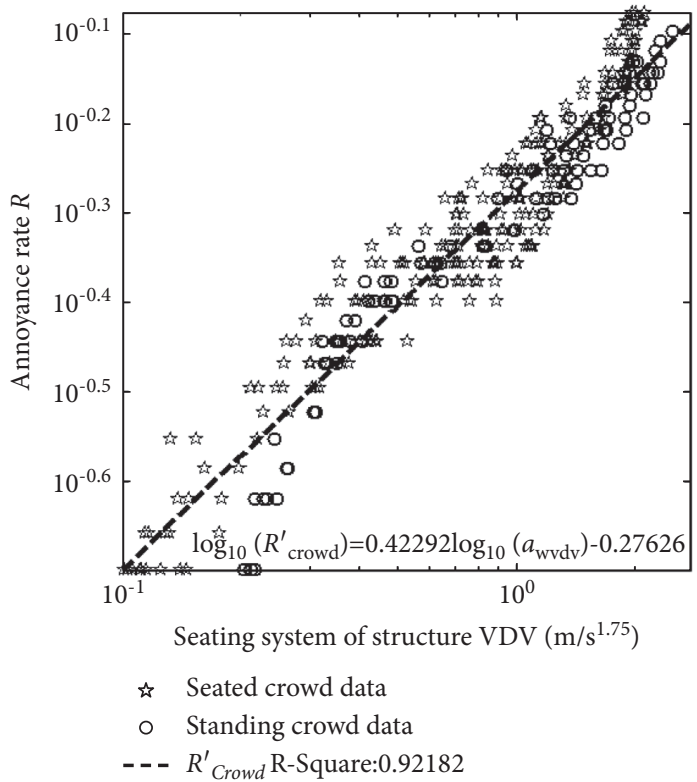

(b)

FiguRE 9: The distribution of crowds annoyance rate according to shaking table tests at logarithmic coordinate. (a) Cartesian coordinate system; (b) logarithmic coordinate system.

especially when the VDV is larger than $2.0 \mathrm{~m} / \mathrm{s}^{1.75}$, which may indicate that the standing crowd is more tolerant to vibration than the seated crowd in this kind of conditions of the experiment. Figure 9(a) shows that the crowd annoyance rate has a significant nonlinear relationship with increasing structural VDV. The distribution of annoyance rate is different in seated or standing crowds. When the data of Figure 9(a) were shown by logarithmic coordinate system in Figure 9(b), it was found that there is a linear relationship between structural VDV and annoyance rate. So, by neglecting the slight difference found in them, the fitting curve is also given in Figure 9(b), and $R_{\text {crowd }}^{\prime}$ is the annoyance rate of the crowd at external excitation experiments. 


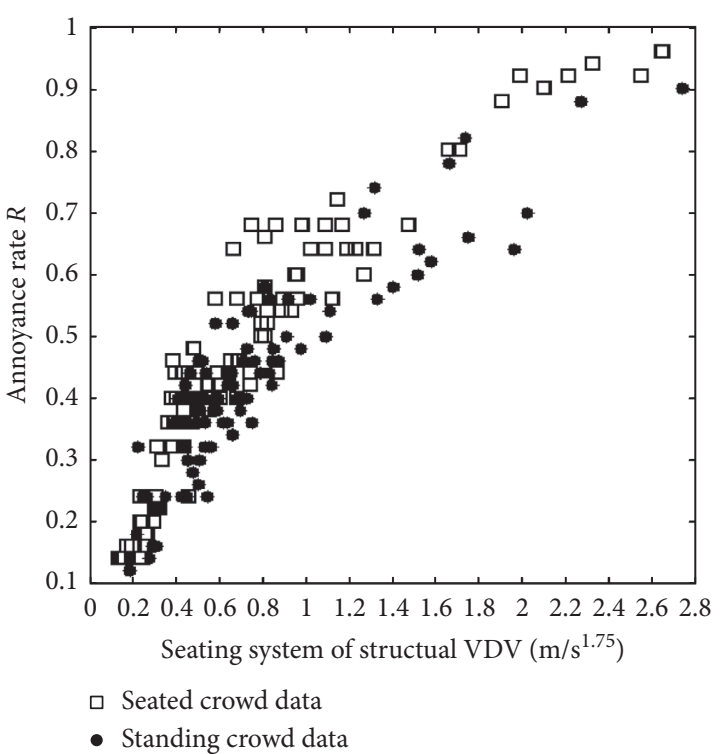

(a)

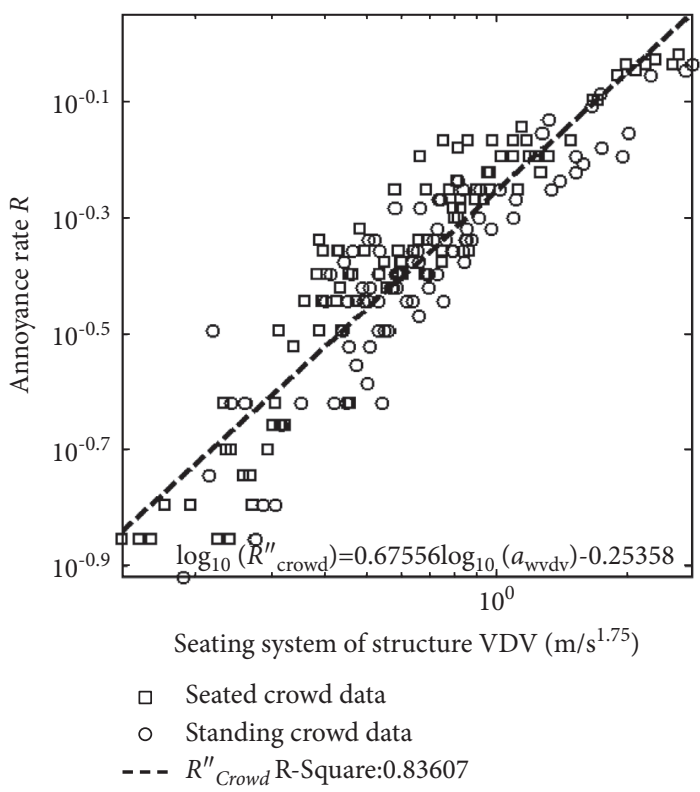

(b)

FIgURE 10: The distribution of crowds annoyance rate in human-induced structural vibration. (a) Cartesian coordinate system; (b) logarithmic coordinate system.

Second, active crowd-induced structure vibration experiment results are also investigated to find the relationship between annoyance rate and structural VDV. When the VDV is higher than $2.8 \mathrm{~m} / \mathrm{s}^{1.75}$, the crowd is in panic, and the annoyance rate is 1.0 , So, only the corresponding values with annoyance rate lower than 1.0 are shown in Figure 10(a). It is indicated that the distribution trend of scatters are similar to Figure 9(a), no matter what the results from standing crowd experiment data (filled dots) or seated crowd experiment data (square dots). It may also indicate that the standing crowd can tolerate more strong structural vibration than the seated crowd when the structural vibration was induced by the swaying crowd, from Figures 9(a) and 10(a), and this finding accords with Nhleko's research [13]. Also, a linear relationship between the structural VDV and annoyance rate at logarithmic coordinate system is fitted when considing the seated crowd data and standing crowd data as a whole sample. The fitting curve is shown in Figure 10(b). $R_{\text {crowd }}^{\prime \prime}$ is the annoyance rate of crowd at human induced vibration experiment.

According to Figures 9(b) and 10(b), it is found that the trends of annoyance rate are similar no matter the structure was oscillated by the shaking table or by swaying crowd. So, both of the two experiment results were considered as a whole to evaluate the annoyance level of vibration. Figure 11 shows all the scatters of annoyance rate with structural VDV at the logarithmic coordinate system. It is clear that the distribution of annoyance rate is approximate with increasing VDV, even if there is a gap of annoyance rate between the results of seismic excitation (filled dots) and the results of human induced vibration (circle dots) when the VDV is smaller than $0.6 \mathrm{~m} / \mathrm{s}^{1.75}$. A linear curve was fitted using (4a), and the formula at Cartesian coordinate system is also given in (4b):

$$
\begin{aligned}
\log _{10}(R) & =0.49119 \log _{10}\left(a_{\mathrm{wvdv}}\right)-0.27607 . \\
a_{\mathrm{wvdv}} & =10^{0.56205} \cdot R^{1 / 0.49118} .
\end{aligned}
$$

So, when the vibration of structure was induced by stochastic and rhythmic excitations, the annoyance rate could be determined by (4a) and (4b).

$R$ is the annoyance rate of crowd on temporary grandstand, and $a_{\mathrm{wvdv}}$ is the acceleration VDV of seating system of temporary grandstand, and its range is 0.1 to $2.8 \mathrm{~m} / \mathrm{s}^{1.75}$. In this paper, $R$ is lower than 0.4 , which indicates that the crowd is comfortable with the structure. $R$ varying from 0.4 to 0.6 means that some people in the crowd feel uncomfortable. $R$ varying from 0.6 to 0.8 means that most of the people feel uncomfortable. and when $R$ is larger than 0.8 that shows that the crowd is in panic [61]. Based on this annoyance levels of vibration and according to (4a) and (4b), the structural acceleration VDV $1.29 \mathrm{~m} / \mathrm{s}^{1.75}$ corresponds to $R=0.6$ as the serviceability limit, and $2.32 \mathrm{~m} / \mathrm{s}^{1.75}$ corresponds to $R=0.8$ as the serviceability limit of the upper boundary.

\section{Parameters Analysis of Interaction Model for Structural Dynamic Response}

The test results of the interaction between the static human body and temporary stand verify that the rationality of the static crowd and structure has been, respectively, simplified into an SDOF calculation system [18]. The combination with dynamic crowd not only provides load but also serves as an SDOF system, respectively $[42,43]$. Thus, the proposition of a 3DOF interaction model between the crowd and 


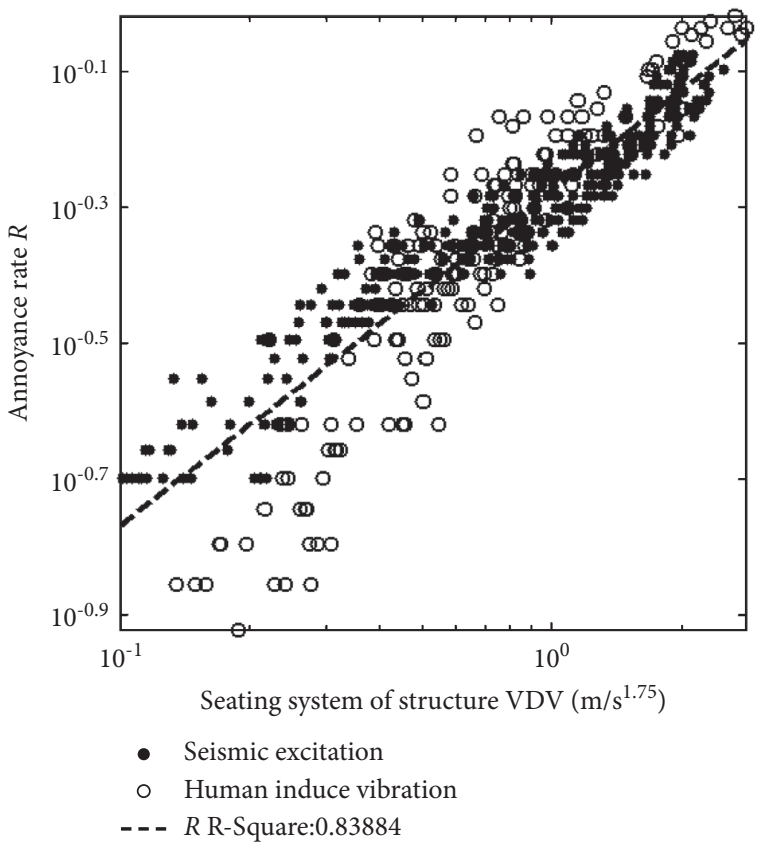

Figure 11: The distribution of crowds annoyance rate of TDGs.

temporary stand is presented. And for the lateral vibration, $m_{3}, f_{3}$, and $\zeta_{3}$ represent the mass, the first-order frequency, and the first-order damping ratio of the static crowd model, $m_{2}, f_{2}$, and $\zeta_{2}$ represent the relevant parameters of dynamic crowd, and $m_{1}, f_{1}$, and $\zeta_{1}$ represent the relevant parameters of effective area of the crowd-structure interaction. The simplified 3DOF calculation model of the crowd-structure interaction represented by these parameters is shown in Figure 12. The effective area of crowd-structure in the model refers to the seat structure area of a temporary stand in direct contact with the crowd (seating system). In view of the spatial changes in the action points of the crowd swaying, it is generally considered that the plane variables, that is, the action points, are the same. Therefore, it is assumed in the model that the crowd is a centralized mass single-point system, rather than a spatial multipoint system. The structural vibration mode $\Phi$ in the model is simplified to 1 , with its influence no longer being reflected.

Firstly, according to the experiment of swaying crowd, the swaying is loaded as the horizontal load for this model.
Second, the reasonable range values of the lateral dynamic parameters of structure and crowd are given. Based on these results $[18,40,44,45]$, it is considered that $f_{2}$ varies between 1.5 and $3.3 \mathrm{~Hz}$ and $\zeta_{2}$ varies between 0.20 and $0.25 ; f_{3}$ varies between 1.4 and $2.8 \mathrm{~Hz}$, and $\zeta_{3}$ varies between 0.3 and $0.5 ; f_{1}$ varies between 1.0 and $5.0 \mathrm{~Hz}$ and $\zeta_{1}$ varies between 0.02 and 0.073 . Then, the crowd and temporary stand interaction models with different parameter combinations are calculated. Finally, different parameters of the interaction model's responses are obtained, and the variation tendencies are analyzed.

In this model, the direction of displacement $x$ is positive, the elastic force and damping force act in the opposite direction, and $x_{1}, x_{2}$, and $x_{3}$ are the lateral displacement of structure, dynamic crowd, and static crowd, respectively. For each mass-damping-spring system, the mechanical relationship followed by each mass is calculated with Newton's second law, as shown in (5a)-(5c):

$$
\begin{aligned}
& \text { Mass of static crowd model } m_{3}:-c_{3}\left(\frac{\mathrm{d} x}{\mathrm{~d} t}-\frac{\mathrm{d} t}{\mathrm{~d} x}\right)-k_{3}\left(x_{3}-x_{1}\right)=m_{3} d^{2} \frac{x_{3}}{\mathrm{~d} t} \\
& \text { Mass of dynamic crowd model } m_{2}:-c_{2}\left(\frac{\mathrm{d} x_{2}}{\mathrm{~d} t}-\frac{\mathrm{d} x_{1}}{\mathrm{~d} t}\right)-K_{2}\left(x_{2}-x_{1}\right)=\frac{m_{2} d^{2} x_{2}}{\mathrm{~d} t+F(t)} \\
& \text { Mass of structure model } m_{1}:-c_{1}\left(\frac{\mathrm{d} x_{1}}{\mathrm{~d} t}-\frac{\mathrm{d} x_{1}}{\mathrm{~d} t}\right)-k_{2}\left(x_{2}-x_{1}\right)=\frac{m_{2} d^{2} x_{2}}{\mathrm{~d} t+F(t)}
\end{aligned}
$$




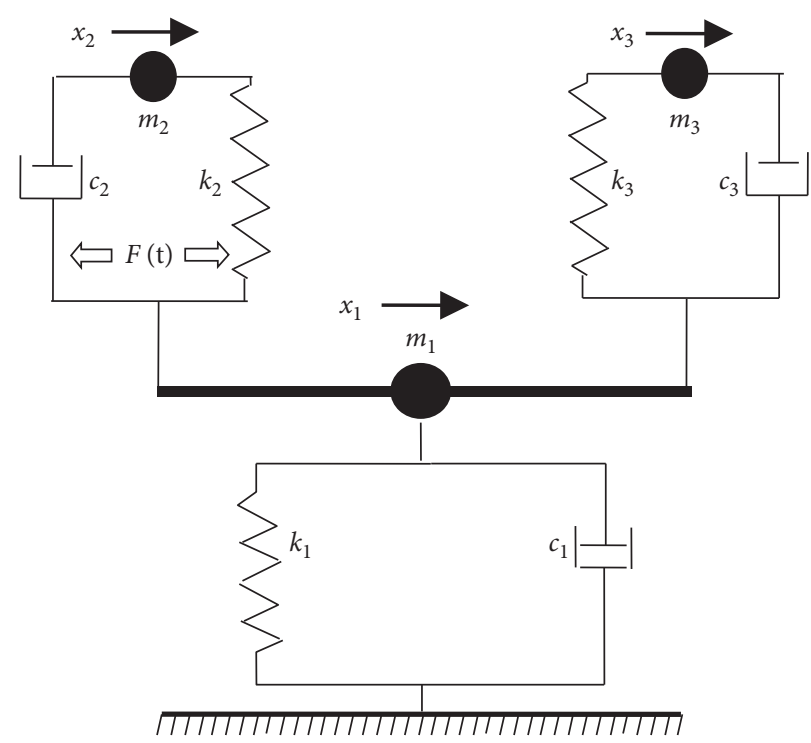

FiguRE 12: Three lumped-DOF representation of crowd-structure interaction model.

Plug equations (5a) and (5b) into (5c) and express them in matrix form as follows:

$$
[M]_{3 \times 3}\lfloor\ddot{X}\rfloor_{3 \times 1}+[C]_{3 \times 3}\lfloor K\rfloor_{3 \times 3}[X]_{3 \times 1}=[F]_{3 \times 1} \text {, }
$$

where damping $c_{i}=4 \pi m_{i} f_{i} \zeta_{1}$; stiffness $k_{i}=4 \pi 2 m_{i} f_{i}^{2}, i=1,2,3$.

The number of dynamic and static crowds will change in the structure during the use of a temporary stand; thus, the changes in the mass of the two models $m_{2}$ and $m_{3}$ are considered and expressed as $m_{3}=\alpha m_{2}$, wherein $\alpha=0$ indicates that all crowds are dynamic, $\alpha$ approaching $+\infty$ indicates that all crowds are static, and the structure is in a static state. It is assumed that there is a relationship $m_{1}=\beta m_{2}$ between the mass of the structure model and the mass of the dynamic crowd model. Dynamic crowds, especially swaying crowds in contact with the structure during movement, provide a certain frequency and damping effect to the structure.

So, the mass matrix $[M]$ in (6) can be expressed as (7a) using the previously mentioned parameters:

$$
[M]=\left[\begin{array}{ccc}
m_{1} & 0 & 0 \\
0 & m_{2} & 0 \\
0 & 0 & m_{3}
\end{array}\right]=m_{3}\left[\begin{array}{ccc}
\beta & 0 & 0 \\
0 & 1 & 0 \\
0 & 0 & \alpha
\end{array}\right] .
$$

Considering the ratio of effective crowd model mass to effective structure model mass studied in another paper [18], there is a certain relationship between the structure mass $m_{1}$ and the crowd mass $m_{2}$ and $m_{3}$. In other words, there is a quantitative relationship $m_{2}+m_{3} \leq 3 m_{1}$, and then $m_{2}+\alpha m_{2} \leq 3 \beta m_{2}$, so $1+\alpha \leq 3 \beta$.

The damping matrix $[C]$ is expressed as follows:

$$
[C]=\left[\begin{array}{ccc}
c_{1}+c_{2}+c_{3} & -c_{2} & -c_{3} \\
-c_{2} & c_{2} & 0 \\
-c_{3} & 0 & c_{3}
\end{array}\right]=4 \pi m_{2}\left[\begin{array}{ccc}
\beta f_{1} \varsigma_{1}+f_{2} \varsigma_{2}+\alpha f_{3} \varsigma_{3} & -f_{2} \varsigma_{2} & -\alpha f_{3} \varsigma_{3} \\
-f_{2} \varsigma_{2} & f_{2} \varsigma_{2} & 0 \\
-\alpha f_{2} \varsigma_{2} & 0 & \alpha f_{3} \varsigma_{2}
\end{array}\right] .
$$

The stiffness matrix $[K]$ is expressed as follows:

$$
[K]=\left[\begin{array}{ccc}
k_{1}+k_{2}+k_{3} & -k_{2} & -k_{3} \\
-k_{2} & k_{2} & 0 \\
-k_{3} & 0 & k_{3}
\end{array}\right]=4 \pi^{2} m_{3}\left[\begin{array}{ccc}
\beta f_{1}^{2}+f_{2}^{2}+f_{3}^{2} & -f_{2}^{2}-\alpha f_{3}^{2} \\
-f_{2}^{2} & f_{2}^{2} & 0 \\
-\alpha f_{3}^{2} & 0 & \alpha f_{3}^{2}
\end{array}\right] .
$$

The dynamic differential equation (6) is transformed into a state equation using the state-space method, and the system displacement is defined as the component of the state vector. The state vector is expressed as follows: 
$Z(t)=\left[\begin{array}{llllll}z_{1} & z_{2} & z_{3} & z_{4} & z_{5} & z_{6}\end{array}\right]^{T}=\left[\begin{array}{llllll}x_{1} & x_{2} & x_{3} & \dot{x}_{1} & \dot{x}_{2} & \dot{x}_{3}\end{array}\right]^{T}$.

If the system is initially in a static state, the state equation and output equation are expressed as follows:

$$
\left\{\begin{array}{l}
\dot{Z}(t)=\mathrm{AZ}(t)+\mathrm{BF} . \\
y(\mathrm{t})=\mathrm{EZ}(t)+\mathrm{DF}
\end{array}\right.
$$

where the transfer space matrix is $[A]=$

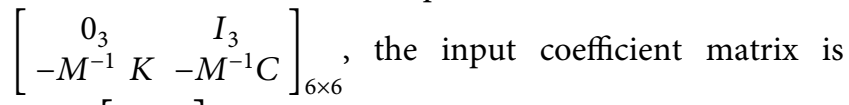
$[B]=\left[\begin{array}{l}0_{3 \times 3} \\ M^{-1}\end{array}\right]_{6 \times 3}$, the input matrix is $[E]=\left[\begin{array}{ll}I_{3 \times 3} & 0_{3 \times 3}\end{array}\right]_{3 \times 6}$, and the direct transfer matrix is $[D]=[0]_{3 \times 3}$.

The value of crowd swaying frequency is set between 1.0 and $1.8 \mathrm{~Hz}$ (in $0.1 \mathrm{~Hz}$ increments), so nine crowd swaying load curves can be simulated using (10), where the constraint parameters $H_{p}, d$, and $f$ are obtained from the experimental (Figures 1(c)-1(e)) data [17]. To ensure that the load is only affected by frequency, it is assumed that each swaying of the crowd is synchronized at each frequency and the most unfavorable state of the structure bearing the swaying load of the crowd is simulated. It is held that the peak value of the swaying curve generated by each frequency is the same. The swaying time is considered $20 \mathrm{~s}$, so nine curves are generated and shown in Figure 13, and the peak value of the curve is $0.2 m_{2} g(\mathrm{~N})$. When calculating the model, enter a time of $25 \mathrm{~s}$, and the last $5 \mathrm{~s}$ displays the attenuation process of the model.

$F_{\mathrm{ss}}(t)=\frac{2 H_{p} \sin (\pi d)}{\pi} \sin (2 \pi \mathrm{ft}) \pm \frac{2 H_{p} \sin (3 \pi d)}{3 \pi} \sin (6 \pi \mathrm{ft})$.

4.1. Changing the Dynamic Crowd Parameters. Different crowd parameters will greatly affect the response of the structure, and the crowd parameters mainly include the swaying load; frequency of static and dynamic crowd model; mass of static and dynamic crowd model; damping of static and dynamic crowd model. In order to analyze the influence of dynamic crowd parameters for structural response, the temporary stand parameters are $f_{1}=2.7 \mathrm{~Hz}, \zeta_{1}=7.3 \%$, and $\beta=1.0$, and it is assumed that $f_{3}=2.0 \mathrm{~Hz}$ and $\zeta_{3}=0.4$ [18], which is first used as a constant.

Considering the static and dynamic crowd in the use stage of the stand, the minimum value of $\alpha$ is set to 0.2 , and then, $0.8,1.4$, and 2.0 are taken as the reduction of the mass of the dynamic crowd in the total crowd. For dynamic crowd parameters, $f_{2}$ forms seven frequency values in $0.3 \mathrm{~Hz}$ increments, from $1.5 \mathrm{~Hz}$ to $3.3 \mathrm{~Hz}$, and $\zeta_{2}$ forms three damping ratios of 0.20 .225 , and 0.25 . By substituting these parameters into (6), the mass matrix, damping matrix, and stiffness matrix expressed only in variable $m_{2}$ can be obtained.

Seven hundred fifty-six coupling models are formed with nine load cases, four $\alpha$ values, three $\zeta_{2}$ values, and seven $f_{2}$ values, and the model of each parameter combination is calculated using MATLAB software (the MATLAB program in Appendix I). Figure 14 shows the acceleration curves of structure, dynamic crowd, and static crowd when $\alpha=2.0$, $f_{2}=3.3 \mathrm{~Hz}, \zeta_{2}=0.25$, and $f=1.8 \mathrm{~Hz}$. As indicated by the comparison of curve peak values, although the latter two are greater than the former, more attention is paid to the response of the structure in practical application. In addition, the structural acceleration curve form obtained by theoretical calculation is similar to the structural response obtained from the measured crowd swaying test (when the crowd is seated and swaying at $1.8 \mathrm{~Hz}$, and the peak value is divided by 16).

Considering that the VDV is the quantitative value of structural response in this paper, the VDV of 756 structural acceleration curves are extracted in Figure 15, where the $x$ axis is the swaying frequency and the $y$-axis is the acceleration of VDV. The seven curves in each figure correspond to the model results of the seven values, respectively. The three graphs in each row represent model results with the same $\alpha, \zeta_{2}=0.200,0.225$, and 0.250 respectively, and the four graphs in each column represent model results with the same $\zeta_{2}$ and $\alpha=0.2,0.8,1.4$, and 2.0, respectively. Qualitative analysis on these curves shows the following tendencies: with increasing $f$, each curve rises first and then descends gently; each curve has only one peak, and the $f$ corresponding to the peak increases with increasing $f_{2}$; the larger the $\alpha, \zeta_{2}$, and $f_{2}$ are, the smaller the structural response will be.

To further determine the impact of dynamic crowd parameter changes on structural response, the relationship between the peak values of seven curves and the corresponding values in each graph of Figure 15 is plotted to form a curve. Twelve curves are shown in Figure 16(a). The curves in the graph reflect the variation tendencies: the larger the $\zeta_{2}$ under the same $\alpha$ is, the smaller the structural response will be; the curve of $\alpha=0.2$ rises first and then descends, while the curve of $\alpha \geq 0.8$ descends directly. It can be seen that different $\alpha$ cause the structural VDV to increase or decrease first or directly with increasing $f_{2}$, and that $f_{2}$ corresponding to the peak are also different. Thus, the model of $\alpha=0.3-0.7$ is calculated and the result of $\zeta_{2}=0.2$ is shown in Figure 16(b). It shows the curve of $\alpha \leq 0.6$ still rises first and then descends, with the peak value appearing at $f_{2}=1.8 \mathrm{~Hz}$, while the curve after $\alpha>0.6 \mathrm{de}$ scends directly, with the peak value appearing at $f_{2}=1.5 \mathrm{~Hz}$. Both figures show that the structural response decreases with increasing $\alpha$.

The influence of variable parameters on structural response is quantitatively analyzed. Figure 17 shows the relationship curve between the maximum value of each graph in Figure 15 (the maximum value of each curve in Figure 16(a)) and each variable parameter. The four curves indicate that the structural response decreases linearly with the linear increase of $\zeta_{2}$, dropping by $19 \%$ when $\alpha=0.2$; by $21 \%$ when $\alpha=0.8$; and by $21 \%$ and $15 \%$ when $\alpha=1.4$ and 2.0 , respectively.

Similarly, the maximum reduction of structural VDV at different $f_{2}, \alpha$ and $\zeta_{2}$ is given in Table 5 . As shown by the data in the table, when the mass of the static crowd increases 10 times, the maximum VDV of the structure decreases by up to $90 \%$ (at $3.3 \mathrm{~Hz}$ ), and the maximum VDV of the structure 

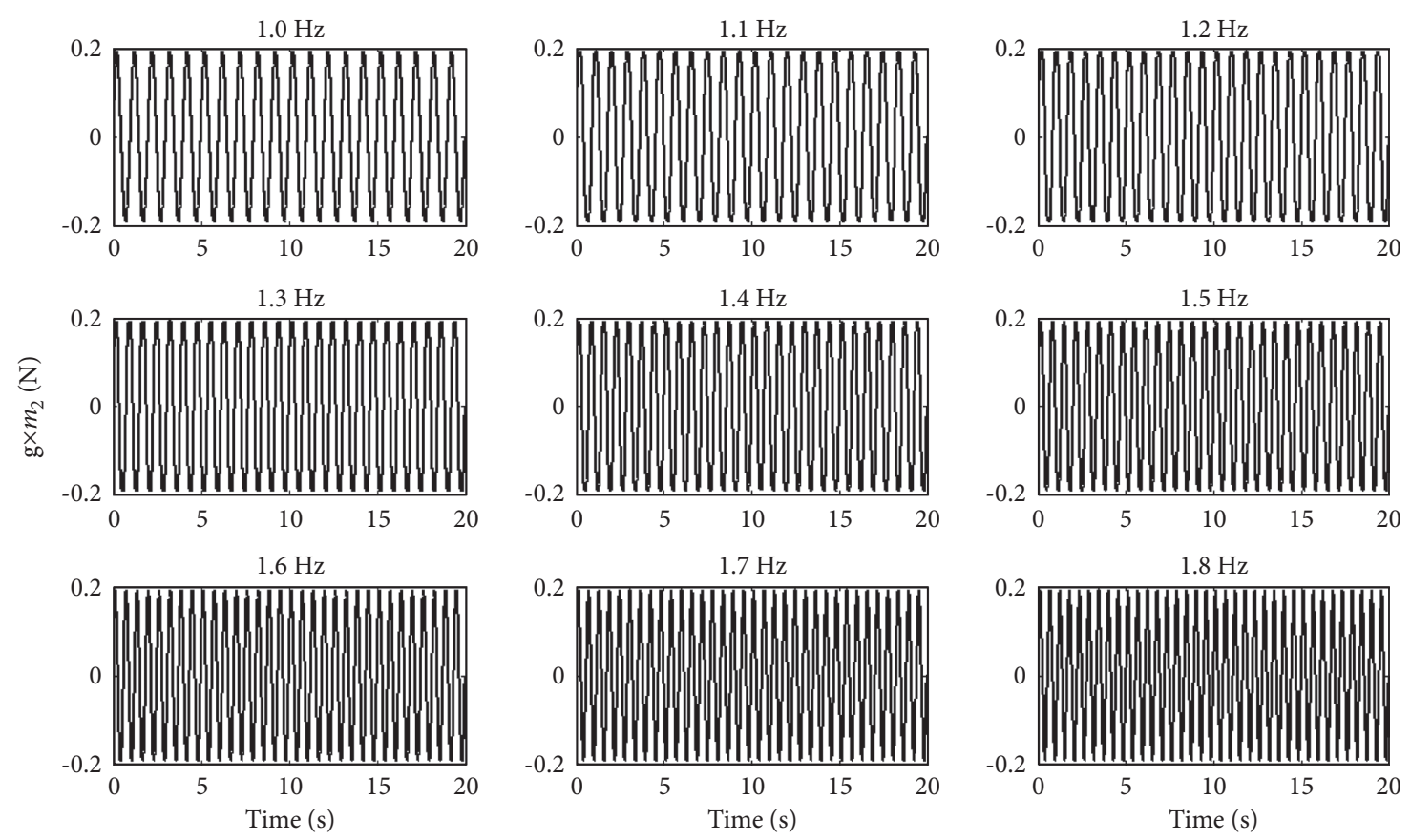

Figure 13: The simulated crowd swaying loads curves at nine frequencies.
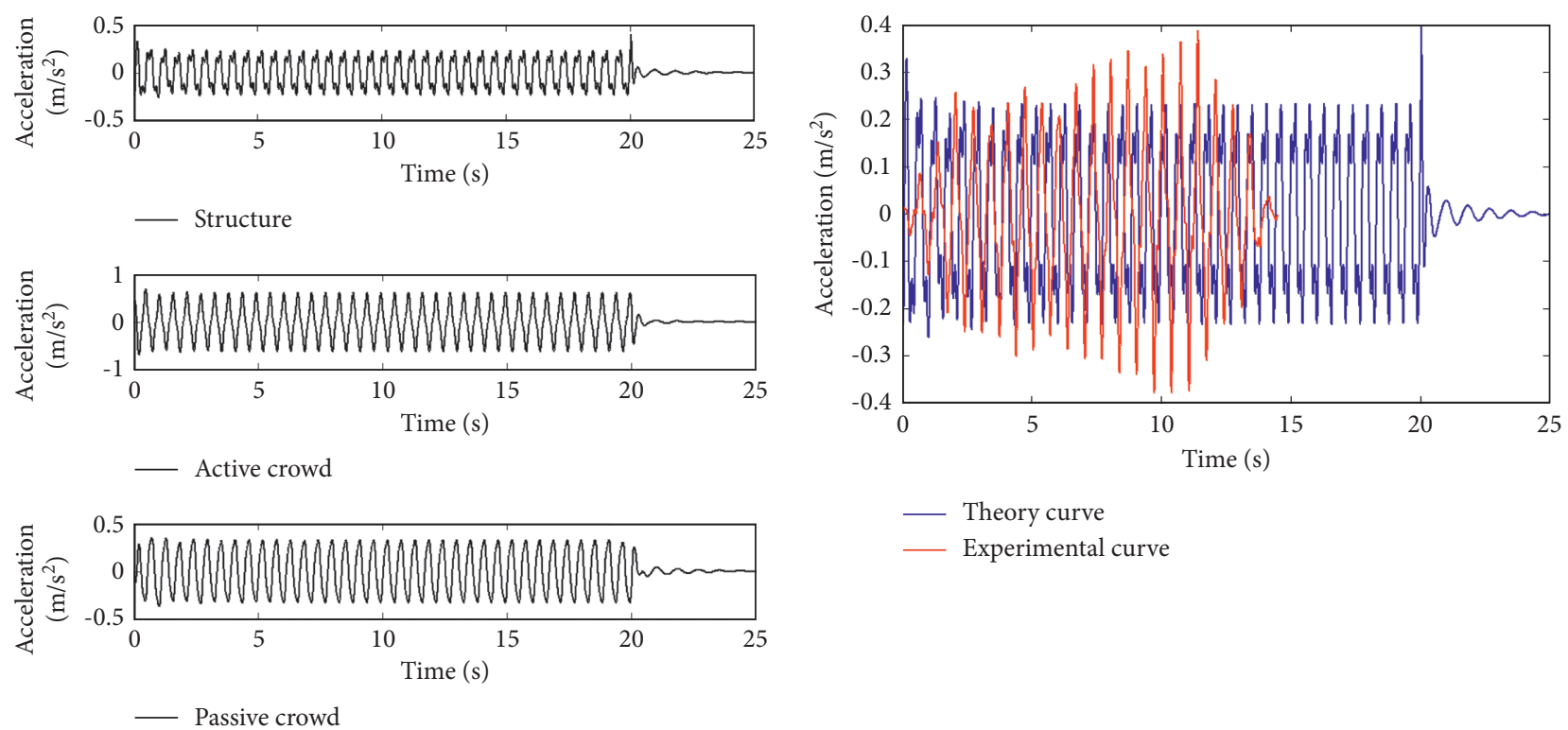

(a)

(b)

FIgURE 14: The simulated acceleration of model at swaying load. (a) The acceleration of model; (b) the theory acceleration and experimental acceleration of structure.

decreases by $23 \%$ (at $2.1 \mathrm{~Hz}$ ) when $\zeta_{2}$ increases by $25 \%$. Besides, considering the different $f_{2}$ influences on the structural response, the structural response decreases by $65-62 \%$ when $\alpha=0.2$; by $88-86 \%$ when $\alpha=0.8$; by $92-90 \%$ when $\alpha=1.4$; by $94-92 \%$ when $\alpha=2.0$.

In addition, the curve in Figure 15 shows that $f$ corresponding to the peak is different. The $f$ corresponding to the peak of the curve is shown in Table 6 .
It can be seen from the numerical trend in the table: under the same $f_{2}$, the smaller the $\alpha$, the larger the $f$ that makes the structure have a greater response; the larger the $f_{2}$, the larger the $f$ that makes the structure have a greater response, from $f=1.4 \mathrm{~Hz}$ when $f_{2}=1.5 \mathrm{~Hz}$ to $f=1.7 \mathrm{~Hz}$ when $f_{2}=3.3 \mathrm{~Hz}$. The distribution of numbers in the table shows that the corresponding $f$ varies from 1.2 to $1.7 \mathrm{~Hz}$, mainly at 1.2 $\mathrm{Hz}, 1.3 \mathrm{~Hz}$, and $1.4 \mathrm{~Hz}$. 

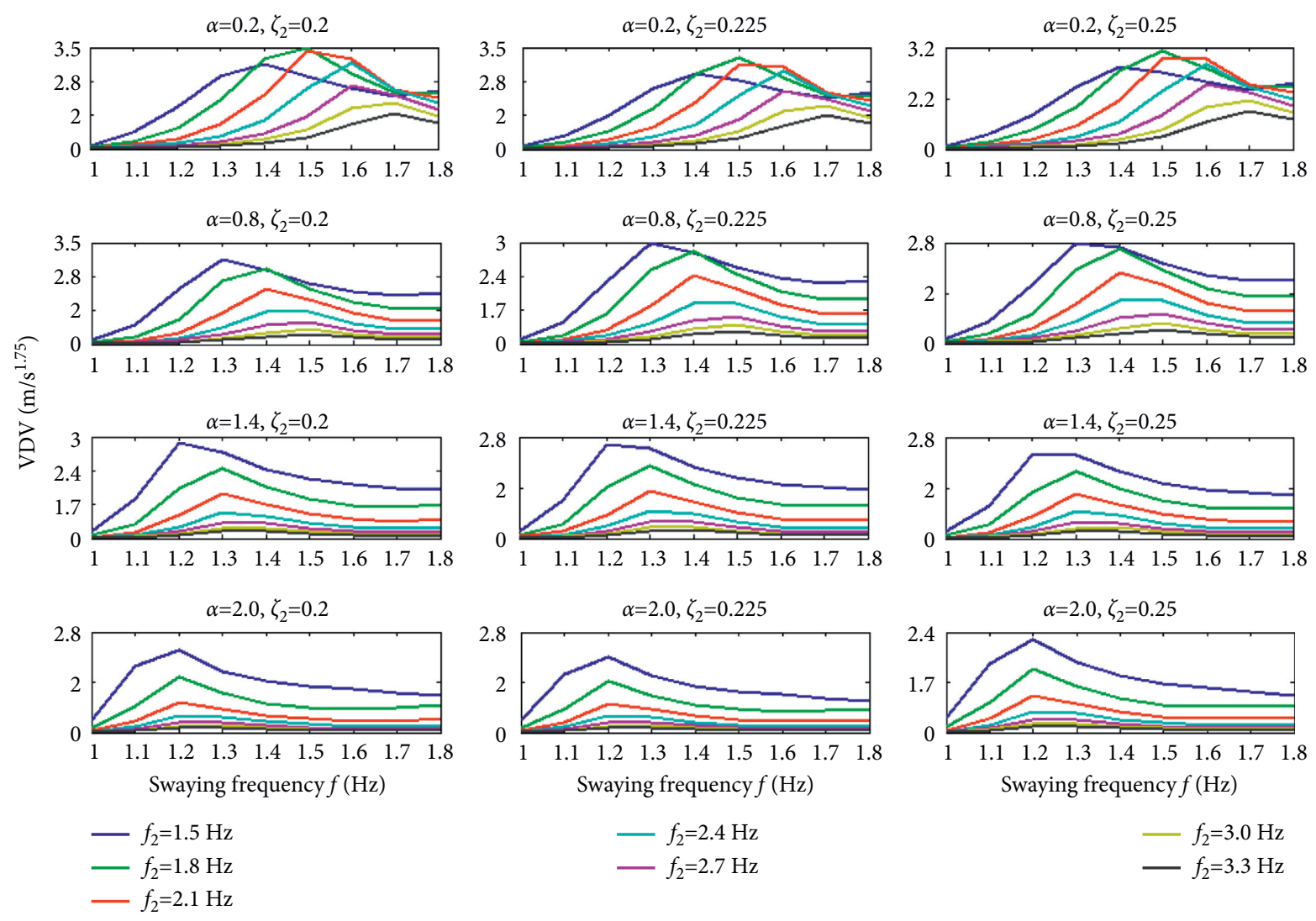

- $f_{2}=2.4 \mathrm{~Hz}$

- $f_{2}=2.7 \mathrm{~Hz}$

$-f_{2}=3.0 \mathrm{~Hz}$

- $f_{2}=3.3 \mathrm{~Hz}$

FIGURE 15: The structural dynamic responses with VDV values.
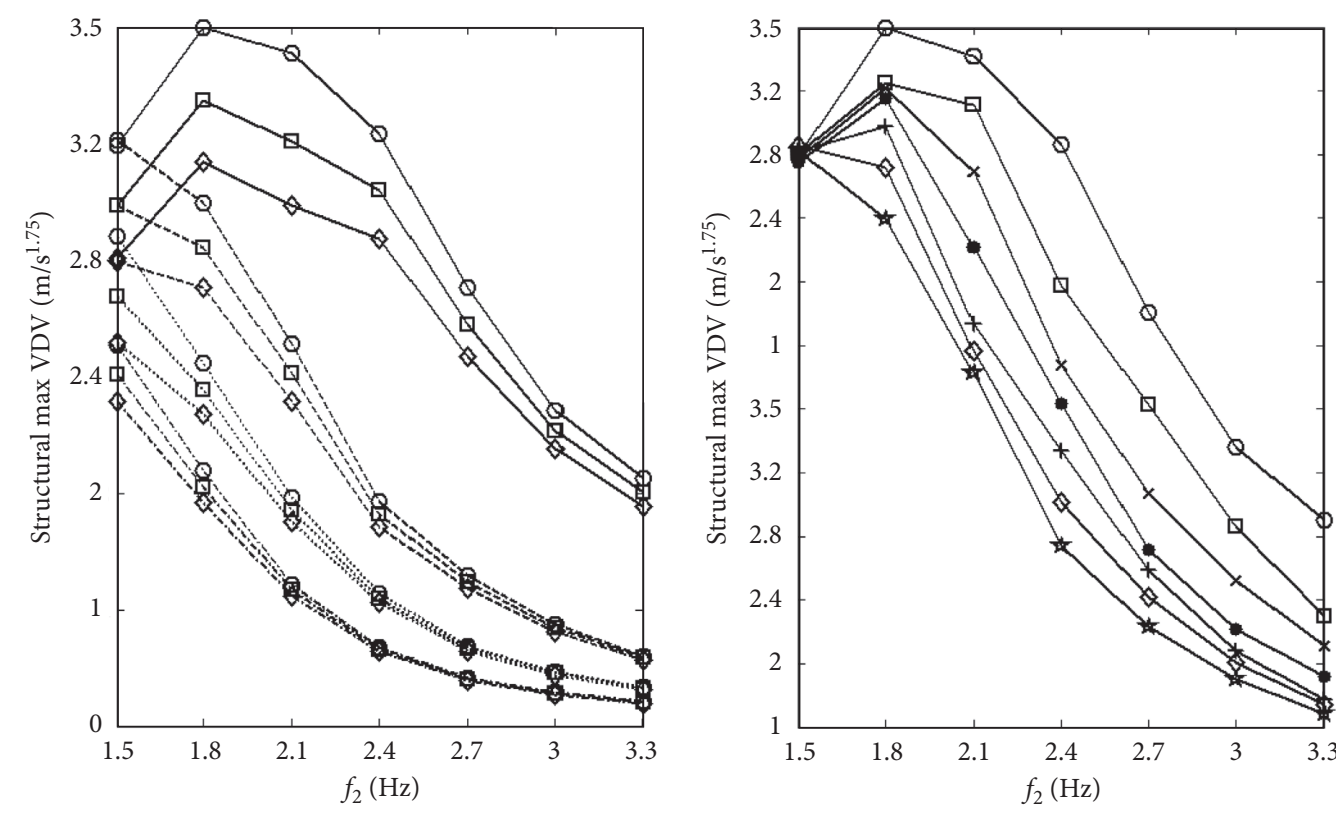

$$
\begin{array}{ll}
-\alpha=0.2, \zeta_{2}=0.2 & \cdots \cdots \alpha=1.4, \zeta_{2}=0.2 \\
\square \alpha=0.2, \zeta_{2}=0.225 & \bullet \cdot \alpha=1.4, \zeta_{2}=0.225 \\
\diamond \alpha=0.2, \zeta_{2}=0.25 & \diamond \cdot \alpha=1.4, \zeta_{2}=0.25 \\
-\ominus-\alpha=0.8, \zeta_{2}=0.2 & \bullet-\alpha=2.0, \zeta_{2}=0.2 \\
-\boxminus-\alpha=0.8, \zeta_{2}=0.225 & \bullet-\alpha=2.0, \zeta_{2}=0.225 \\
-\diamond-\alpha=0.8, \zeta_{2}=0.25 & \diamond-\alpha=2.0, \zeta_{2}=0.25
\end{array}
$$

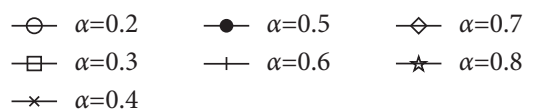

(a)

(b)

FIGURE 16: The influence of active crowd parameters on structural dynamic responses. (a) The max VDV with $f_{2} \alpha \zeta_{2}$; (b) the max VDV when $\alpha$ between 0.2 and 0.8 . 


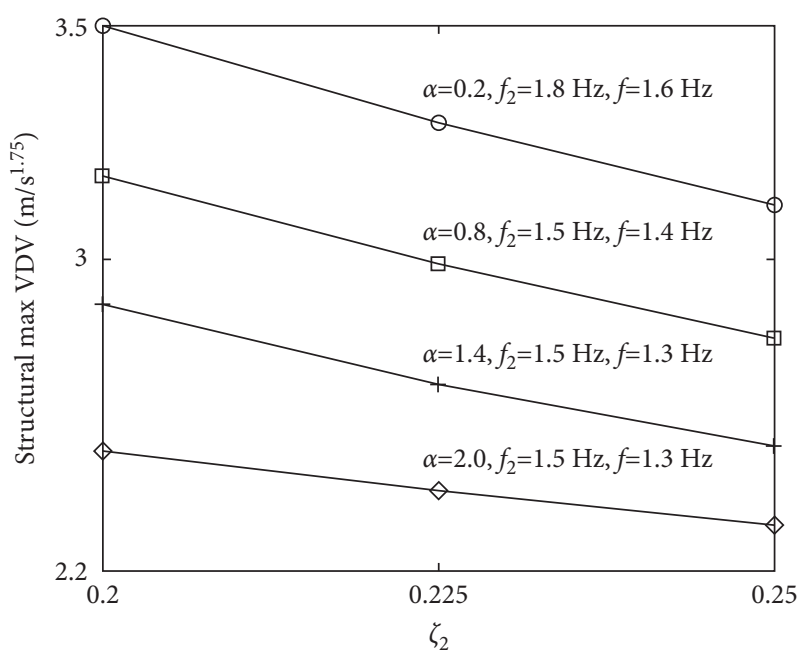

Figure 17: The influence of $\zeta_{2}$ on structural dynamic responses.

TABLE 5: The max VDV corresponding to variate parameters of active crowd.

\begin{tabular}{lcccccccc}
\hline \multicolumn{2}{l}{ Parameter } & \multicolumn{9}{c}{ The degree of reduction (\%) } \\
& & $1.5 \mathrm{~Hz}$ & $1.8 \mathrm{~Hz}$ & $2.1 \mathrm{~Hz}$ & $2.4 \mathrm{~Hz}$ & $2.7 \mathrm{~Hz}$ & $3.3 \mathrm{~Hz}$ & $3.3 \mathrm{~Hz}$ \\
\hline$\alpha$ & $0.2-2.0$ & 34 & 64 & 79 & 87 & 89 & 89 & 90 \\
$\zeta_{2}$ & $0.20-0.25$ & 22 & 19 & 23 & 18 & 16 & 12 \\
\hline
\end{tabular}

TAвLE 6: The peak of structural dynamic response corresponding to swaying frequencies.

\begin{tabular}{|c|c|c|c|c|c|c|c|}
\hline \multirow{2}{*}{$f(\mathrm{~Hz})$} & \multicolumn{7}{|c|}{$f_{2}(\mathrm{~Hz})$} \\
\hline & 1.5 & 1.8 & 2.1 & 2.4 & 2.7 & 3.0 & 3.3 \\
\hline \multicolumn{8}{|l|}{1.0} \\
\hline \multicolumn{8}{|l|}{1.1} \\
\hline $\begin{array}{l}1.2 \\
1.3\end{array}$ & $\begin{array}{l}a-l \\
d-f\end{array}$ & ${ }^{j-l}$ & $j-l$ & $j-l$ & $l$ & & \\
\hline $\begin{array}{l}1.3 \\
1.4\end{array}$ & $d-f$ & $g-i$ & $g-i$ & $g-i$ & $g-k$ & $g-l$ & $g-l$ \\
\hline 1.4 & $a-c$ & $d-f$ & $d-f$ & $d-f$ & $d-f$ & & \\
\hline 1.5 & & $a-c$ & $a-c$ & & & $d-f$ & $d-f$ \\
\hline 1.6 & & & & $a-c$ & $a-c$ & & \\
\hline 1.7 & & & & & & $a-c$ & $a-c$ \\
\hline 1.8 & & & & & & & \\
\hline
\end{tabular}

$a$ to $l$ stands for $a-\alpha=0.2, \zeta_{2}=0.2 ; b-\alpha=0.2, \zeta_{2}=0.225 ; c-\alpha=0.2, \zeta_{2}=0.25 ; d-\alpha=0.8, \zeta_{2}=0.2 ; e-\alpha=0.8, \zeta_{2}=0.225 ; f-\alpha=0.8, \zeta_{2}=0.25 ; g-\alpha=1.4, \zeta_{2}=$ $0.2 ; h-\alpha=1.4, \zeta_{2}=0.225 ; i-\alpha=1.4, \zeta_{2}=0.25 ; j-\alpha=2.0, \zeta_{2}=0.2 ; k-\alpha=2.0, \zeta_{2}=0.225 ; l-\alpha=2.0, \zeta_{2}=0.25$.

4.2. Changing the Static Crowd Parameters. The content in Section 3.1 is prepared based on $f_{3}=2.0 \mathrm{~Hz}$ and $\zeta_{3}=0.4$. The curve in Figure 16(a) shows that, due to different $\alpha$, the structure VDV may reach its maximum when $f_{2}=1.5 \mathrm{~Hz}$ and $\zeta_{2}=0.2$ or $f_{2}=1.8 \mathrm{~Hz}$ and $\zeta_{2}=0.2$. According to this, for analyzing the influence of static crowd parameters of model's structural responses, $f_{3}$ is set between 1.4 and $2.8 \mathrm{~Hz}$ and taken at $0.2 \mathrm{~Hz}$ intervals (eight in total), $\zeta_{3}$ is set between 0.3 and 0.5 and taken at 0.1 intervals (three in total), and $\alpha$ is set at $0.2,0.8,1.4$, and 2.0 . Then, 864 coupling model parameter combinations are formed (the program of MATLAB software is shown in Appendix I).

First, taking the model of $f_{2}=1.5 \mathrm{~Hz}, \zeta_{2}=0.2$ as an example, the structural acceleration curves of models $f_{3}=2.8 \mathrm{~Hz}, \zeta_{3}=0.5, \alpha=2.0$, and $f=1.8 \mathrm{~Hz}$ are shown in
Figure 18(a), and the curve form is still similar to the measured structural curve (crowd standing and swaying at $1.8 \mathrm{~Hz}$, and the peak value is divided by 4 ). Just like Figure 15, the relationship curves between the VDV of all model structures and different dynamic crowd parameters are obtained, as shown in Figure 18(b). The curve variation tendencies are as follows: with increasing $f$, the curve first rises and then descends gently, and there is a unique peak. The larger the $f_{3}$, the greater the structural response. The $f$ corresponding to the peak value of the curve decreases with increasing $\alpha$. To check whether the variation tendencies of acceleration curves in the other two forms are consistent with the previously mentioned phenomena, the RMS and peak value curve in the bottom right corner of Figure 14(b) are given in this paper, as shown in Figure 18(c). Compared 


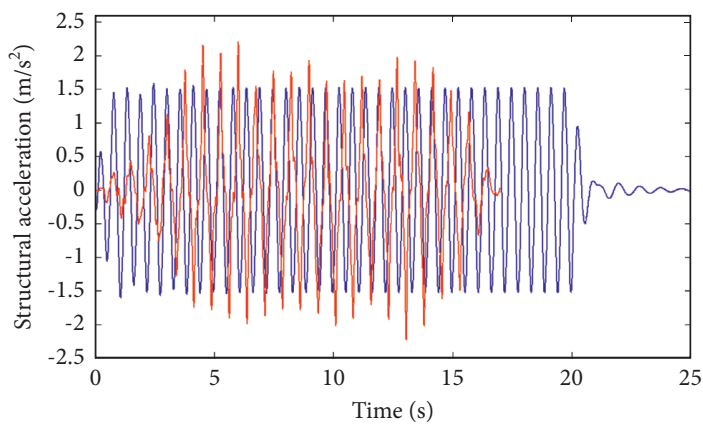

the measured structual curve

(a)

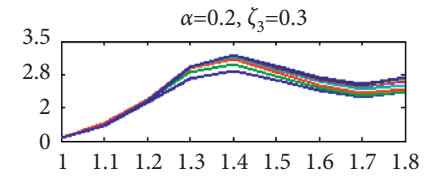

$\alpha=0.2, \zeta_{3}=0.4$
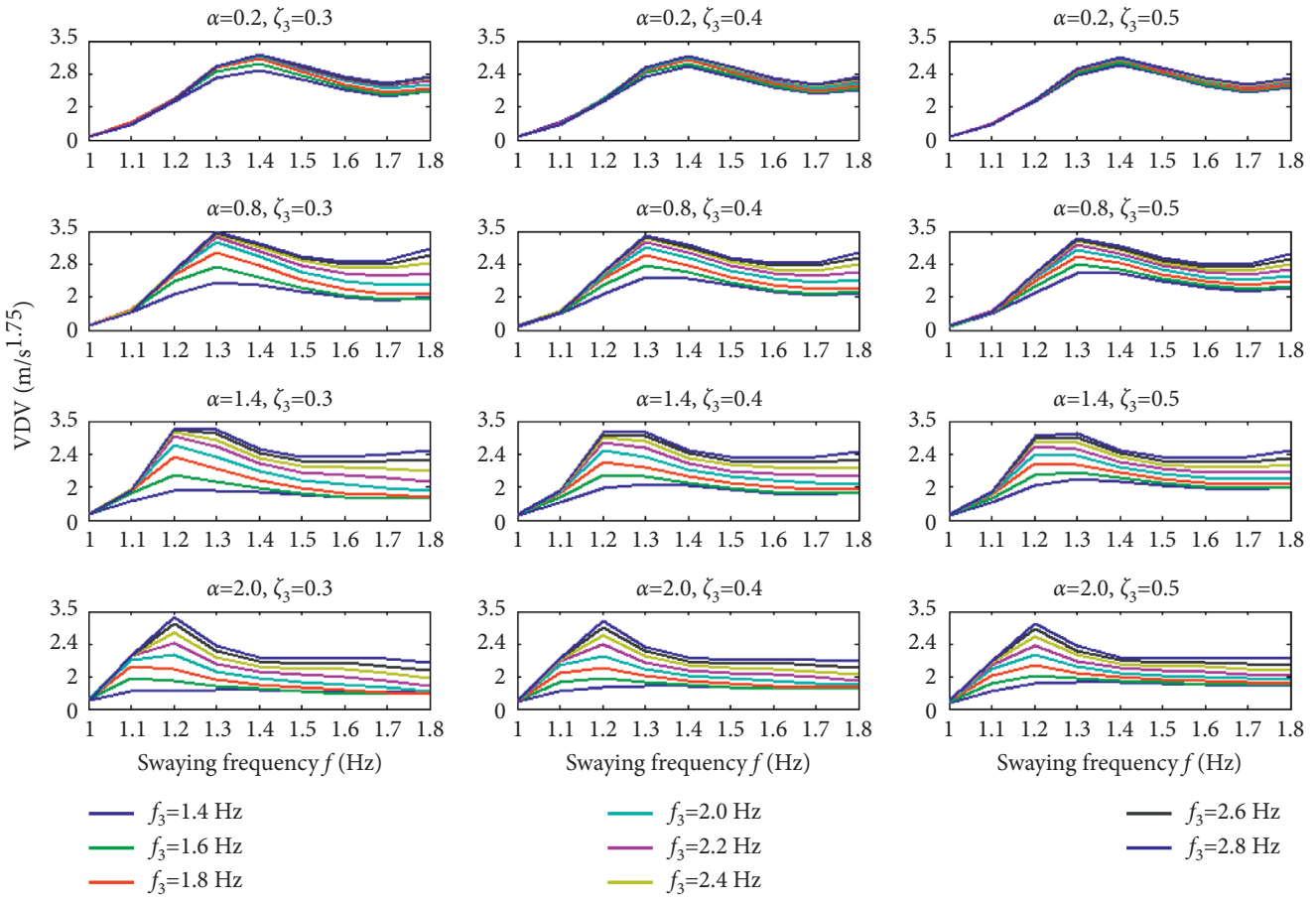

$-f_{3}=2.0 \mathrm{~Hz}$
$-f_{3}=2.2 \mathrm{~Hz}$
$f_{3}=2.4 \mathrm{~Hz}$

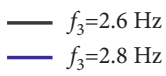

(b)
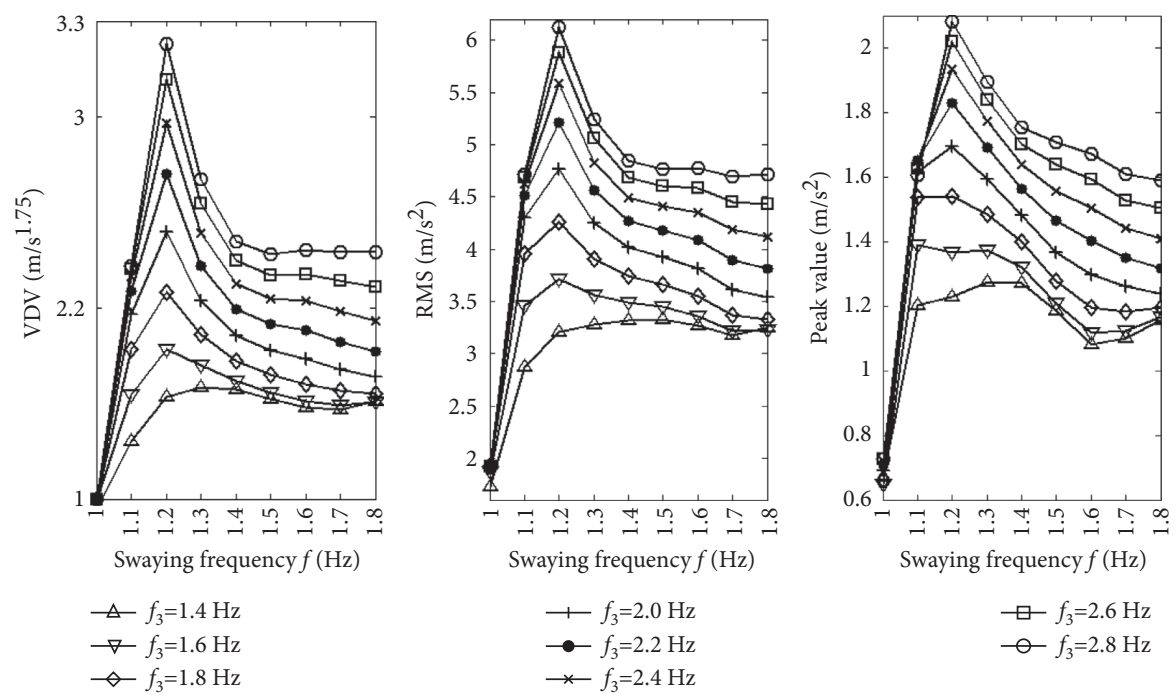

$\square f_{3}=2.6 \mathrm{~Hz}$

$-f_{3}=2.8 \mathrm{~Hz}$

(c)

FIGURE 18: The structural dynamic responses of models with different passive crowd parameters. (a) The structural acceleration curve of one model at swaying load; (b) the structural acceleration VDV of models; (c) the acceleration VDV, RMS and peak values with swaying frequencies. 
with the VDV curve, except for different values, the variation tendencies of each corresponding curve are basically the same, especially the curve represented by RMS. The rationality of analyzing the variation of static crowd parameters to structural response with VDV is hereby further proved.

Second, the relationship curve between the peak value of each curve and the $f_{3}$ in Figure 18(b) is given, as shown in Figure 19. The curve in the figure shows the following variation tendencies: with increasing $f_{3}$, the structural response increases and reaches its maximum when $f_{3}=2.8 \mathrm{~Hz}$; for the curve with the same $\alpha$, the higher the $\zeta_{3}$ is, the larger the structural response will be. Only when $f_{3}$ is greater than a certain value (e.g., $f_{3} \geq 1.8 \mathrm{~Hz}$ when $\alpha=0.2 ; f_{3} \geq 1.7 \mathrm{~Hz}$ when $\alpha=0.8$ and 1.4; and $f_{3} \geq 2.0 \mathrm{~Hz}$ when $\alpha=2.0$ ), the higher the $\zeta_{3}$ is, the smaller the structural response will be. In addition, the structural response of the model with $\alpha>0.2$ is larger than that of the model with $\alpha=0.2$. For example, when $\alpha=0.8$, the structural response is significantly larger than that of other cases.

From the curve variations in Figure 19, it can be concluded that there is no negative correlation between the $\alpha$ and the structure's VDV. Therefore, other $\alpha(0.4,0.6,1.0,1.2$, 1.6 , and 1.8) are also calculated. The model results of $\zeta_{3}=0.3$ and $\zeta_{3}=0.5$ are, respectively, shown in the left and right graphs of Figure 20. The $x$-axis represents the $\alpha$, and each curve represents the change in maximum VDV of the structure's $f_{3}$. The curves show that the VDV of the structure with $\alpha=0.2$ reaches its maximum when $f_{3} \leq 1.8 \mathrm{~Hz}$ (red curves), the VDV of the structure with $\alpha=0.8$ reaches its maximum when $f_{3}=2.0-2.4 \mathrm{~Hz}$ (bule curves), and the VDV of the structure with $\alpha=1.0$ reaches the maximum when $f_{3}=2.6-2.8 \mathrm{~Hz}$ (black curves). It maybe indicated that not the more static crowd the responses of structure is little, it also depends on $f_{3}$.

Third, the same drawing method is used to sort out the model results of other $f_{2}$, and the result curve of $\zeta_{3}=0.3$ is taken as an example, as shown in Figure 21. There are six graphs in the figure, respectively, representing the model of $f_{2}$ at $1.8-3.3 \mathrm{~Hz}$. Compared with Figure 20, it is found that, with increasing $f_{2}$, the curve variation tendencies gradually becomes unified and decreases with increasing $\alpha$. Moreover, by comparing the values of each curve, it is concluded that the smaller $f_{2}$ and the larger $f_{3}$ are, the greater the model structure's VDV will be. Then, the result curve with $\zeta_{3}=0.5$ is given, as shown in Figure 22. The curve variation tendencies and the structural VDV variations caused by parameters are basically the same as Figure 21.

Finally, the decrease (increase) of structural response caused by different static crowd parameters under the previously mentioned dynamic crowd parameter model is calculated. Table 7 shows the maximum structure VDV caused by difference in $\alpha$ and $\zeta_{3}$, and the negative value indicates that the structural response is increasing. According to the data, $\alpha$ influences on structural response are greater than $\zeta_{3}$ influences, and what is interesting is that when $f_{2}=2.7 \mathrm{~Hz}$ and $f_{2}=3.3 \mathrm{~Hz}$. The higher the $\zeta_{3}$ is, the greater the model structure's VDV will be. Besides, the structural response with the $\zeta_{3}$ increasing from $1.4 \mathrm{~Hz}$ to $2.8 \mathrm{~Hz}$ shows an average increase of 3.8 times.
Similarly, the $f$ corresponding to the maximum VDV of the model structure is sorted out, as shown in Table 8. The numbers in brackets represent the model results of $\zeta_{3}=0.3$, and the numbers outside the brackets represent the model results of $\zeta_{3}=0.5$. According to the distribution of numbers, with increasing $\alpha$, the lower the swaying frequency, the greater the structural response, and $f$ is mainly concentrated between $1.2-1.4 \mathrm{~Hz}$. The swaying frequency range is similar to the results of dynamic crowd parameter analysis (Table 6).

To explain the reason for this phenomenon, the structural response of models $f_{2}=1.5 \mathrm{~Hz}, \zeta_{2}=0.2, f_{3}=2.0 \mathrm{~Hz}$, $\zeta_{3}=0.3$, and $\alpha=2.0$ at $f=1.0 \mathrm{~Hz}, 1.3 \mathrm{~Hz}$, and $1.8 \mathrm{~Hz}$ are taken as examples, and the time domain curve and frequency domain results are given, as shown in Figure 23. The peak value of the time-history curve in the figure shows that the peak value of the structural acceleration appears at $1.3 \mathrm{~Hz}$. As shown by the corresponding frequency domain analysis, both first-order and third-order $1.3 \mathrm{~Hz}$ and $1.8 \mathrm{~Hz}$ swaying loads contribute to the structure, while the contribution to the structure is the largest under the action of the $1.3 \mathrm{~Hz}$ swaying load. The reason may be that $f_{1}$ in the coupling model is set to $2.7 \mathrm{~Hz}$, and $f=1.3 \mathrm{~Hz}$ is close to $1 / 2$ of the structural frequency. The reason why the third-order frequency acts on the structure is that the contribution of the third-order frequency is considered in the calculation formula of the swaying load curve.

4.3. Changing the Structure Parameter. Because $1+\alpha \leq 3 \beta$ in the first part of Section 3, and when $\beta$ is set as $0.5, \alpha \leq 0.5$, so $\alpha$ is set as $0.2,0.3,0.4$, and 0.5 (four in total). In order to analyze the different structure parameters influence on structural response, the crowd parameters should be regarded as constants. According to the crowd frequency without loss of generality, the $f_{2}$ changes between $1.5 \mathrm{~Hz}$ and $3.3 \mathrm{~Hz}$ (in $0.3 \mathrm{~Hz}$ increments), for a total of seven values, and the $f_{3}$ changes between $1.4 \mathrm{~Hz}-2.8 \mathrm{~Hz}$ (in 0.2 increments), for a total of eight values. Although $f_{2}$ and $f_{3}$ are variables, any combination of the two is taken as a constant in this section. For the crowd damping ratio, only the parameter values making the structure produce the maximum VDV are considered to simplify the complexity of the model parameters. Since it has been determined above that, when $\zeta_{2}=0.2$, the model structure VDV reaches its maximum. Considering that $\zeta_{3}=0.3$ and $\zeta_{3}=0.5$ have a little impact on the response of the structure, $\zeta_{3}=0.3$ and $\zeta_{2}=0.2$ are taken as invariants. As shown in Figure 24, the change relationship between VDV and the $f$ of the model structure with combination parameters $f_{2}=1.8 \mathrm{~Hz}$ and $f_{3}=2.8 \mathrm{~Hz}$ is displayed. Four longitudinal graphs show the model results of $\alpha=0.2$, $0.3,0.4$, and 0.5 ; three transverse graphs show the model results of $\zeta_{1}=0.02,0.05$, and 0.073 .

Furthermore, the peak value of the curve in Figure 24 and the $f$ corresponding to other model curves are sorted out. It is concluded that when $f_{1}=1.0-1.5 \mathrm{~Hz}$, the peak value appears at $f=1.8 \mathrm{~Hz}$, and, when $f_{1}=2.0 \mathrm{~Hz}$, the peak value appears at $f=1.0 \mathrm{~Hz}$. Then, with increasing the structural frequency, the $f$ making the structure produce the maximum response increases from $1.1 \mathrm{~Hz}$ to $1.7 \mathrm{~Hz}$. 

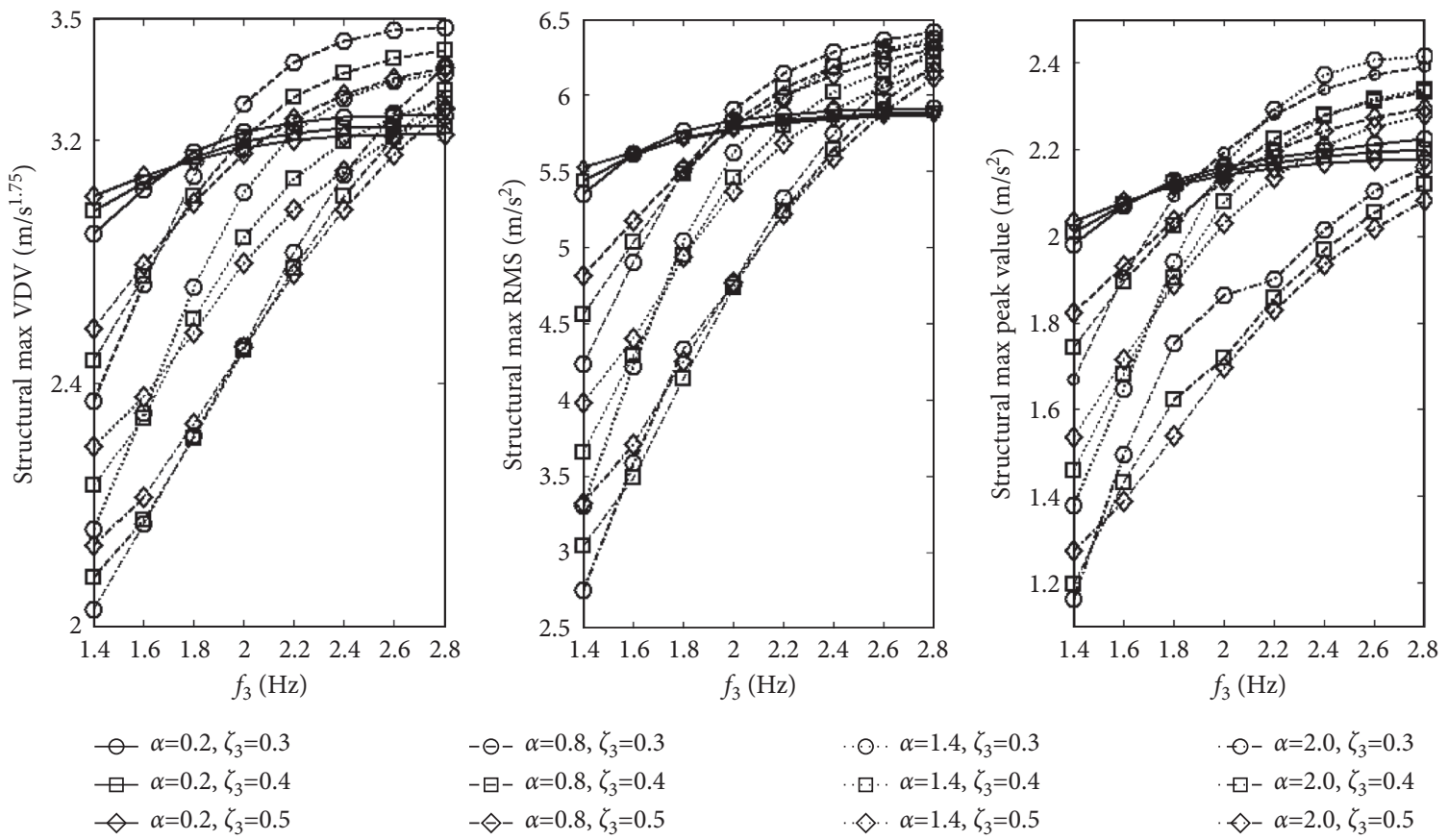

$\odot-\alpha=2.0, \zeta_{3}=0.3$

$\bigoplus-\alpha=2.0, \zeta_{3}=0.4$

$\diamond-\alpha=2.0, \zeta_{3}=0.5$

FIGURE 19: The influence of passive crowd parameters on structural dynamic responses of max acceleration VDV, RMS, and peak values.
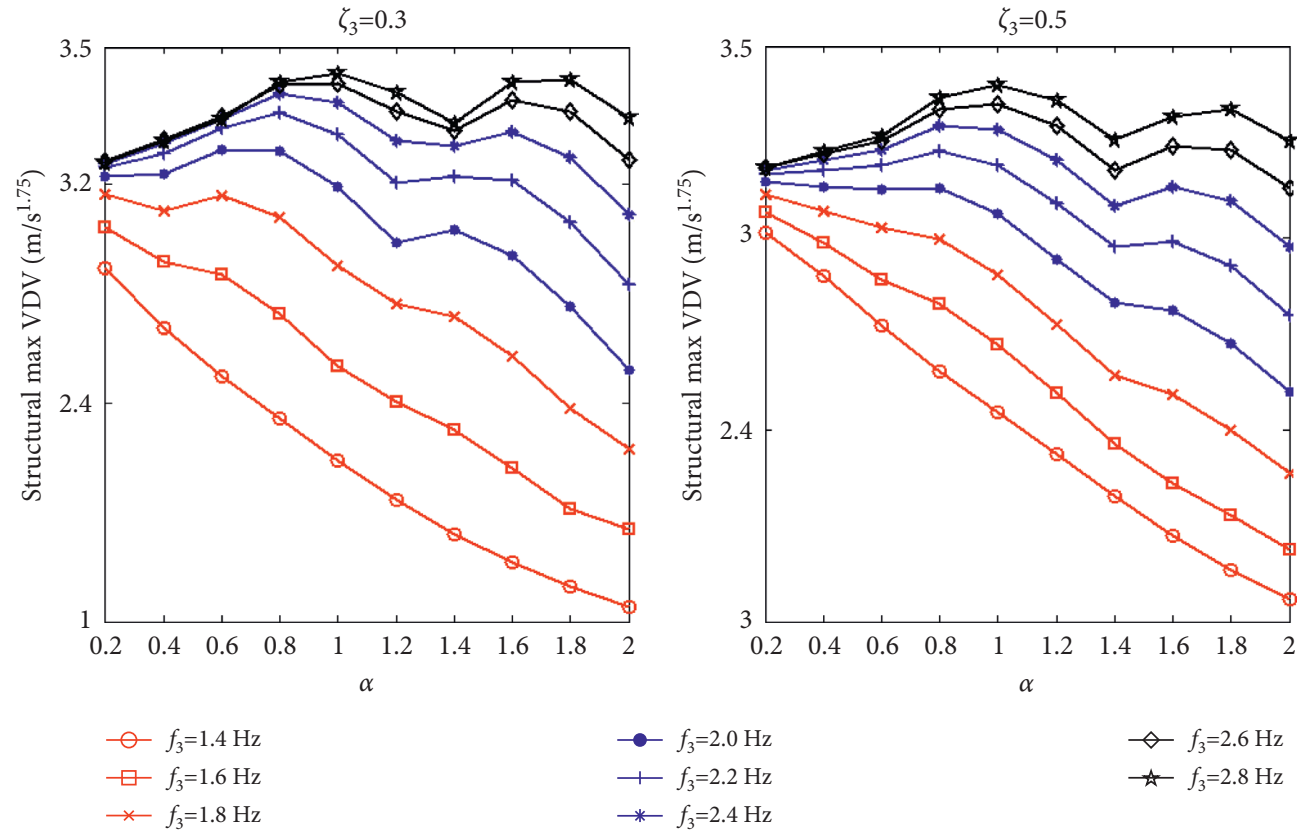

Figure 20: The influence of different $\alpha$ on max acceleration VDV when $f_{2}=1.5 \mathrm{~Hz}$.

To analyze the curve variation tendencies in more detail, for example, the model results of $\alpha=0.5, \zeta_{1}=0.073$ are represented by VDV, RMS, and peak value, respectively, as shown in Figure 25. The variation tendency of the three curves are basically the same; that is, the structural response of $f_{1} \leq 1.5 \mathrm{~Hz}$ increases unidirectionally with $f$, the structural response of $f_{1}=2.0 \mathrm{~Hz}$ decreases first and then increases, and the structural response of $f_{1} \geq 2.5 \mathrm{~Hz}$ increases first and then decreases.
When analyzing the structure parameter influences on structural response, the relationship curve between the maximum VDV and $f_{1}$ with the same $\alpha$ and different $\zeta_{1}$ is given, as shown in Figure 26. The curve in the figure shows that the smaller the $\zeta_{1}$ is, the greater the structural response will be, but the influence of $\zeta_{1}$ on structural response is related to $f_{1}$. Only when $f_{1}$ is between 2.0 and $4.0 \mathrm{~Hz}$ will an increase in the $\zeta_{1}$ effectively reduce the structural VDV. In addition, the curve rises first and then descends, and the 

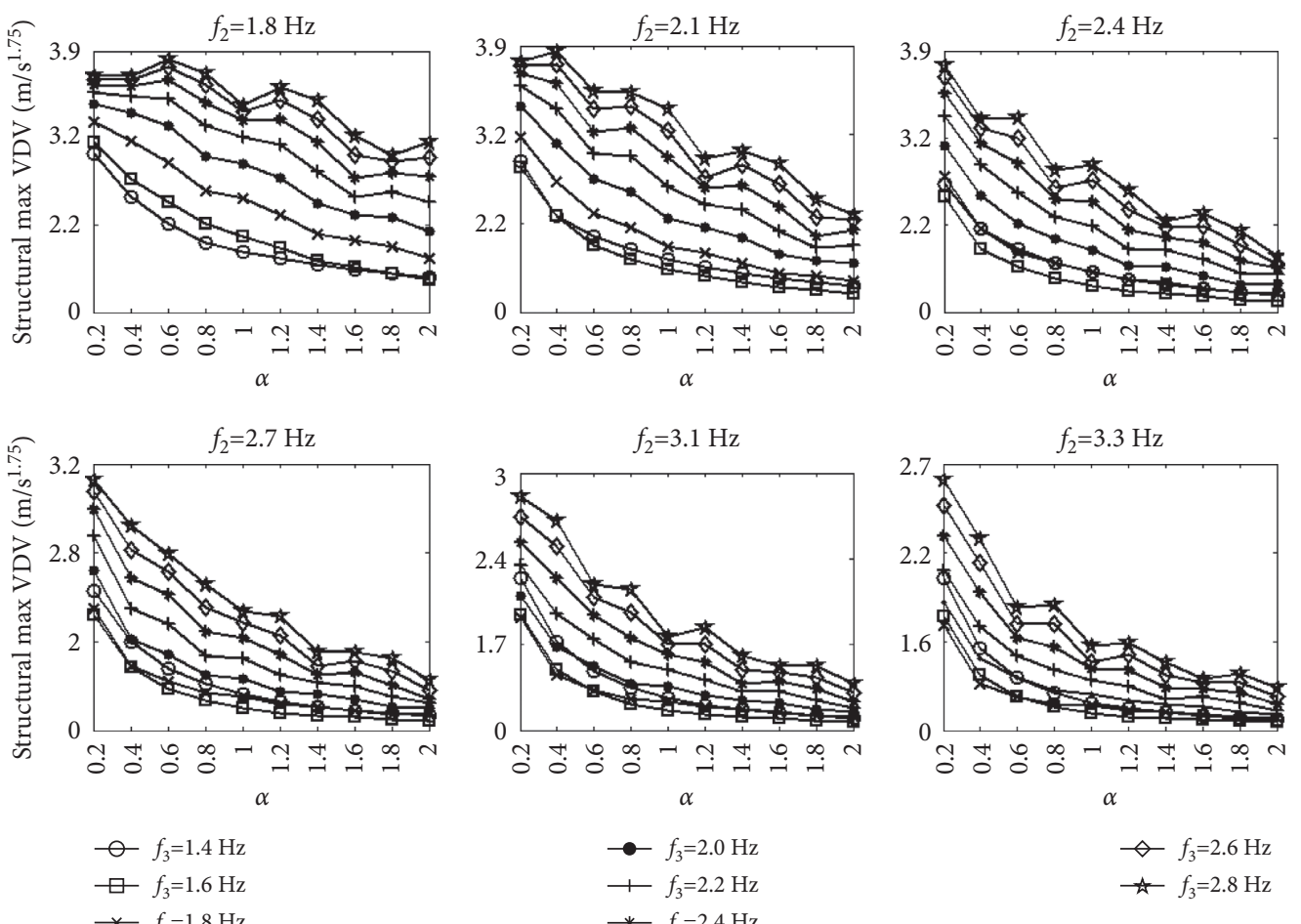

$$
\begin{aligned}
& \curvearrowleft f_{3}=1.4 \mathrm{~Hz} \\
& \square f_{3}=1.6 \mathrm{~Hz} \\
& \times f_{3}=1.8 \mathrm{~Hz}
\end{aligned}
$$$$
\longrightarrow f_{3}=2.0 \mathrm{~Hz}
$$$$
+f_{3}=2.2 \mathrm{~Hz}
$$$$
\text { * } f_{3}=2.4 \mathrm{~Hz}
$$

Figure 21: The influence of other $f_{2}$ values on structural dynamic responses when $\zeta_{3}=0.3$.
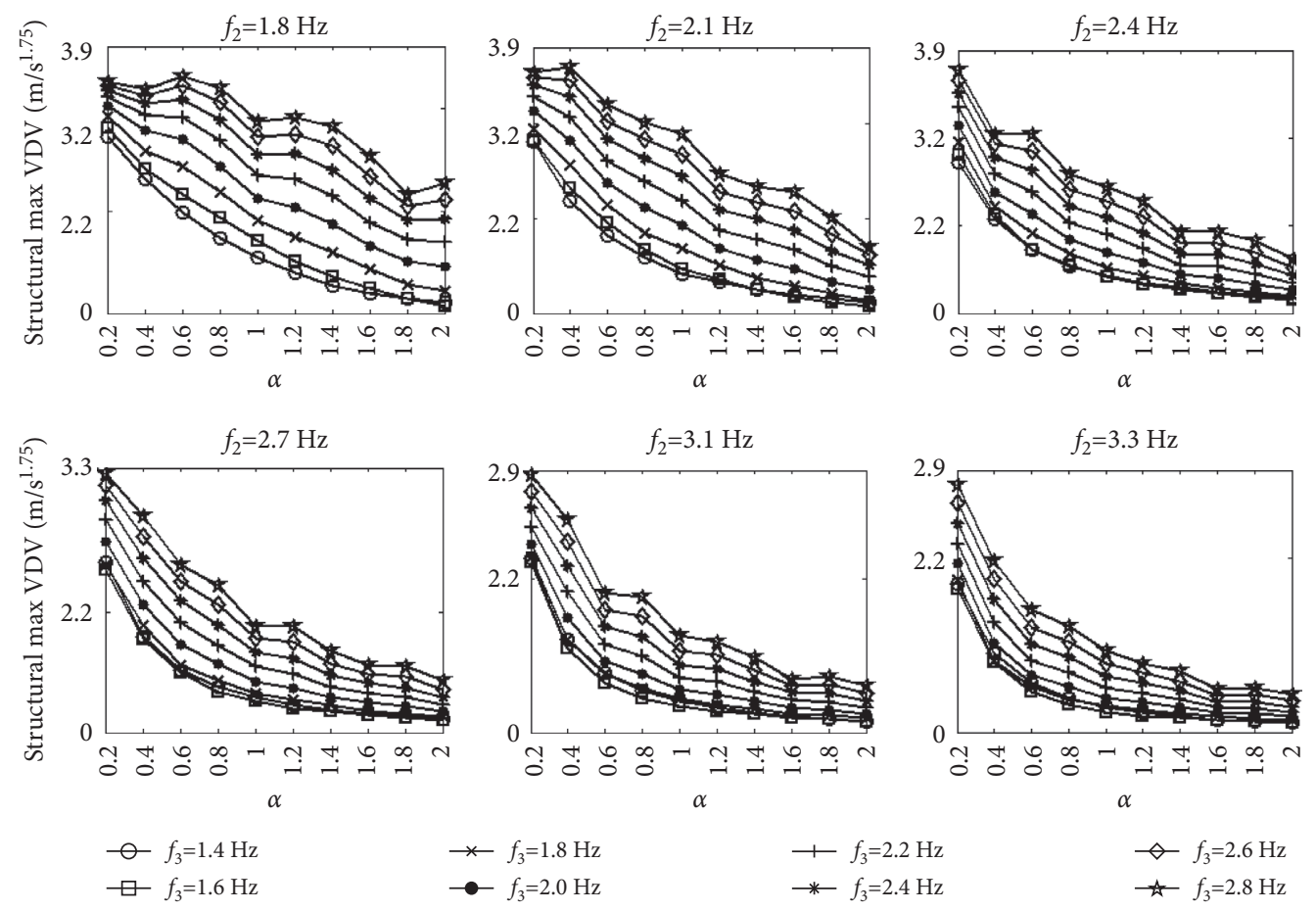

FIGURE 22: The influence of other $f_{2}$ values on structural dynamic responses when $\zeta_{3}=0.5$.

peak value appears at $f_{1}=2.5 \mathrm{~Hz}$ or $3.0 \mathrm{~Hz}$, indicating that the structure with this frequency is easy to produce a large VDV under swaying load. The model of the crowd parameter combination shows that the structure parameter corresponding to the maximum structural VDV is $f_{1}=2.5 \mathrm{~Hz}, \zeta_{1}=2 \%$, and $\alpha=0.5$.
The influence of structure parameters on structural response under the combination of other $f_{2}$ and $f_{3}$ is further analyzed. It has been determined that the structural response is largest when $\zeta_{1}=2 \%$; for simplicity, only the model results corresponding to this parameter are analyzed. Figures $27(\mathrm{a})-$ 27 (d) show the model results of $\alpha=0.2,0.3,0.4$, and 0.5 , 
TABLE 7: The max VDV corresponding to variate parameters of passive crowd.

\begin{tabular}{lccccccccc}
\hline \multicolumn{2}{l}{ Parameter } & \multicolumn{9}{c}{ The degree of reduction (\%) } \\
& & $1.4 \mathrm{~Hz}$ & $1.6 \mathrm{~Hz}$ & $1.8 \mathrm{~Hz}$ & $2.0 \mathrm{~Hz}$ & $2.2 \mathrm{~Hz}$ & $2.4 \mathrm{~Hz}$ & $2.6 \mathrm{~Hz}$ & $2.8 \mathrm{~Hz}$ \\
\hline$\alpha$ & $0.2-2.0$ & 63 & 60 & 57 & 64 & 61 & 69 & 68 \\
$\zeta_{3}$ & $0.3-0.5$ & -47 & -12 & -3 & 26 & 30 & 31 & 30 \\
\hline
\end{tabular}

TABLE 8: The peak of structural dynamic response corresponding to $f$ with three kinds of model.

\begin{tabular}{|c|c|c|c|c|c|c|c|c|}
\hline \multirow{2}{*}{$f(\mathrm{~Hz})$} & \multicolumn{8}{|c|}{$f_{3}(\mathrm{~Hz})$} \\
\hline & 1.4 & 1.6 & 1.8 & 2.0 & 2.2 & 2.4 & 2.6 & 2.8 \\
\hline 1.2 & & $g h j-l(j-k)$ & $g-l(j-1)$ & $g-l(j-k)$ & $g-l(j-k)$ & $g-l(j-k)$ & $g-l(j-k)$ & $g-l(j-k)$ \\
\hline 1.3 & $d-l$ & $d-f i(g-i)$ & $\vec{d}-f(g-i)$ & $\vec{d}-f j(g-i)$ & $\vec{d}-f j(g-i)$ & $\vec{d}-f j(g-i)$ & $\vec{d}-f j(g-i)$ & $d-j(g-i)$ \\
\hline 1.4 & $a-c j(i)$ & $a-c(d-f)$ & $a-c(d-f)$ & $a-c(d-f)$ & $a-c(d-f)$ & $a-c(d-f)$ & $a-c(d-f)$ & $a-c(d-f)$ \\
\hline 1.5 & $(a-h)$ & $a-c$ & $a-c$ & $a-c$ & $a-c$ & $a-c$ & $a-c$ & $a-c$ \\
\hline 1.8 & $(j-l)$ & $(l)$ & & & & & & \\
\hline
\end{tabular}

$a$ to $l$ stands for $a-\alpha=0.2, \zeta_{3}=0.3 ; b-\alpha=0.2, \zeta_{3}=0.4 ; c-\alpha=0.2, \zeta_{3}=0.5 ; d-\alpha=0.8, \zeta_{3}=0.3 ; e-\alpha=0.8, \zeta_{3}=0.4 ; f-\alpha=0.8, \zeta_{3}=0.5 ; g-\alpha=1.4, \zeta_{3}=0.3 ; h-$ $\alpha=1.4, \zeta_{3}=0.4 ; i-\alpha=1.4, \zeta_{3}=0.5 ; j-\alpha=2.0, \zeta_{3}=0.3 ; k-\alpha=2.0, \zeta_{3}=0.4 ; l-\alpha=2.0, \zeta_{3}=0.5$.
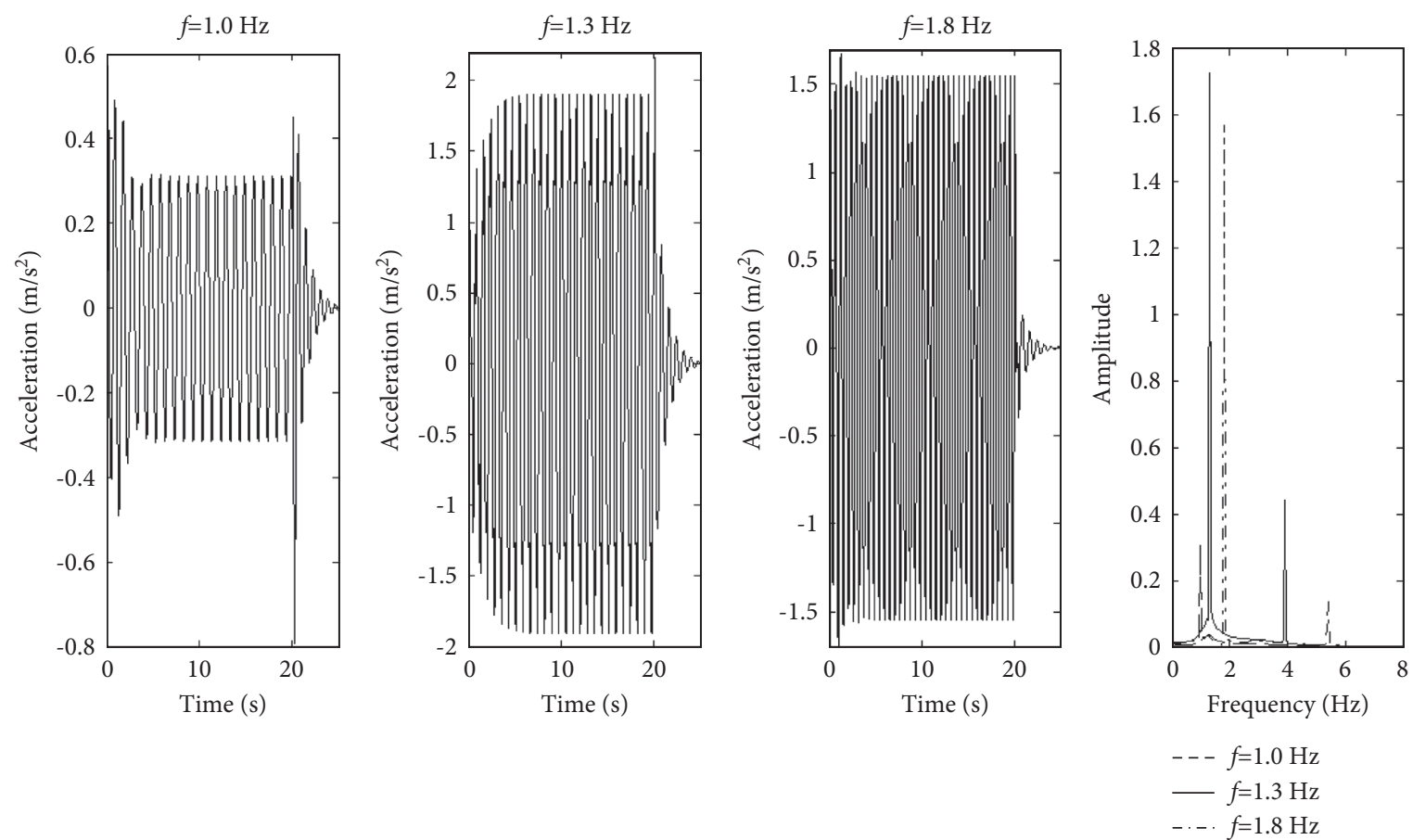

FIgURE 23: The time domain and frequency domain analysis of structure response.

respectively. There are eight curves in the graphs representing the model results of the eight $f_{3}$, and there are 56 curves in each figure. All curves rise first and then descend with increasing $f_{1}$, and the $f_{1}$ corresponding to the peak value of the curve varies between 2.5 and $3.5 \mathrm{~Hz}$. When comparing the curve values of different $f_{2}$, it is found that, with the change of $\alpha$, the maximum value of the curve is not in the model of the same $f_{2}$. For example, the curve value of $f_{2}=2.1 \mathrm{~Hz}$ is the largest in the model of $\alpha=0.2$, the curve value of $f_{2}=2.4 \mathrm{~Hz}$ is the largest in the model of $\alpha=0.3$, and the curve value of $f_{2}=1.8 \mathrm{~Hz}$ is the largest in the models of $\alpha=0.4$ and 0.5 . When comparing the curve values of different $f_{3}$, it can be determined that the structural VDV is the largest when $f_{3}=2.8 \mathrm{~Hz}$.
Then, to analyze the change of structural response with different $\alpha$, taking the curve of $f_{3}=2.8 \mathrm{~Hz}$ in Figure 27 as an example, the change curve of structural response with $f_{1}$ and $\alpha$ under each $f_{2}$ of the model is given. As shown in Figure 28, the curve values is affected by the $f_{2}$ and the structural response does not strictly follow the tendency that the larger the $\alpha$ is, the smaller the structural response is.

The structure parameters influence on structural VDV is considered. As shown in Table 9, the maximum range of structural response reduction with $\alpha, \zeta_{1}$, and $f_{1}$ is given. The maximum influence of crowd mass on structural response is $83 \%$, and this number will be reduced by $77 \%$ when the structural frequency is changed and by $56 \%$ when structural damping is increased. 

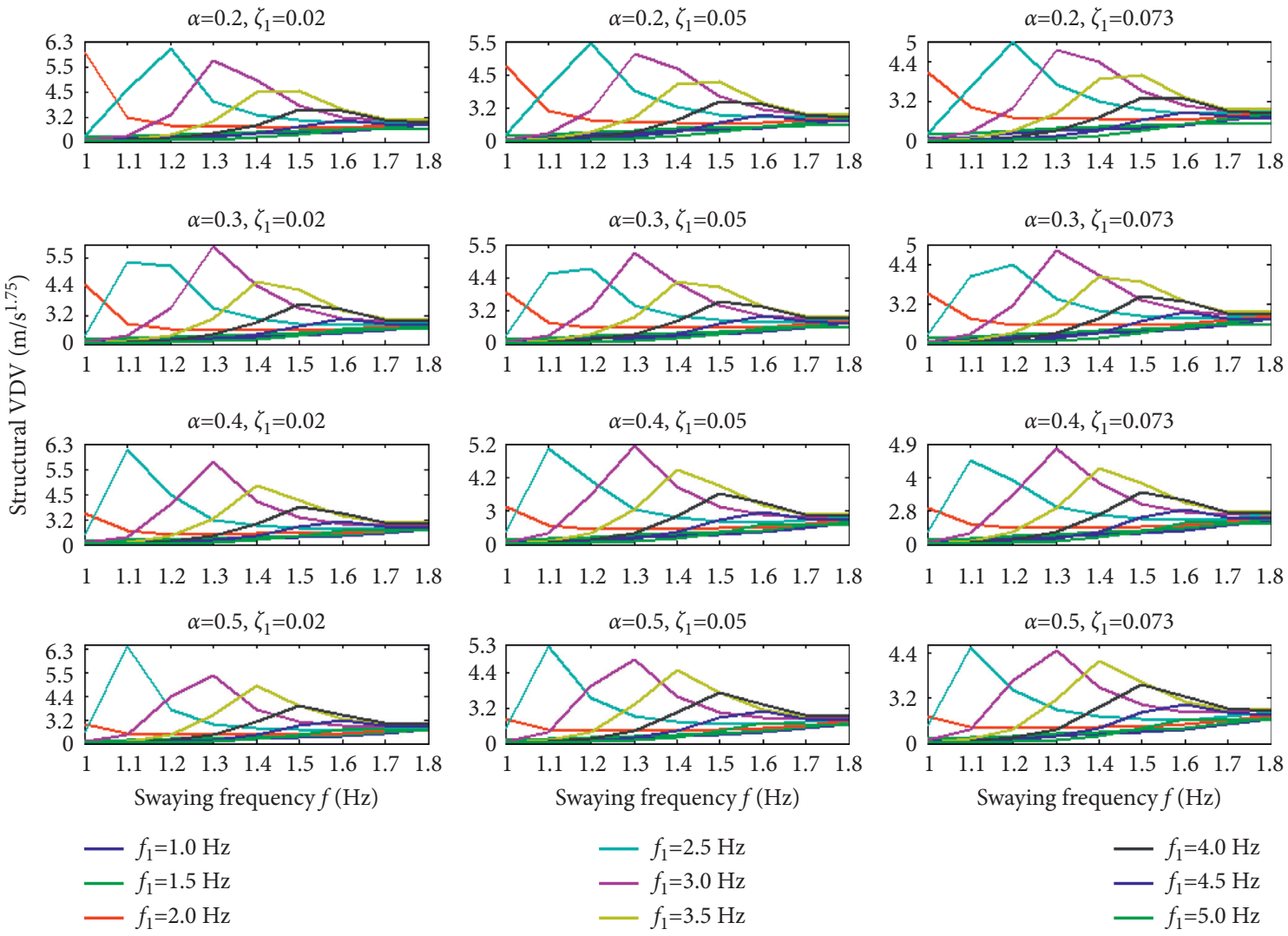

FIgURe 24: The structural VDV results when $f_{2}=1.8 \mathrm{~Hz}$.
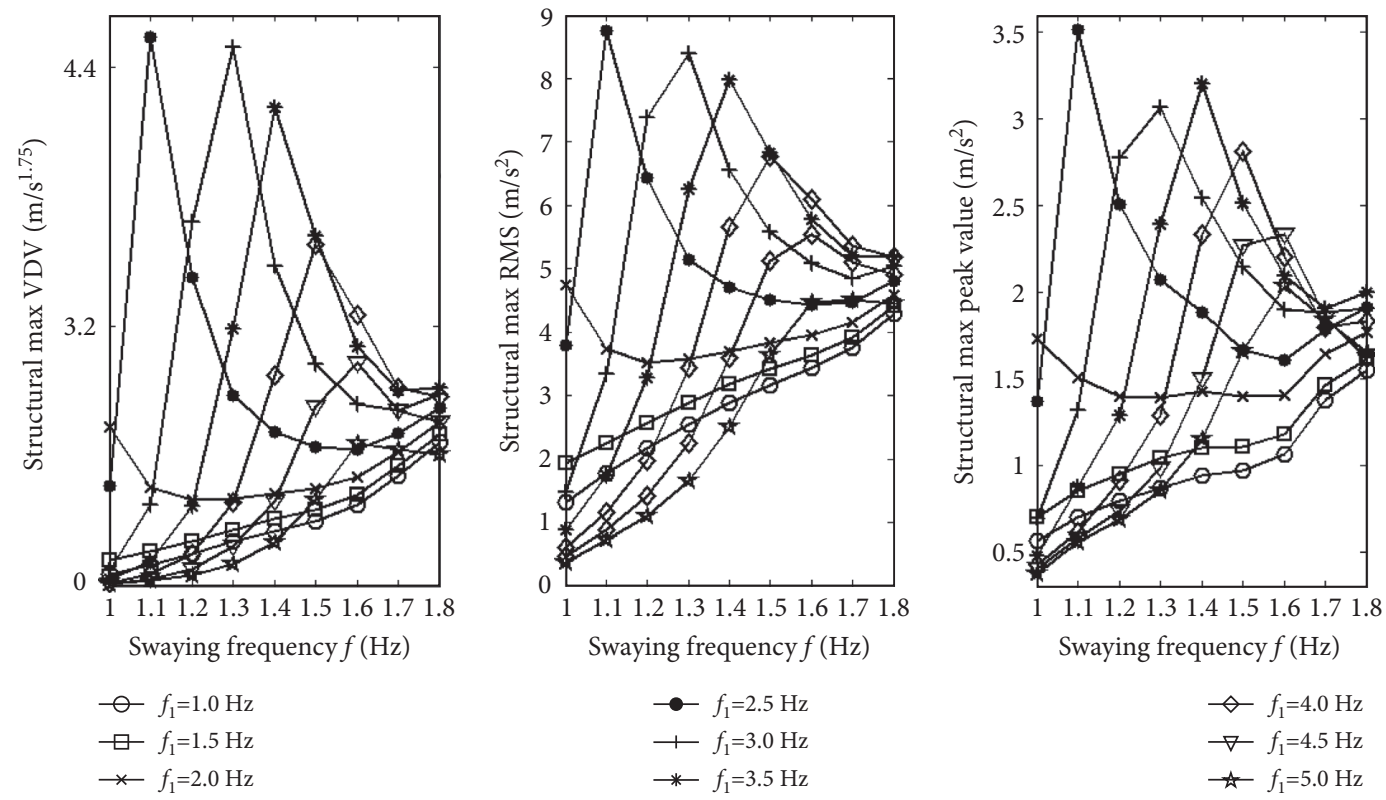

FIGURE 25: The max VDV, RMS, and peak values plotted against swaying frequencies.

When $\beta=1.0$, the value range of $\alpha$ is set between 0.2 and 2.0. In Section 3.1, the structural VDV when $f_{3}=2.8 \mathrm{~Hz}$ is calculated on the premise that $f_{1}=2.7 \mathrm{~Hz}$. It is necessary to calculate the influence of structure parameter change on structural response under different combinations of $f_{2}$ and $f_{3}$.
For example, the model results of $f_{2}=1.8 \mathrm{~Hz}, f_{3}=2.8 \mathrm{~Hz}$, and $\alpha=0.2,0.8,1.4$, and 2.0 are taken as examples to illustrate the relationship between structural VDV and structure parameter changes. As shown in Figure 29, there is only one peak in each curve. Similarly, to analyze the curve variation 

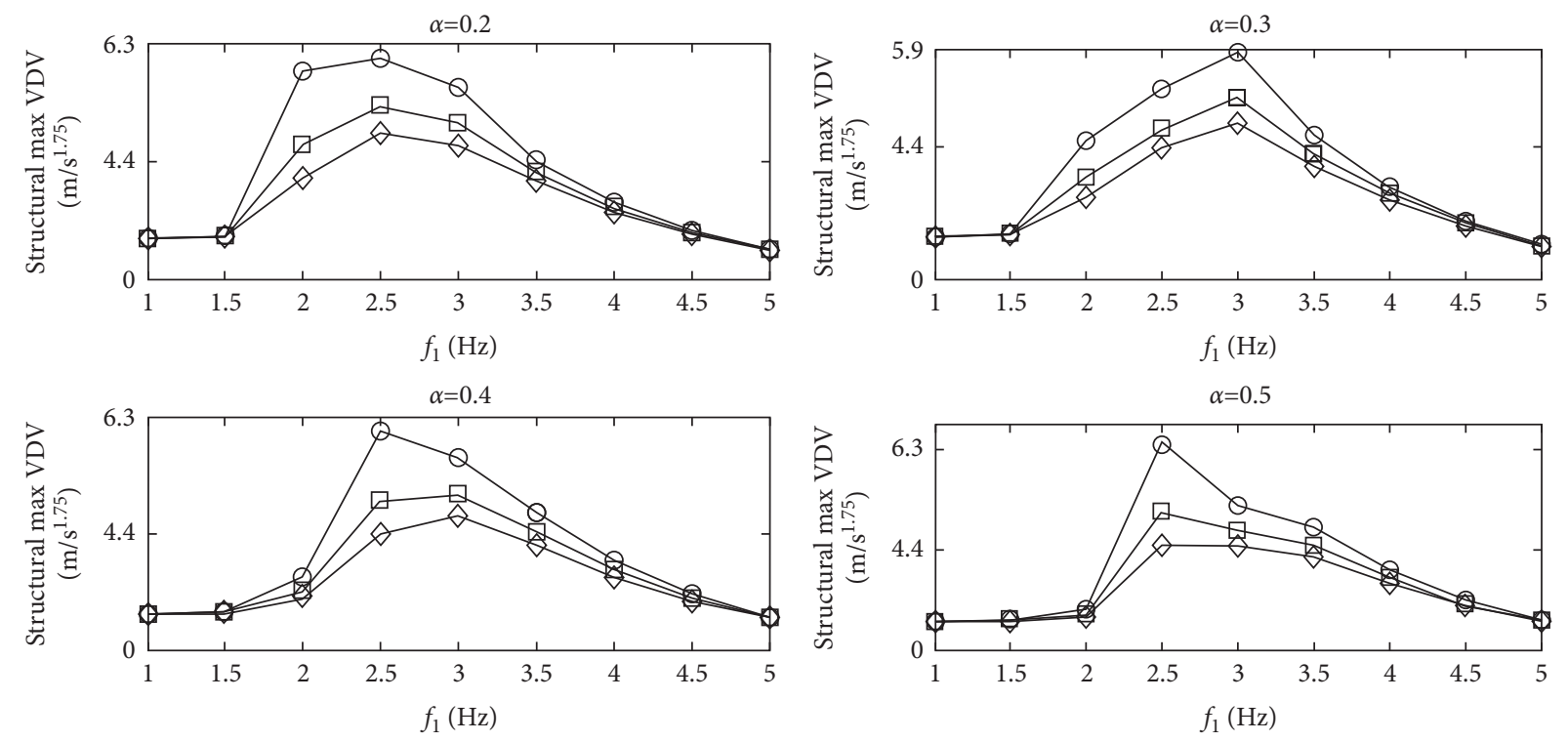

$$
\begin{aligned}
& \smile \zeta_{3}=2 \% \\
& \neg \zeta_{3}=5 \% \\
& \neg \zeta_{3}=7.3 \%
\end{aligned}
$$

FIGURE 26: The max VDVs corresponding to structural dynamic parameters.
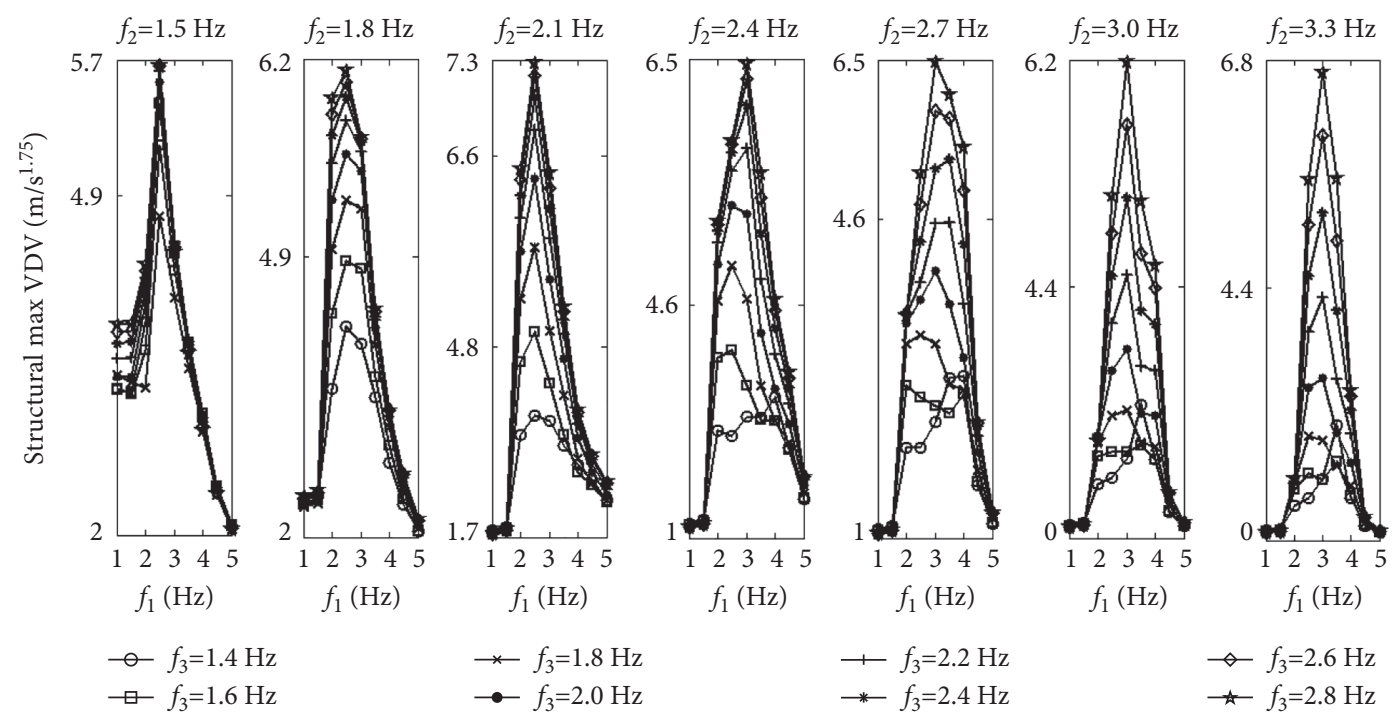

$-f_{3}=1.4 \mathrm{~Hz}$
$\square-f_{3}=1.6 \mathrm{~Hz}$
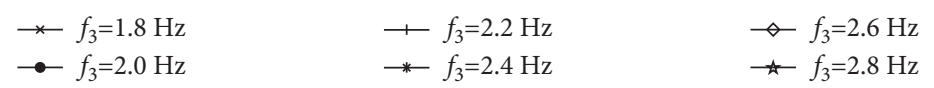

(a)

FIgURE 27: Continued. 

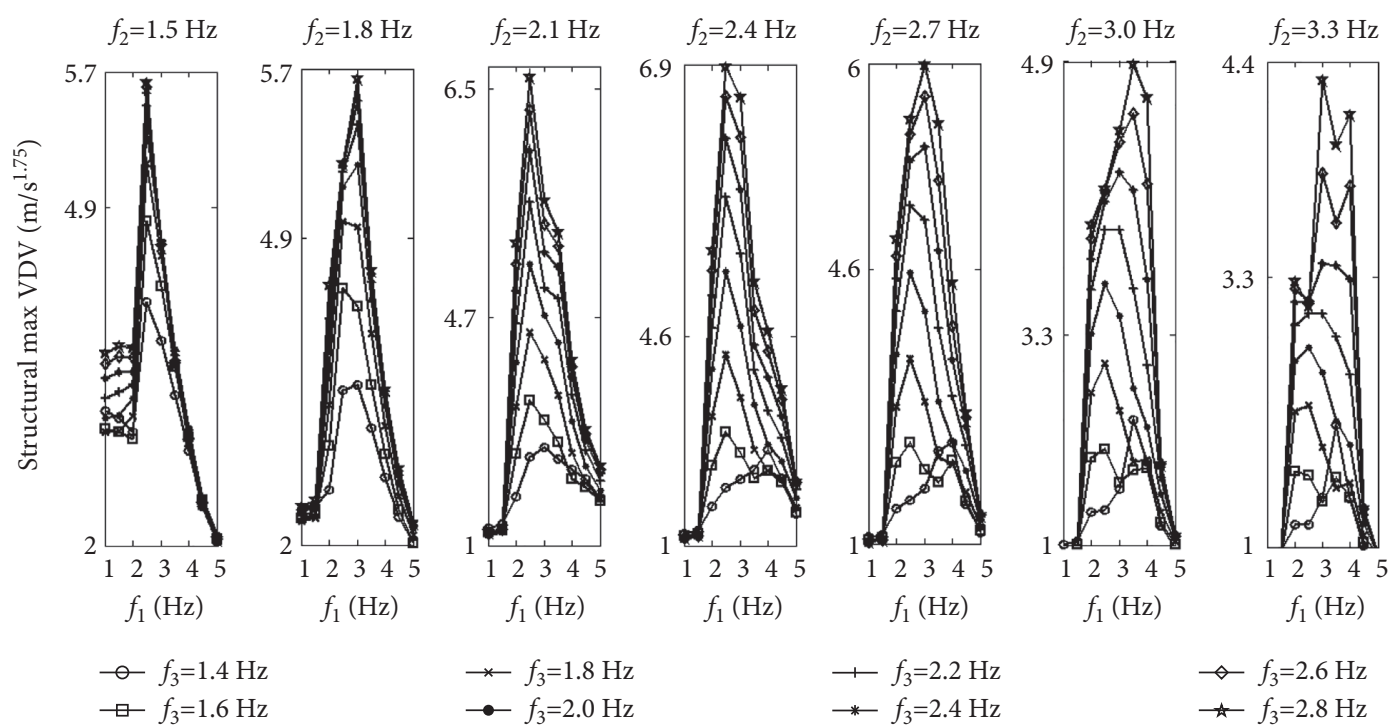

(b)
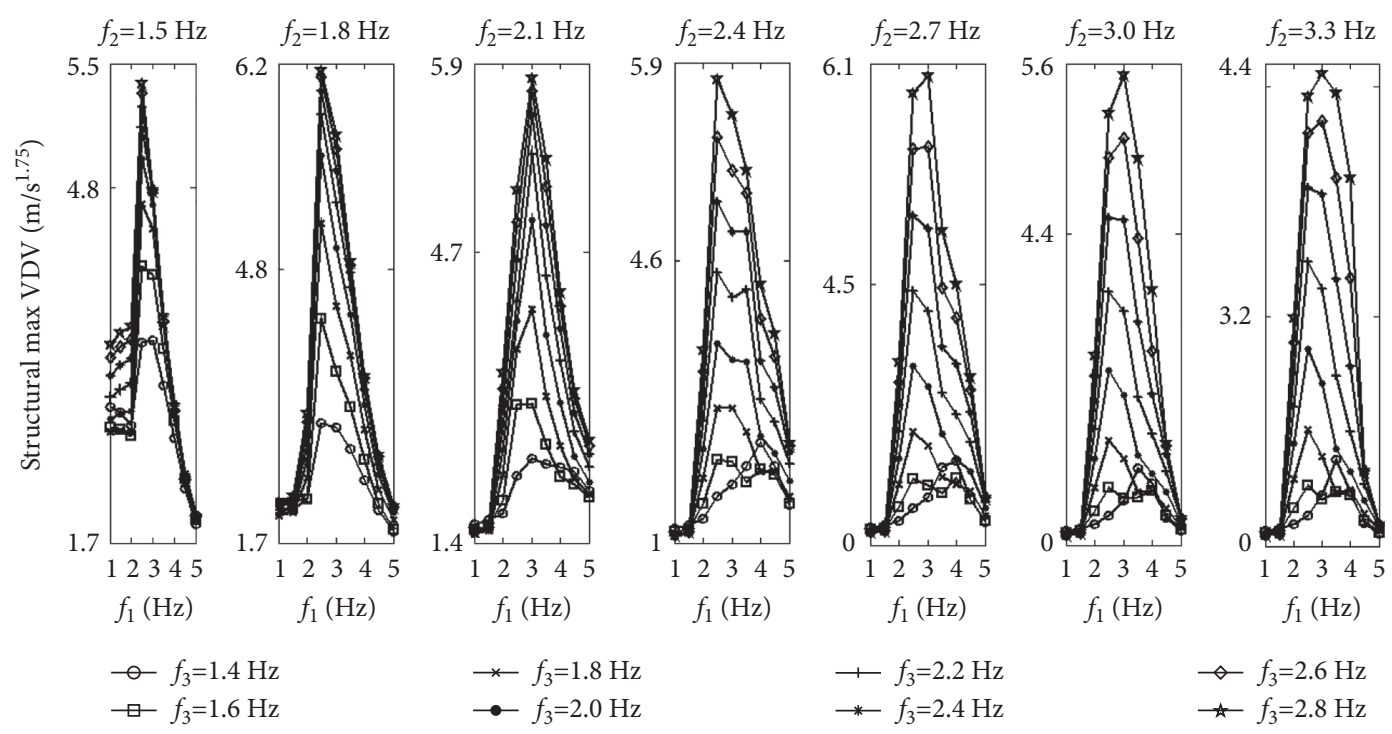

(c)
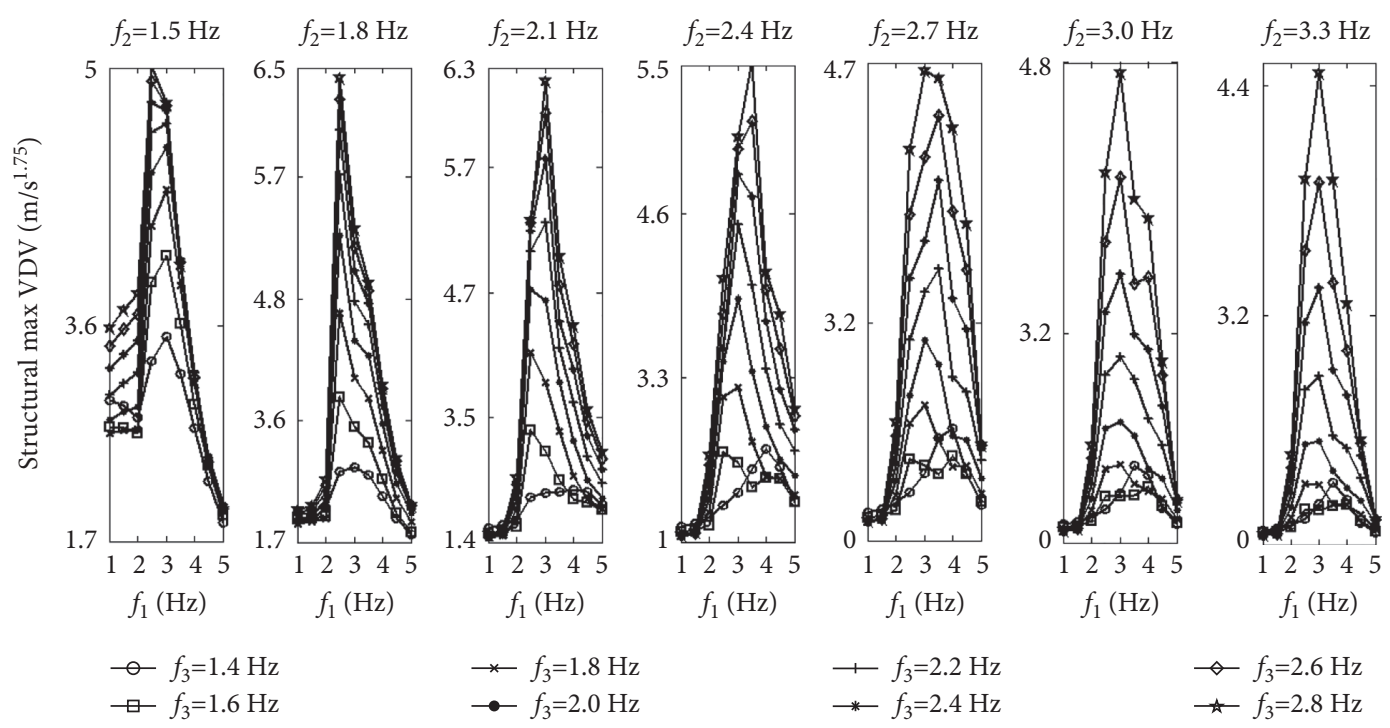

$\multimap f_{3}=1.4 \mathrm{~Hz}$
$\square f_{3}=1.6 \mathrm{~Hz}$

十 $f_{3}=2.2 \mathrm{~Hz}$
* $f_{3}=2.4 \mathrm{~Hz}$

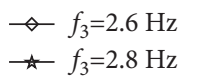

(d)

Figure 27: The structural parameters plotted against VDVs with different $f_{2}$ and $f_{3}$ of models. (a) The model results when $\alpha=0.2$, (b) the model results when $\alpha=0.3$, (c) the model results when $\alpha=0.4$, and (d) the model results when $\alpha=0.5$. 

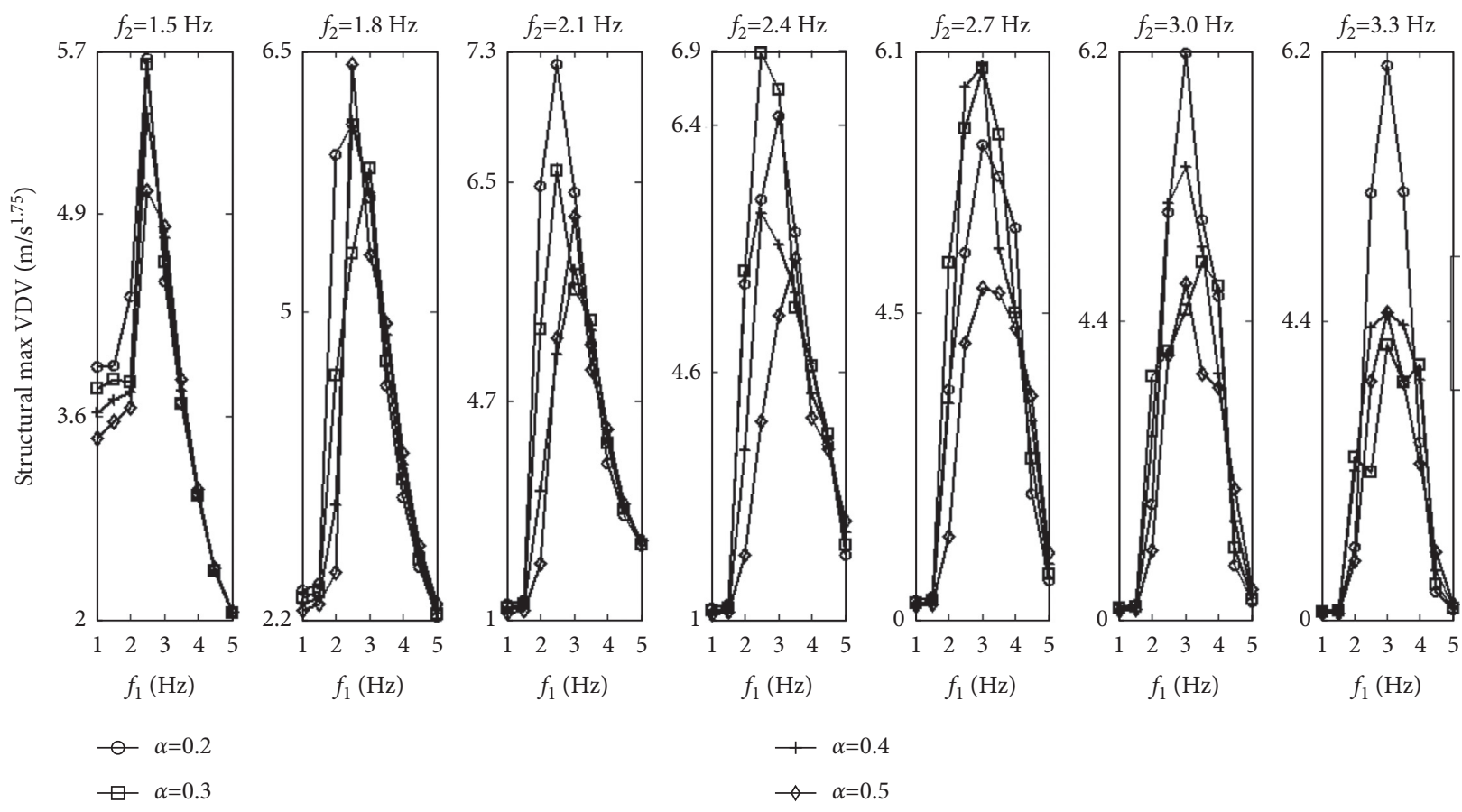

$$
\begin{aligned}
& \multimap \alpha=0.4 \\
& \neg \alpha=0.5
\end{aligned}
$$

Figure 28: The results of model with different $\alpha$ when $f_{3}=2.8 \mathrm{~Hz}$.

TABle 9: The max reduce amplitude of structural dynamic with $\alpha, \zeta_{1}$, and $f_{1}$.

\begin{tabular}{lccc}
\hline & \multicolumn{3}{c}{ Parameter } \\
& $\alpha(0.2-0.5)(\%)$ & $\zeta_{1}(2.0-7.3)(\%)$ & $f_{1}(1.0-5.0 \mathrm{~Hz})(\%)$ \\
\hline The degree of reduction & 83 & 56 & 77 \\
\hline
\end{tabular}
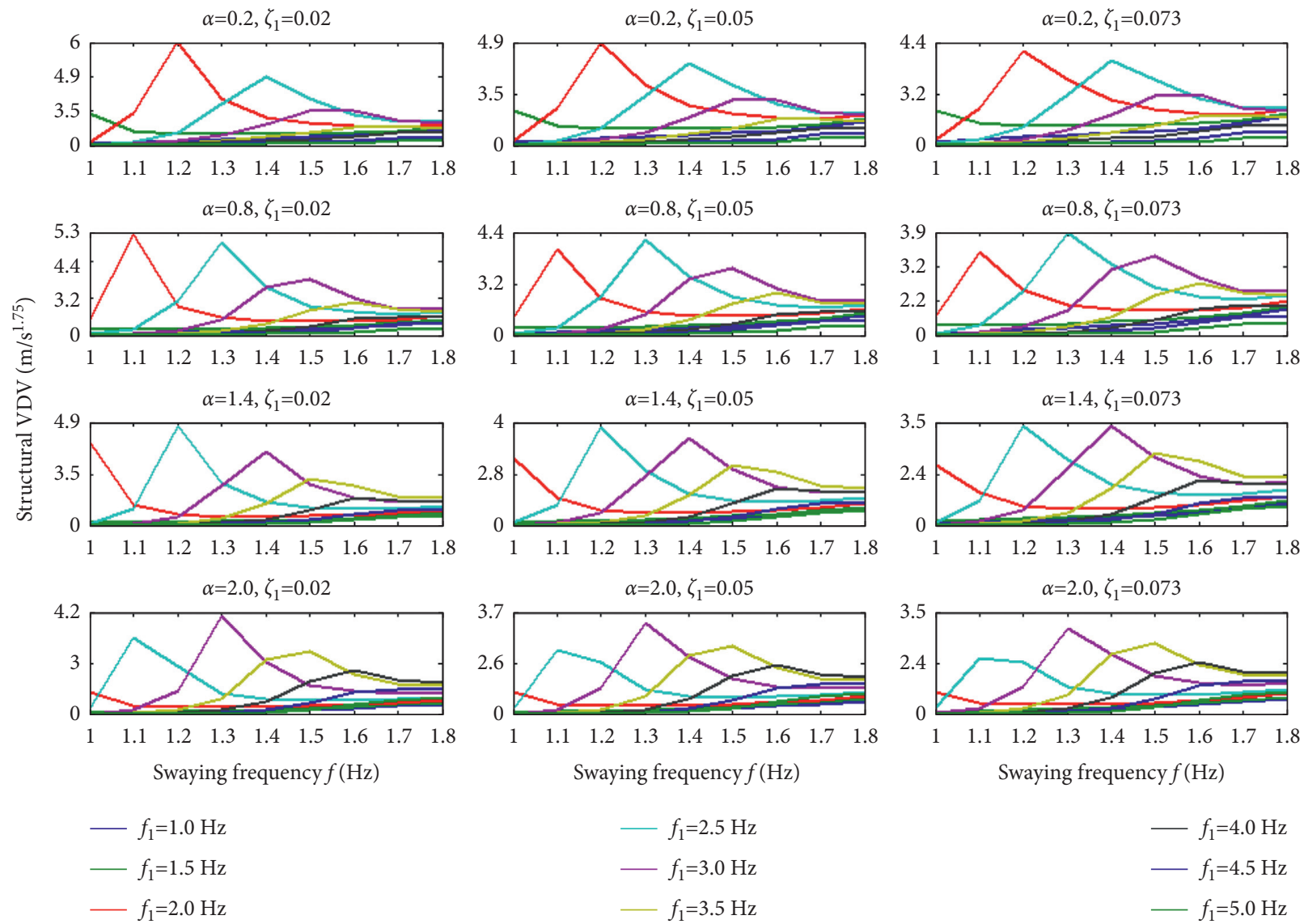

$$
\begin{aligned}
-f_{1} & =2.5 \mathrm{~Hz} \\
-f_{1} & =3.0 \mathrm{~Hz} \\
f_{1} & =3.5 \mathrm{~Hz}
\end{aligned}
$$

$$
\begin{aligned}
-f_{1} & =4.0 \mathrm{~Hz} \\
-f_{1} & =4.5 \mathrm{~Hz} \\
-f_{1} & =5.0 \mathrm{~Hz}
\end{aligned}
$$

FIgUre 29: The structural VDV results when $f_{2}=1.8 \mathrm{~Hz}, f_{3}=2.8 \mathrm{~Hz}$ of model. 

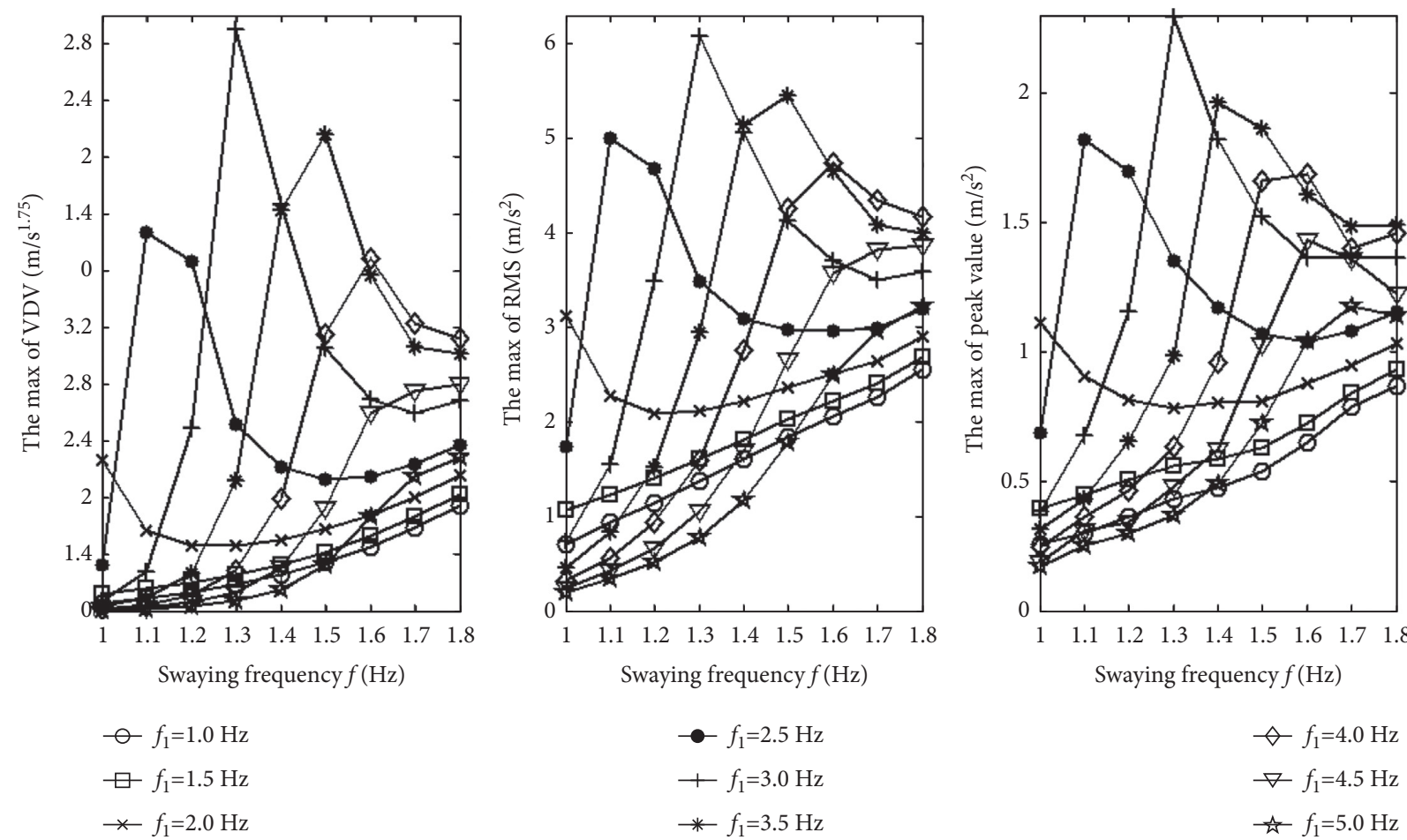

FIgURE 30: The max VDV, RMS, and peak values plotted against swaying frequencies.
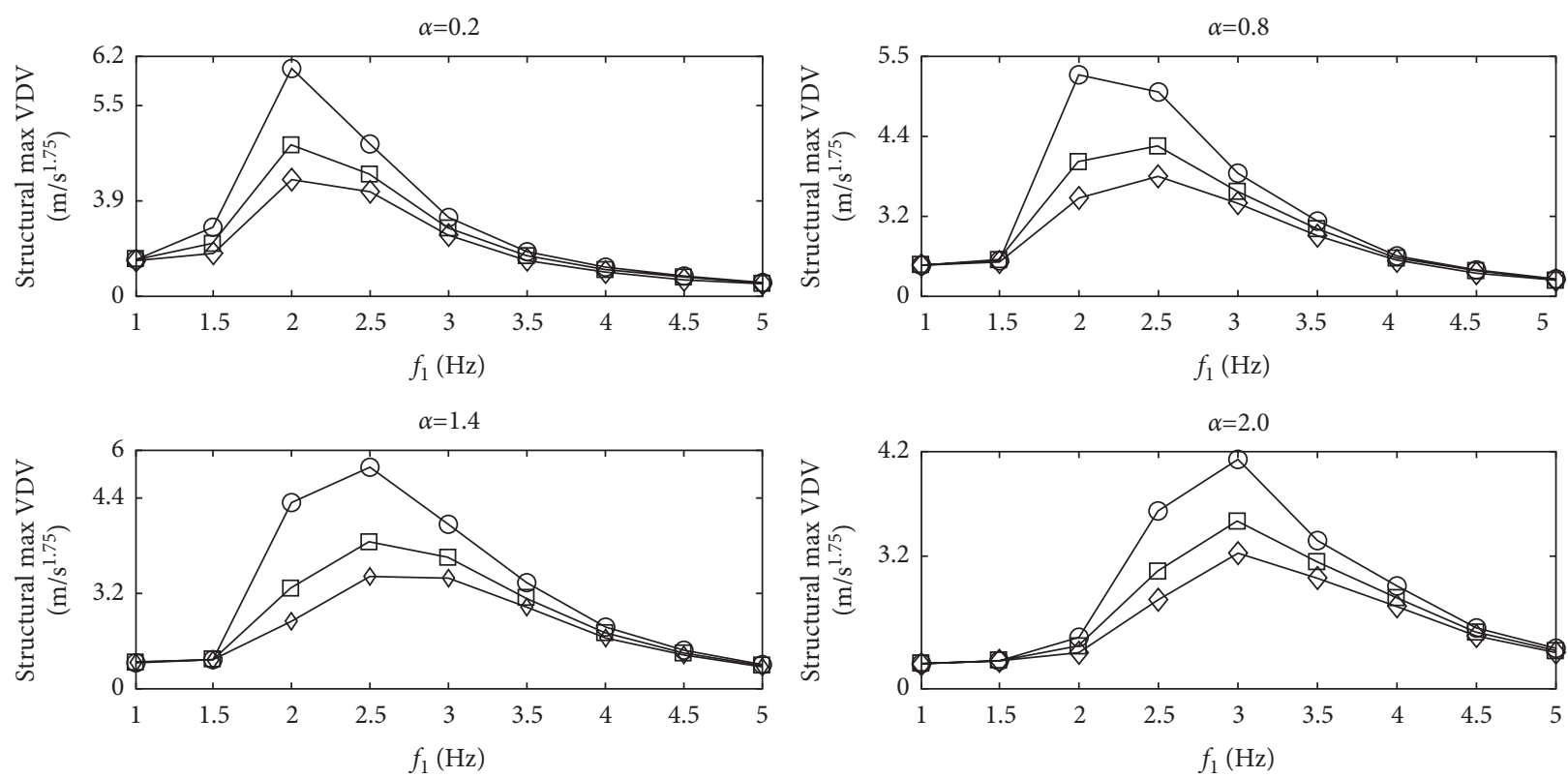

$$
\begin{aligned}
& \curvearrowleft \zeta_{1}=2 \% \\
& \square \zeta_{1}=5 \% \\
& \oslash \zeta_{1}=7.3 \%
\end{aligned}
$$

FIGURE 31: The max VDVs corresponding to structural dynamic parameters.

tendencies in more detail, the model results of $\alpha=2.0$, $\zeta_{1}=7.3 \%$ are represented by VDV, RMS, and peak value, respectively. As shown in Figure 30, three curves show the following variation tendencies: when $f_{1} \leq 1.5 \mathrm{H}$, the structural response increases roughly linearly with $f$; when $f_{1}=2.0 \mathrm{~Hz}$, the structural response decreases first and then 

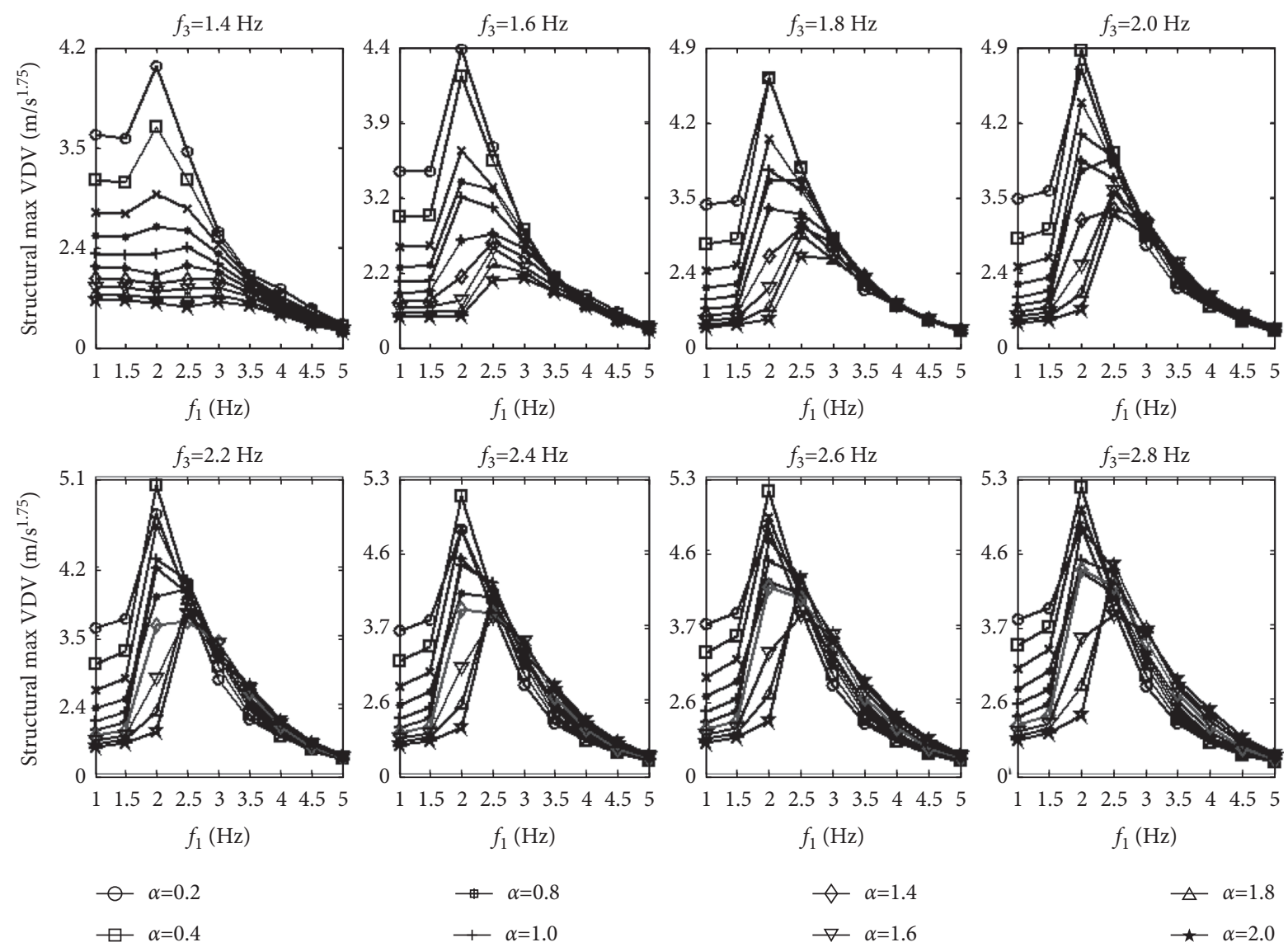

$$
\begin{array}{ll}
\neg & \alpha=0.2 \\
\square & \alpha=0.4
\end{array}
$$$$
\text { ॠ } \alpha=0.8
$$$$
\text { 十 } \alpha=1.0
$$$$
\diamond \alpha=1.4
$$$$
\nabla \alpha=1.6
$$$$
\star \alpha=2.0
$$

Figure 32: The structural VDV of models with different $f_{3}$ when $f_{2}=1.5 \mathrm{~Hz}$.

increases; when $2.5 \mathrm{~Hz} \leq f_{1} \leq 4.0 \mathrm{~Hz}$, the structural response increases first and then decreases; when $f_{1} \geq 4.5 \mathrm{~Hz}$, the structural response increases roughly nonlinearly and unidirectionally with $f$.

The relationship between the peak value of each curve in Figure 29 and $f_{1}$ is discussed, as shown in Figure 31. The curves in the figure show that the smaller the $\zeta_{1}$, the greater the structural response, but the influence of $\zeta_{1}$ on the structural response is related to the structural frequency. An increase in the structural damping ratio will effectively reduce the structural response only when $f_{1}$ is between 2.0 and $3.0 \mathrm{~Hz}$. In addition, the $f_{1}$ corresponding to the peak value of the curve transits from $2.5 \mathrm{~Hz}$ to $3.0 \mathrm{~Hz}$ with the increase of $\alpha$. The parameter model shows that the structural VDV reaches its maximum when $\alpha=0.2, \zeta_{1}=2 \%$, and $f_{1}=2.0 \mathrm{~Hz}$.

Then, the model results of different parameter combinations of $f_{2}$ and $f_{3}$ are calculated. Considering the maximum curve value of $\zeta_{1}=2 \%$ in Figure 31, and taking the corresponding results of this parameter as an example, the curves between the maximum VDV of the structure and the structure parameters is given for the combination of $f_{2}=1.5 \mathrm{~Hz}$ and other $f_{3}$ (Figure 32). The figure shows that, with different $f_{3}$ of models, the curve is slightly different with $f_{1}$. Only $f_{3}=1.4 \mathrm{~Hz}$, and when $\alpha=0.2-0.6$, the curve rise first and then descend; when $\alpha \geq 1.4$, the curve begins to descend after $f_{1}=3.0 \mathrm{~Hz}$. In other $f_{3}$ models. All curves first rise and then descend with increasing $f_{1}$, and the $f_{1}$ corresponding to the curve peak transits from $2.0 \mathrm{~Hz}$ to $2.5 \mathrm{~Hz}$ with increasing $\alpha$. By comparing the maximum value of the curve in each graph, it is found that the curve value in the model with $f_{3}=2.8 \mathrm{~Hz}$ is greater than that in the model with other $f_{3}$. When sorting out the results of the combination of six other $f_{2}$ and $f_{3}$, it shows that the curve value of the combined model with $f_{3}=2.8 \mathrm{~Hz}$ is the largest. Then, the combined model curves of $f_{2}=1.8-3.3 \mathrm{~Hz}$ (six values) and $f_{3}=2.8 \mathrm{~Hz}$ are given, as shown in Figure 33. Each curve in the figure represents the model result of one $\alpha$. All curves first rise and then descend with increasing $f_{1}$; the $f_{1}$ corresponding to the peak value of the curve changes between $2.0 \mathrm{~Hz}$ and $3.0 \mathrm{~Hz}$, and the $\alpha$ corresponding to the maximum peak value of the curve is 0.2 . Moreover, it is found that, after comparing the curve values in different graphs, the structural VDV of the model with $f_{2}=1.8 \mathrm{~Hz}$ is the largest.

In addition, the $f$ corresponding to the maximum VDV of the structure is analyzed, with the results shown in Table 10. Similar to the model result of $\beta=0.5$, when the $f_{1}$ is $1.0-1.5 \mathrm{~Hz}$, the corresponding $f$ is $1.8 \mathrm{~Hz}$ or $1.0 \mathrm{~Hz}$. With increasing $f_{1}$, the corresponding $f$ transits from $1.1-1.3 \mathrm{~Hz}$ to $1.7-1.8 \mathrm{~Hz}$. Finally, the change of structural VDV caused by the change of different structure parameters is calculated, as shown in Table 11. Only cases with the greatest impact on the 

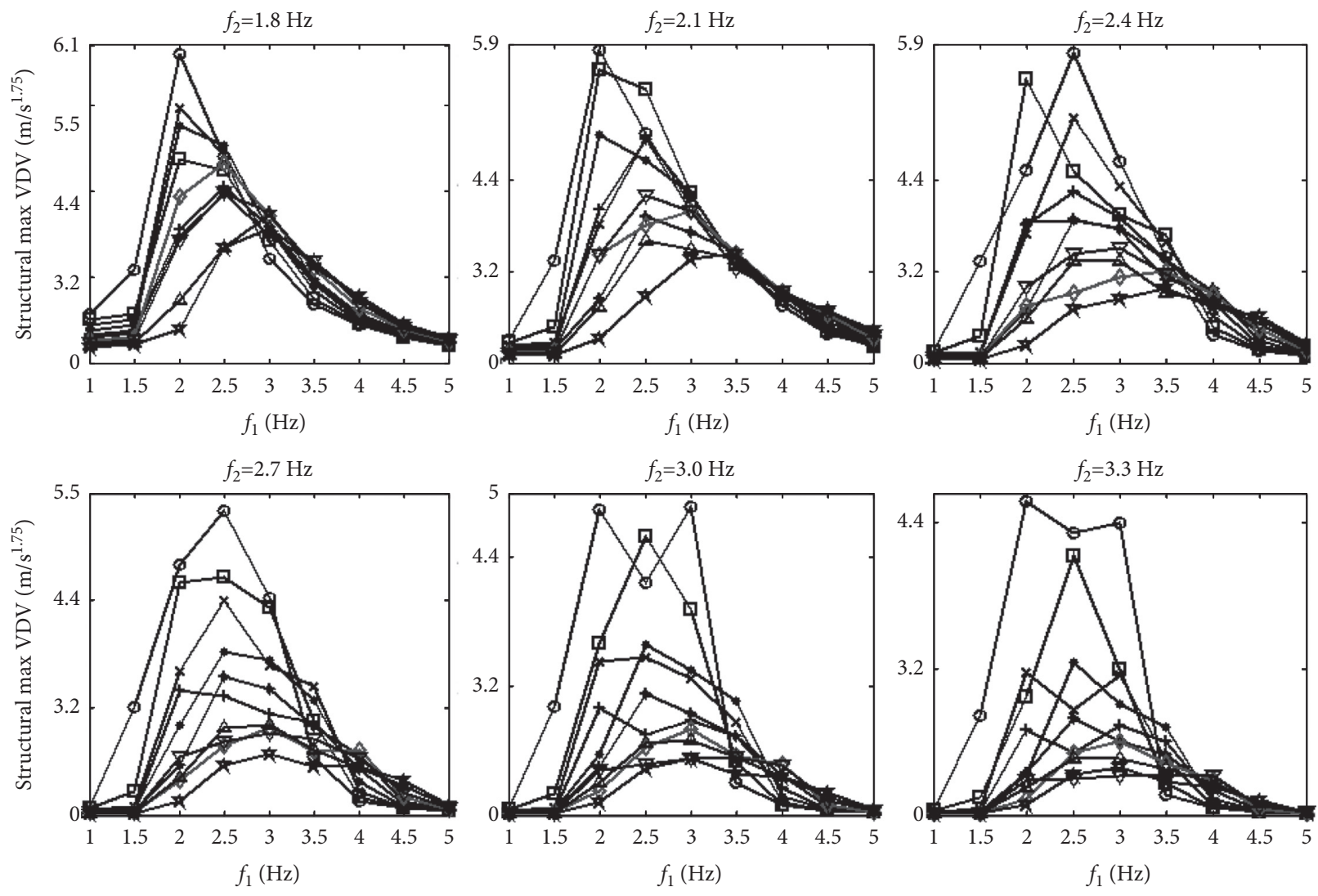

$$
\begin{array}{ll}
-\alpha=0.2 & \rightarrow-\alpha=0.8 \\
\square \alpha=0.4 & -\alpha=1.0 \\
-\alpha=0.6 & -\quad \alpha=1.2
\end{array}
$$$$
\diamond \alpha=1.4
$$$$
\nabla \alpha=1.6
$$$$
\triangle \alpha=1.8
$$$$
\star \alpha=2.0
$$

Figure 33: The structural VDV of models with different $f_{2}$ when $f_{3}=2.8 \mathrm{~Hz}$.

TABLE 10: The max structural VDV value corresponding swaying frequencies.

\begin{tabular}{lccccccccc}
\hline Swaying frequency & \multicolumn{9}{c}{$f_{1}(\mathrm{~Hz})$} \\
& 1.0 & 1.5 & 2.0 & 2.5 & 3.0 & 3.5 & 4.0 & 4.5 \\
\hline$f(\mathrm{~Hz})$ & 1.8 & $1.8,1.0$ & $1.1-1.3$ & $1.3-1.6$ & $1.4-1.8$ & $1.5-1.8$ & $1.5-1.8$ & $1.6-1.8$ & $1.7-1.8$ \\
\hline
\end{tabular}

TABLE 11: The max reduced amplitude of structural dynamic responses with $\alpha, \zeta_{1}$, and $f_{1}$.

\begin{tabular}{lcccc}
\hline & & Parameter \\
& $\alpha(0.2-2.0)(\%)$ & $\zeta_{1}(2 \%-7.3(\%)$ & $f_{1}(1.0-5.0 \mathrm{~Hz})(\%)$ \\
\hline The degree of reduction & 98 & 60 & 89 \\
\hline
\end{tabular}

structure within the parameter range are given in the table. Increase in $\alpha, \zeta_{1}$, and $f_{1}$ will significantly reduce the structural response, with a maximum decrease of $98 \%, 60 \%$, and $89 \%$, respectively.

\section{Discussion}

Bear all this in mind; with analyzing the experiment data of crowd shocked by shaking table and swaying at temporary grandstand, respectively, it is indicated that crowd annoyance rate may not have a linear relationship with vibration, and the indicated crowd may adjust their reaction for comfort when they under a certain range of vibration intensity. It is also indicated that the standing crowd may have more tolerance to vibration than seated crowd. The serviceability limit of $1.29 \mathrm{~m} / \mathrm{s}^{1.75}$ and the upper boundary of $2.32 \mathrm{~m} / \mathrm{s}^{1.75}$ suggested by VDV are obtained. There is also a need to investigate more experiments such as a big temporary grandstand with a large number of crowds (active/ passive) in lab or in site. Also, through predicting dynamic structural VDV with different dynamic parameters of crowd and structure based on a simplified three-degree-of-freedom lumped dynamic model for different crowd dynamic parameters, it is considered that the VDV of structure will be 
decreased with increasing $\alpha$ and $\zeta_{2}$. The influence of $f_{2}$ for structure response relates to $\alpha$. The max response of the model is $\alpha \leq 0.6, f_{2}=1.8 \mathrm{~Hz}$ or $\alpha>0.6, f_{2}=1.5 \mathrm{~Hz}$. The VDV of structure will be decreased with increasing $f_{33}$. The influence of $\zeta_{3}$ for structure response relates to $\alpha$ and $f_{3}$, and the notable model is not the $\max \zeta_{3}$ of the model. For different structural dynamic parameters, it is considered that the VDV of structure first rises and then descends with the increase of $f_{1}$ (the max response of the model is $\left.f_{1}=2.5-3.5 \mathrm{~Hz}\right)$ and decreases with increasing $\zeta_{1}$. The notable model is not the model that $\alpha$ and $\beta$ have the minimum value. It was also found that most of the predicting-peak VDVs of structure are higher than the serviceability limit value, which may indicate why the crowd can be easily susceptible to TDG's vibrations. These results are only based on a three-degree-of-freedom lumped dynamic model. While the model of structure and model of body are not a simple single-degree-of-freedom lumped model, more coupled equation system will need to be analyzed in the future and combined with more experiments.

\section{Conclusion}

This paper tried to address the annoyance levels of lateral vibration on temporary grandstand, which is based on the lateral vibration experiments of shake table and crowds, and to analyze the responses of structure with different dynamic parameters of $3 \mathrm{DOF}$ crowd and structure interaction model. For TDG, the lateral serviceability limit of $1.29 \mathrm{~m} / \mathrm{s}^{1.75}$ and the upper boundary of $2.32 \mathrm{~m} / \mathrm{s}^{1.75}$ are suggested. Based on the experimental data, the interaction models are calculated, and the predicting responses of structure are obtained and discussed. For different crowd parameters, with increasing $\alpha$ and $\zeta_{2}$, the VDV of structure will be decreased. The influence of $f_{2}$ for structure response relates to $\alpha$. With increasing $f_{3}$, the VDV of structure will be decreased. The influence of $\zeta_{3}$ for structure response relates to $\alpha$ and $f_{3}$. The notable model is not the $\max \zeta_{3}$ of the model. For different parameters of structure, the VDV of structure first rises and then descends with the increase of $f_{1}$ and decreases with increasing $\zeta_{1}$. The notable model is not the mixture of $\alpha$ and $\beta$ of the model. It was also found that most of the predicting-peak VDVs of the structure are higher than the serviceability limit value. These results may be useful for analyzing the vibration serviceability of temporary grandstand.

\section{Appendix}

\section{The part of MATLAB program for calculating the models}

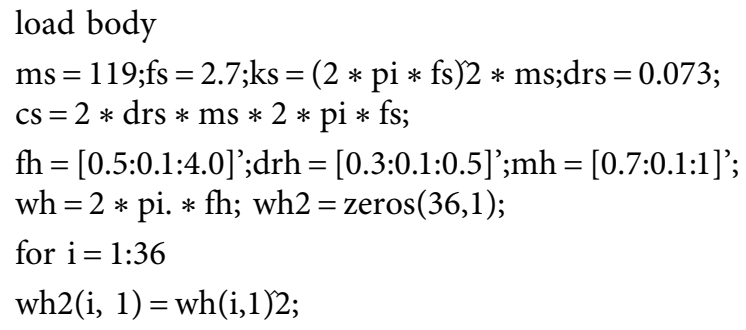

end

$\mathrm{mh}=\mathrm{mh} * 350 ; \mathrm{kh}=\mathrm{mh} * \mathrm{wh} 2 ;$

ch1 $=2 * 0.3 * \mathrm{mh} * \mathrm{wh}^{\prime} ; \quad \operatorname{ch} 2=2 * 0.4 * \mathrm{mh} * \mathrm{wh}^{\prime} ;$

$\operatorname{ch} 3=2 * 0.5 * \mathrm{mh} *$ wh'; $\quad$ modelcd $1=\operatorname{zeros}(18,27)$;

$\mathrm{A} 1=\operatorname{zeros}(4,36) ; \operatorname{errch} 1=\operatorname{zeros}(1,36) ; \mathrm{A} 2=\operatorname{zeros}(4,36) ;$

errch2 $=$ zeros $(1,36) ; \quad \mathrm{A} 3=\operatorname{zeros}(4,36)$;

$\operatorname{errch} 3=\operatorname{zeros}(1,36) ; \mathrm{AA}=\operatorname{zeros}(12,36)$; for $s=1: 9$

for $p=1: 18$

for $i=1: 4$

$\mathrm{M}=[\mathrm{ms} 0 ; 0 \mathrm{mh}(\mathrm{i}, 1)]$;

for $j=1: 36$

$\mathrm{K}=[(\mathrm{ks}+\mathrm{kh}(\mathrm{i}, \mathrm{j}))-\mathrm{kh}(\mathrm{i}, \mathrm{j}) ;-\mathrm{kh}(\mathrm{i}, \mathrm{j}) \mathrm{kh}(\mathrm{i}, \mathrm{j})] ; \mathrm{C}=$ $[(\operatorname{cs}+\operatorname{ch} 1(\mathrm{i}, \mathrm{j}))-\operatorname{ch} 1(\mathrm{i}, \mathrm{j}) ;-\operatorname{ch} 1(\mathrm{i}, \mathrm{j}) \operatorname{ch} 1(\mathrm{i}, \mathrm{j})] ; \quad \mathrm{A}=\operatorname{cat}(1, \mathrm{cat}$ $(2$, zeros $(2,2)$, eye $(2))$, cat $(2,-\operatorname{inv}(\mathrm{M}) * \mathrm{~K}$,-inv $(\mathrm{M}) * \mathrm{C})$ ); $\mathrm{G}=\operatorname{eye}(2) ; \mathrm{B}=\operatorname{cat}(1, \mathrm{zeros}(2,2),-\operatorname{inv}(\mathrm{M}) * \mathrm{G}) ; \quad \mathrm{C} 0=$ cat $(2$, eye(2),zeros(2,2)); $\mathrm{D}=$ zeros $(2,2)$; mass $=\operatorname{zeros}(48001,3) ; \quad \operatorname{mass}(:, 1)=\operatorname{cda} 2(:, 1) ; \quad$ mass(: ,2) $=(-\operatorname{cda} 2(:, \mathrm{s}+1)) * \operatorname{vdvratio}(\mathrm{p}, 1) *(\mathrm{~ms}+\mathrm{mh}(\mathrm{i}, 1))$;

mass = mass'; save $\mathrm{mn}$ mass; sim('twodof); $\operatorname{err} 1=\operatorname{zeros}(48001,1)$; for $\mathrm{m}=1: 48001$

$\operatorname{err} 1(\mathrm{~m}, 1)=\operatorname{abs}(\mathrm{a} 1(\mathrm{~m}, 3)-\operatorname{cda} 1(\mathrm{~m}, \mathrm{~s}+1)) 2 ; \quad \operatorname{errch} 1(1, \mathrm{j})=$ $\operatorname{sqrt}(\operatorname{sum}(\operatorname{err} 1) / 48001)$;

end

$$
\mathrm{C}=[(\operatorname{cs}+\operatorname{ch} 2(\mathrm{i}, \mathrm{j})) \quad-\operatorname{ch} 2(\mathrm{i}, \mathrm{j}) ;-\operatorname{ch} 2(\mathrm{i}, \mathrm{j}) \quad \operatorname{ch} 2(\mathrm{i}, \mathrm{j})] ;
$$

$\mathrm{A}=\operatorname{cat}(1, \operatorname{cat}(2, \mathrm{zeros}(2,2), \operatorname{eye}(2)), \operatorname{cat}(2,-\operatorname{inv}(\mathrm{M}) * \mathrm{~K}$,$\operatorname{inv}(M) * C)) ; G=\operatorname{eye}(2) ; B=\operatorname{cat}(1, \operatorname{zeros}(2,2),-\operatorname{inv}(M) *$ $\mathrm{G}) ; \quad \mathrm{C} 0=\operatorname{cat}(2, \operatorname{eye}(2), \operatorname{zeros}(2,2)) ; \mathrm{D}=\operatorname{zeros}(2,2)$; mass $=\operatorname{zeros}(48001,3) ; \operatorname{mass}(:, 1)=\operatorname{cda} 2(:, 1) ; \operatorname{mass}($ : $, 2)=(-\operatorname{cda} 2(:, \mathrm{s}+1)) * \operatorname{vdvratio}(\mathrm{p}, 1) *(\mathrm{~ms}+\mathrm{mh}(\mathrm{i}, 1))$; mass $=$ mass'; save $\mathrm{mn}$ mass; sim('twodof); $\operatorname{err} 2=\operatorname{zeros}(48001,1)$; for $m=1: 48001$

$\operatorname{err} 2(\mathrm{~m}, 1)=\operatorname{abs}(\mathrm{a} 1(\mathrm{~m}, 3)-\mathrm{cda} 1(\mathrm{~m}, \mathrm{~s}+1)) 2 ;$

$\operatorname{errch} 2(1, \mathrm{j})=\operatorname{sqrt}(\operatorname{sum}(\mathrm{err} 2) / 48001)$;

end

$\mathrm{C}=[(\operatorname{cs}+\operatorname{ch} 3(\mathrm{i}, \mathrm{j})) \quad-\operatorname{ch} 3(\mathrm{i}, \mathrm{j}) ;-\operatorname{ch} 3(\mathrm{i}, \mathrm{j}) \quad \operatorname{ch} 3(\mathrm{i}, \mathrm{j})]$; $\mathrm{A}=\operatorname{cat}(1, \operatorname{cat}(2, \mathrm{zeros}(2,2)$,eye $(2))$, cat $(2,-\operatorname{inv}(\mathrm{M}) * \mathrm{~K}$,$\operatorname{inv}(M) * C)) ; G=\operatorname{eye}(2) ; B=\operatorname{cat}(1, \operatorname{zeros}(2,2),-\operatorname{inv}(M) *$ $\mathrm{G}) ; \quad \mathrm{C} 0=\operatorname{cat}(2, \operatorname{eye}(2)$, zeros $(2,2)) ; \mathrm{D}=\operatorname{zeros}(2,2)$; mass $=\operatorname{zeros}(48001,3) ; \quad$ mass $(:, 1)=\operatorname{cda} 2(:, 1) ; \quad$ mass(: $, 2)=(-\operatorname{cda} 2(:, \mathrm{s}+1)) * \operatorname{vdvratio}(\mathrm{p}, 1) *(\mathrm{~ms}+\mathrm{mh}(\mathrm{i}, 1))$; mass = mass'; save $\mathrm{mn}$ mass; sim('twodof); err3 = zeros $(48001,1)$; for $m=1: 48001$

$\operatorname{err} 3(\mathrm{~m}, 1)=\operatorname{abs}(\mathrm{a} 1(\mathrm{~m}, 3)-\mathrm{cda} 1(\mathrm{~m}, \mathrm{~s}+1)) 2$;

$\operatorname{errch} 3(1, \mathrm{j})=\operatorname{sqrt}(\operatorname{sum}(\operatorname{err} 3) / 48001)$;

end

end

$\mathrm{A} 1(\mathrm{i},:)=\operatorname{errch} 1 ; \mathrm{A} 2(\mathrm{i},:)=\operatorname{errch} 2 ; \mathrm{A} 3(\mathrm{i},:)=\operatorname{errch} 3 ;$ end

$\mathrm{AA}(1: 4,:)=\mathrm{A} 1 ; \mathrm{AA}(5: 8,:)=\mathrm{A} 2 ; \mathrm{AA}(9: 12,:)=\mathrm{A} 3$;

$[\operatorname{modelcd} 1(\mathrm{p}, 3 * \mathrm{~s}-2), \operatorname{modelcd} 1(\mathrm{p}, 3 * \mathrm{~s}-1)]=$

find $(\mathrm{AA}==\min (\min (\mathrm{AA})))$;

$\operatorname{modelcd} 1(\mathrm{p}, 3 * \mathrm{~s})=\min (\min (\mathrm{AA}))$; 
end

end

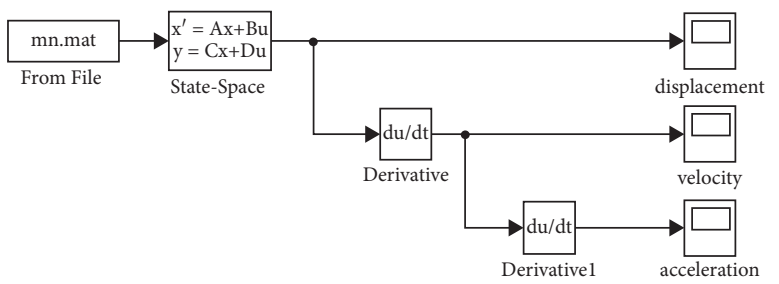

load active

$\mathrm{f} 1=2.7 ; \mathrm{c} 1=0.073 ; \mathrm{m} 1=1 ; \%$ structure constant

$\mathrm{f} 3=2 ; \mathrm{c} 3=0.4 ; \%$ passive crowd constant

$\mathrm{m} 3=[0.2,0.3,0.4,0.5]^{\prime} ; \%$ passive crowd mass

$\mathrm{f} 2=[1.5,1.8,2.1,2.4,2.7,3.0,3.3]$ ';\%active crowd frequency $7 * 1$

c2 $=[0.2,0.225,0.25]^{\prime} ; \%$ active crowd damping ratio $3 * 1$

$\mathrm{f} 2 \mathrm{c} 2=\mathrm{f} 2 * \mathrm{c} 2 ; \% 7 * 3$

for $\mathrm{m}=1: 9$

for $\mathrm{n}=1: 4$

$\mathrm{M}=[\mathrm{m} 1,0,0 ; 0,1,0 ; 0,0, \mathrm{~m} 3(\mathrm{n}, 1)] ;$ for $\mathrm{s}=1: 3$

for $\mathrm{i}=1: 7 \%$

$\mathrm{C}=4 * \mathrm{pi} *[\mathrm{~m} 1 * \mathrm{f} 1 * \mathrm{c} 1+\mathrm{f} 2 \mathrm{c} 2(\mathrm{i}, \mathrm{s})+\mathrm{m} 3(\mathrm{n}, 1) * \mathrm{f} 3 * \mathrm{c} 3,-$

$\mathrm{f} 2 \mathrm{c} 2(\mathrm{i}, \mathrm{s}),-\mathrm{m} 3(\mathrm{n}, 1) * \mathrm{f} 3 * \mathrm{c} 3 ;-\mathrm{f} 2 \mathrm{c} 2(\mathrm{i}, \mathrm{s}), \mathrm{f} 2 \mathrm{c} 2(\mathrm{i}, \mathrm{s}), 0$;-

$\mathrm{m} 3(\mathrm{n}, 1) * \mathrm{f} 3 * \mathrm{c} 3,0, \mathrm{~m} 3(\mathrm{n}, 1) * \mathrm{f} 3 * \mathrm{c} 3]$;

$\mathrm{K}=4 * \mathrm{pi} * \mathrm{pi} *[\mathrm{~m} 1 * \mathrm{f} 1 * \mathrm{f} 1+\mathrm{f} 2(\mathrm{i}, 1) *$

$\mathrm{f} 2(\mathrm{i}, 1)+\mathrm{m} 3(\mathrm{n}, 1) * \mathrm{f} 3 * \mathrm{f} 3,-\mathrm{f} 2(\mathrm{i}, 1) * \mathrm{f} 2(\mathrm{i}, 1),-\mathrm{m} 3(\mathrm{n}, 1) *$

$\mathrm{f} 3 * \mathrm{f} 3 ;-\mathrm{f} 2(\mathrm{i}, 1) * \mathrm{f} 2(\mathrm{i}, 1), \mathrm{f} 2(\mathrm{i}, 1) * \mathrm{f} 2(\mathrm{i}, 1), 0 ;-\mathrm{m} 3(\mathrm{n}, 1) *$

$\mathrm{f} 3 * \mathrm{f} 3,0, \mathrm{~m} 3(\mathrm{n}, 1) * \mathrm{f} 3 * \mathrm{f} 3]$;

$\mathrm{A}=\operatorname{cat}(1, \operatorname{cat}(2, \mathrm{zeros}(3,3)$,eye $(3)), \operatorname{cat}(2,-\operatorname{inv}(\mathrm{M}) * \mathrm{~K}$,-

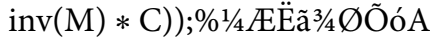

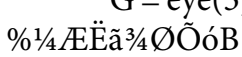

$$
\mathrm{G}=\operatorname{eye}(3) ; \mathrm{B}=\operatorname{cat}(1, \mathrm{zeros}(3,3),-\operatorname{inv}(\mathrm{M}) * \mathrm{G}) \text {; }
$$

$$
\mathrm{C} 0=\operatorname{cat}(2, \operatorname{eye}(3), \operatorname{zeros}(3,3)) ; \mathrm{D}=\operatorname{zeros}(3,3) ;
$$

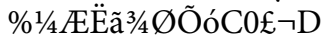

mass $=\operatorname{zeros}(2501,4) ; \operatorname{mass}(:, 1)=\mathrm{t} ; \operatorname{mass}(:, 2)=$ yy(:,m);\%F(t)

$$
\operatorname{mass}(:, 3)=-y y(:, m) ; \%-F(t)
$$

mass = mass'; save mn mass; sim('twodof); sq1 $=\mathrm{a} 1(:, 2) .4 ; \quad \mathrm{v} 1=\operatorname{sum}(\mathrm{sq} 1) * 0.01 ; \quad \operatorname{vdv} 1=\operatorname{sqrt}(\mathrm{sqrt}$ (v1)); $\quad \mathrm{sq} 2=\mathrm{a} 1(:, 3) .4 ; \quad \mathrm{v} 2=\operatorname{sum}(\mathrm{sq} 2) * 0.01 ; \quad \mathrm{vdv} 2=$ sqrt(sqrt(v2)); sq3 =a1(:,4).4; v3 = $\operatorname{sum}(\mathrm{sq} 3) * 0.01$; $\operatorname{vdv} 3=\operatorname{sqrt}(\operatorname{sqrt}(\mathrm{v} 3)) ; \operatorname{VDV} 1(\mathrm{i}, \mathrm{s})=\operatorname{vdv} 1 ; \operatorname{VDV} 2(\mathrm{i}, \mathrm{s})=$ vdv2; $\quad \operatorname{VDV} 3(\mathrm{i}, \mathrm{s})=\mathrm{vdv} 3 ; \quad \operatorname{sm} 1=\mathrm{a} 1(:, 2) .2 ; \quad \mathrm{rm} 1=$ $\operatorname{sum}(\mathrm{sm} 1) * 0.01 ; \quad \operatorname{rms} 1=\operatorname{sqrt}(\mathrm{rm} 1) ; \quad \operatorname{sm} 2=\mathrm{a} 1(:, 3) .2 ;$ $\mathrm{rm} 2=\operatorname{sum}(\mathrm{sm} 2) * 0.01 ; \operatorname{rms} 2=\operatorname{sqrt}(\mathrm{rm} 2) ; \operatorname{sm} 3=\mathrm{a} 1($ : ,4).2; $\quad \operatorname{rm} 3=\operatorname{sum}(\mathrm{sm} 3) * 0.01 ; \quad \operatorname{rms} 3=\operatorname{sqrt}(\mathrm{rm} 3)$; $\operatorname{RMS1}(\mathrm{i}, \mathrm{s})=\mathrm{rms} 1 ; \operatorname{RMS} 2(\mathrm{i}, \mathrm{s})=\mathrm{rms} 2 ; \operatorname{RMS} 3(\mathrm{i}, \mathrm{s})=\mathrm{rms} 3$; $\mathrm{p} 1=\max (\mathrm{a} 1(:, 2)) ; \mathrm{p} 2=\max (\mathrm{a} 1(:, 3)) ; \mathrm{p} 3=\max (\mathrm{a} 1(:, 4))$; $\mathrm{P} 1(\mathrm{i}, \mathrm{s})=\mathrm{p} 1 ; \mathrm{P} 2(\mathrm{i}, \mathrm{s})=\mathrm{p} 2 ; \mathrm{P} 3(\mathrm{i}, \mathrm{s})=\mathrm{p} 3$; end

end

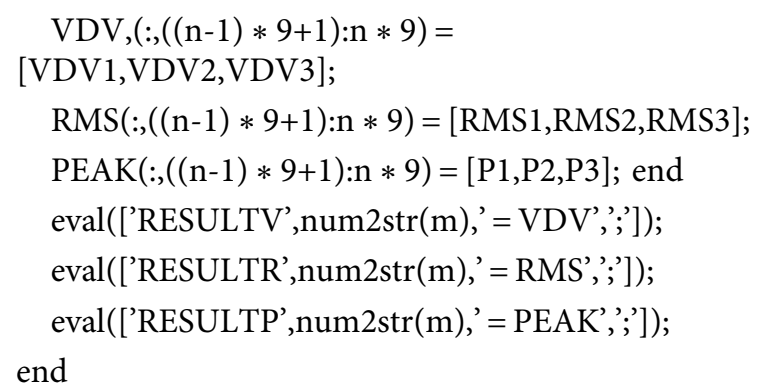

\section{Data Availability}

In this paper, all the experiment data are real and available. Requests for data (6 to 12 months after publication of this article) will be considered by the corresponding author.

\section{Conflicts of Interest}

The authors declare that they have no conflicts of interest.

\section{Acknowledgments}

The authors are grateful for the support of Project 2014BAK14B05 of the Ministry of Science and Technology. This work was supported by Engineering Research Projects of No. 5(230103).

\section{References}

[1] H. Bachmann, Vibrations of Building Structures Caused by Human Activities, Case Study of a Gymnasium, National Research Council of Canada, Ottawa, ON, Canada, Technical Translation 2077, 1884.

[2] P. Dallard, T. Fitzpatrick, A. Flint et al., "London millennium bridge: pedestrian-induced lateral vibration," Journal of Bridge Engineering, vol. 6, no. 6, pp. 412-417, 2001.

[3] M. Kasperski, "Actual problems with stand structures due to spectator induced vibrations," in Proceedings of the $3 \mathrm{rd} \mathrm{Eu-}$ ropean Conference on Structural Dynamics: EURODYN 96, pp. 455-461, Balkema, Florence, Italy, June 1996.

[4] C. A. Jones, P. Reynolds, and A. Pavic, "Vibration serviceability of stadia structures subjected to dynamic crowd loads: a literature review," Journal of Sound and Vibration, vol. 330, no. 8, pp. 1531-1566, 2011.

[5] M. Setareh, "Evaluation and assessment of vibrations owning to human activity," Structures and Buildings, vol. 165, no. SB5, pp. 219-230, 2012.

[6] A. Bolton, "Fatal mix caused stand Fall," New Civil Engineer, pp. 5-6, 1992.

[7] Interim Guidance on Assessment and Design, Dynamic Performance Requirements for Permanent Grandstands Subject to Crowd Action, The Institution of Structural Engineers, London, UK, 2001.

[8] H. Reiher and F. J. Meister, "Die Empfindlichkeit des Menschen gegen Erschütterungen," Forschung auf dem Gebiete des Ingenieurwesens, vol. 2, no. 11, pp. 381-386, 1931.

[9] F. Khan and R. Parmelee, "Service criteria for tall buildings for wind loading," in Proceedings of the 3rd International Conference on Wind Effects on Buildings and Structures, Saikon, Tokyo, Japan, 1971. 
[10] P. Chen and I. L. Robertson, "Human perception thresholds of horizontal motion," Journal of the Structural Division, vol. 98, no. ST8, pp. 1681-1695, 1972.

[11] J. F. Wiss and M. Parmelee, "Human perception of transient vibrations," Journal of the Structural Division, vol. 100, no. ST4, pp. 773-787, 1974.

[12] G. G. Browning, Human Perception of Vibrations Due to Synchronised Crowd Loading in Grandstands, The University of Bath, Somerset, UK, 2011.

[13] S. Nhleko, Human-induced Lateral Excitation of Public Assembly Structures, The University of Oxford, Oxford, England, UK, 2000.

[14] B. R. Ellis, T. Ji, and J. D. Littler, "The response of grandstands to dynamic crowd loads," Proceedings of the Institution of Civil Engineers - Structures and Buildings, vol. 140, no. 4, pp. 355-365, 2000.

[15] S. Živanovi, "Modelling human actions on lightweight structures: experimental and numerical developments," MATEC Web of Conferences, vol. 24, Article ID 01005, 13 pages, 2015.

[16] F. N. Catbas, O. Celik, O. Avci, O. Abdeljaber, M. Gul, and N. T. Do, "Sensing and monitoring for stadium structures: a review of recent advances and a forward look," Frontiers in Built Environment, vol. 3, no. 38, pp. 1-18, 2017.

[17] J. H. H. Sim, Human-structure interaction in Cantilever stands, Ph.D. Thesis, The University of Oxford, Oxford, England, UK, 2006.

[18] J. Sim, A. Blakeborough, and M. Williams, "Modelling effects of passive crowds on grandstand vibration," Proceedings of the Institution of Civil Engineers-Structures and Buildings, vol. 159, no. 5, pp. 261-272, 2006.

[19] H. X. Han, D. Zhou, and T. Ji, "Mechanical parameters of standing body and applications in human-structure interaction," International Journal of Applied Mechanics, vol. 9, no. 2, 2017.

[20] J. Yuan, L. He, F. Fan, and C. Liu, "The dynamic parameters of passive human at temporary demountable grandstands during exposure to lateral vibration," Journal of Civil Engineering and Management, vol. 24, no. 4, pp. 265-283, 2018.

[21] P. Reynolds, A. Pavic, and Z. Ibrahim, Changes of Modal Properties of a Stadium Structure Occupied by a Crowd, Proceeding of the 22nd International Modal Analysis Conference IMAC XXII, Lugano, Switzerland, 2004.

[22] P. Reynolds, A. Pavic, and Z. Ibrahim, "A remote monitoring system for stadia dynamics," Proceedings of the Institution of Civil Engineers-Structures and Buildings, vol. 157, no. 6, pp. 385-393, 2004.

[23] P. Reynolds and A. Pavic, "Vibration performance of a large cantilever grandstand during an international football match," Journal of Performance of Constructed Facilities, vol. 20, no. 3, pp. 202-212, 2006.

[24] A. Caprioli, A. Castellani, A. Cigada et al., "Vibration monitoring of the g. meazza stadium in milano during concerts and football matches, Proceeding of the Society for Experimental Mechanics Series IMAC-XXIII," in Proceedings of the Conference and Exposition on Structural DynamicsStructural Health Monitoring, Orlando, FL, USA, 2005.

[25] A. Caprioli, P. Reynolds, M. Vanali et al., "Comparison of the effects of a moving crowd on different grandstands during similar events," in Proceedings of the Society for Experimental Mechanics Series IMAC-XXIV: Conference and Exposition on Structural Dynamic-Looking Forward, Technologies for IMAC, St Louis, MI, USA, 2006.
[26] K. A. Salyards, "Utilization of simple dynamic models to explore load estimation method based on in-service structural responses," in Proceedings of the Society for Experimental Mechanics Series IMAC-XXVI: Conference and Exposition on Structural Dynamics-Technologies for Civil Structures, Orlando, FL, USA, 2008.

[27] A. Cigada, A. Caprioli, M. Redaelli et al., "Numerical modeling and experimental modal analysis of a concrete grandstand structure to structural health monitoring purposes," in Proceedings of the Society for Experimental Mechanics Series IMAC-XXVI: Conference and Exposition on Structural Dynamics-Technologies for Civil Structures, Orlando, FL, USA, 2008.

[28] A. Cigada, A. Caprioli, M. Redaelli, and M. Vanali, "Vibration testing at meazza stadium: reliability of operational modal analysis to health monitoring purposes," Journal of Performance of Constructed Facilities, vol. 22, no. 4, pp. 228-237, 2008.

[29] A. Comer, A. Blakeborough, and M. S. Williams, "Grandstand simulator for dynamic human-structure interaction experiments," Experimental Mechanics, vol. 50, no. 6, pp. 825-834, 2010.

[30] G. Parkhouse and L. Ward, "Design charts for the assessment of grandstands subject to dynamic crowd action," Institution of Structural Engineers, vol. 88, no. 7, pp. 27-34, 2010.

[31] C. A. Jones, A. Pavic, P. Reynolds, and R. E. Harrison, "Verification of equivalent mass-spring-damper models for crowd-structure vibration response prediction," Canadian Journal of Civil Engineering, vol. 38, no. 10, pp. 1122-1135, 2011.

[32] Z. Ibrahim and P. Reynolds, "Finite element modelling for evaluating the dynamic characteristic of a grandstand," International Journal of Engineering and Technology, vol. 4, no. 2, pp. 235-244, 2007.

[33] P. Mandal and T. Ji, "Modeling dynamic behaviour of a cantilever grandstand," Structures and Buildings, vol. 157, no. SB3, pp. 173-184, 2003.

[34] K. A. Salyards and L. M. Hanagan, "Evaluation of a finite element model for dynamic characteristic prediction of a stadium facility," in Proceedings of the Society for Experimental Mechanics Series IMAC-XXIII: Conference and Exposition on Structural Dynamics-Structural Health Monitoring, Bethel, Conn, Orlando, FL, USA, January 2005.

[35] G. Saudi, P. Reynolds, M. Zaki, and H. Hodhod, "Finite-element model tuning of global modes of a grandstand structure using ambient vibration testing," Journal of Performance of Constructed Facilities, vol. 23, no. 6, pp. 467-479, 2009.

[36] A. Pavic and P. Reynolds, "Experimental verification of novel 3dof model for grandstand crowd-structure dynamic interaction," in Proceedings of the Society for Experimental Mechanics Series IMAC-XXVI: Conference and Exposition on Structural Dynamics-Technologies for Civil Structures, Orlando, FL, USA, Januray 2008.

[37] J. Yuan, L. He, F. Fan, C. Liu, and K. Zhang, "Dynamic modeling and vibration analysis of temporary grandstand due to crowd-jumping loads," in Proceedings of the 9th International Conference on Structural Dynamics EURODYN 2014, pp. 1051-1057, Porto, Portugal, June 2014.

[38] C. Liu, L. He, Z. Wu, and J. Yuan, "Experimental study on joint stiffness with vision-based system and geometric imperfections of temporary member structure," Journal of Civil Engineering and Management, vol. 24, no. 1, pp. 43-52, 2018.

[39] C. Y. Tang, T. X. Zhang, and J. Q. Song, "Evaluation of comfortability during vibration on basis of annoyance rate," 
Journal of Northeastern University, vol. 27, no. 7, pp. 802-805, 2006.

[40] C. Tang, Y. Zhang, G. Zhao, and Y. Ma, "Annoyance rate evaluation method on ride comfort of vehicle suspension system," Chinese Journal of Mechanical Engineering, vol. 27, no. 2, pp. 296-303, 2014.

[41] Y. P. Guo and G. Q. Song, "Dynamic comfort evaluation of high-speed train based on annoyance rate model," Journal of Northeastern University, vol. 34, no. 11, pp. 1620-1624, 2013.

[42] A. M. Yuan, W. X. Wu, M. Xu, H.-b. Cheng, and L. Ma, "Study on pedestrian bridge's vibration comfort evaluation based on annoyance rate," Journal of Water Resources and Architectural Engineering, vol. 11, no. 4, pp. 135-140, 2013.

[43] X. Z. Shen and J. Teng, "Vibration serviceability assessment method for floor structures based on random walking force and annoyance rate," Journal of Vibration and Shock, vol. 31, no. 22, pp. 71-75, 2012.

[44] J. Wei, R. Chen, J. Wu, and M. Hu, "Appraisement of the vibration serviceability for a long-span pre-stressed floor based on annoyance rate," Zhejiang Construction, vol. 32, no. 1, pp. 19-23, 2015.

[45] Y. F. Huang, G. Q. Di, Y. T. Zhu, Y. P. Hong, and B. G. Zhang, "Pair-wise comparison experiment on subjective annoyance rating of noise samples with different frequency spectrums but same a-weighted level," The Science of the Total Environment, vol. 69, no. 12, pp. 1205-1211, 2018.

[46] R. H. Bakker, E. Pedersen, G. P. Van Den Berg, R. E. Stewart, W. Lok, and J. Bouma, "Impact of wind turbine sound on annoyance, self-reported sleep disturbance and psychological distress," The Science of the Total Environment, vol. 425, no. 5, pp. 42-51, 2012.

[47] Bs 6472-1, Guide to Evaluation of Human Exposure to Vibration in Buildings-Part 1: Vibration Sources Other than Blasting, British Standards Institution, Chennai, Tamil Nadu, India, 2008.

[48] Iso 2631-1, Mechanical Vibration and Shock-Evaluation of Human Exposure to Whole-Body Vibration, Part 1: General Requirement, 1997

[49] Z. G. Song and W. L. Jin, "A fuzzy-stochastic model for human response to vibrations," Journal of Basic Science and Engineering, vol. 10, no. 3, pp. 287-294, 2002.

[50] Z. G. Song, A New Annoyance-Based Vibration Comfort Design Theory on Engineering Structures, Zhejiang University, Zhejiang, China, 2003.

[51] Z. G. W. Song and L. Jin, "Serviceability design of ice induced platform vibration based on ice zoning map of Bohai seaacceptable acceleration levels," Ocean Engineering, vol. 123, no. 12, pp. 61-65, 2005.

[52] Z. Li, Q. Zhang, F. Fan, and S. Shen, "Analysis of dynamic properties and vibration comfort of large-scale stands," Building Research \& Information, vol. 48, no. 7, pp. 802-816, 2020.

[53] Z. Li, Q. Zhang, F. Fan, and S. Shen, "A method for calculating uncomfortable rates of people due to vertical floor vibrations using corresponding assessment values based on fuzzy reliability theory," Journal of Building Engineering, vol. 28, Article ID 101061, 2020.

[54] Q. Zhang, Z. Li, Y. Zhang, and T. Ji, "Parameter identification of the interaction body model using available measurements," Engineering Review, vol. 40, no. 3, pp. 1-12, 2020.

[55] S. Yu, J. Yuan, W. Wang, W. Wang, C. Gao, and C. Liu, "Analysis the lateral vibration serviceability of temporary grandstand and human comfort based on experiment," in
Proceedings of the XI International Conference on Structural Dynamics EURODYN 2020, Athens, Greece, 2020.

[56] L. He, J. Yuan, F. Fan, and C. Liu, "Management of lateral vibration serviceability of temporary grandstand and human health risk assessment based on experiment," https://www. preprints.org/manuscript/201805.0468/v1.

[57] L. He, J. Yuan, F. Fan, and C. Liu, "Dynamic forces of swaying human and responses of temporary demountable grandstands and based on experiment and simulation," Shock and Vibration, vol. 2018, no. 1, Article ID 2791491, 22 pages, 2018.

[58] K. Cherry, "A look at introspection Wundt's experimental technique," 2018, https://www.verywell.mind.com/what-isintrospection-2795252.

[59] J. P. Guidford, Psychometric Methods, McGraw-Hill, New York, NY, USA, 1954.

[60] G. G. Browning, Human Perception of Vibrations Due to Synchronised Crowd Loading in Grandstands, Ph.D Thesis, University of Bath, England, UK, 2011.

[61] Z. Song, A New Annoyance-Based Vibration comfort Design Theory on Engineering Structures, Ph.D. Thesis, Zhejiang University, ZheJiang, China, 2003.

[62] ISO 2631 Mechanical Vibration and Shock-Evaluation of Human Exposure to Whole-Body Vibration. Part 1: General Requirement, International Organization for Standardization (ISO), Geneva, Switzerland, 1997.

[63] ISO 2631 Mechanical Vibration and Shock-Evaluation of Human Exposure to Whole-Body Vibration. Part 1: Vibration in Buildings ( $1 \mathrm{~Hz}$ to $80 \mathrm{~Hz}$ ), International Organization for Standardization (ISO), Geneva, Switzerland, 2003.

[64] Bs 6841, Guide to Measurement and Evaluation of Human Exposure to Whole Body Mechanical Vibration and Repeated Shock, British Standards Institution, Chennai, Tamil Nadu, India, 1987.

[65] Nbcc, User's Guide National Building Code of Canada 2005, Structural Commentaries (Part 4 of Division B) Commentary $D$, National Building Code of Canada, NBCC, Chennai, Tamil Nadu, India, 2005.

[66] Bs 7085, Medical Contra-indications to Participation in Experiments Involving Whole-Body Mechanical Vibration, British Standards Institution, Chennai, Tamil Nadu, India, 1987.

[67] Bs 6472, Guide to Evaluation of Human Exposure to Vibration in Buildings (1 Hz to $80 \mathrm{~Hz}$ ), British Standards Institution, Chennai, Tamil Nadu, India, 1992.

[68] ISO 10137, Basis for the Design of Structures-Serviceability of Buildings against Vibration, International Organization for Standardization (ISO), Geneva, Switzerland, 2007.

[69] Bre Digest 426, The Response of Structures to Dynamic Crowd Loads, BRE, Bricket Wood, UK, 2nd edition, 2004.

[70] M. J. Griffin, Handbook of Human Vibration, Academic Press, London, UK, 1990.

[71] B. R. Ellis and J. D. Littler, "Response of cantilever grandstands to crowd loads. Part 1: serviceability evaluation," Proceedings of the Institution of Civil Engineers-Structures and Buildings, vol. 157, no. 4, pp. 235-241, 2004. 